Boletín de la Sociedad Geológica Mexicana

Volumen Conmemorativo del Centenario

Revisión de Algunas Tipologías de Depósitos Minerales de México

Tомо LVIII, NÚM. 1, 2006, P. 27-81

\title{
Depósitos epitermales en México: actualización de su conocimiento y reclasificación empírica
}

\author{
Antoni Camprubí1,*, Tawn Albinson ${ }^{2}$ \\ ${ }^{1}$ Centro de Geociencias, Universidad Nacional Autónoma de México, \\ Campus Juriquilla, Carretera 57 km. 15.5, 76023 Santiago de Querétaro, Qro., México \\ ${ }^{2}$ Exploraciones del Altiplano S.A. de C.V., \\ Sinaloa 106 - oficina 302, Colonia Roma Norte, 06760 México, D.F. México \\ *camprubi@geociencias.unam.mx
}

\begin{abstract}
Resumen
La tipología de yacimientos minerales ha sido tradicionalmente la más importante para México en términos económicos, con renombrados depósitos de clase mundial como los de los distritos de Pachuca - Real del Monte, Guanajuato, Fresnillo, Taxco, Tayoltita, y Zacatecas. También es uno de los temas más interesantes para la investigación científica y para la exploración de depósitos minerales, especialmente tras la determinación de sus nexos genéticos con otras tipologías como los depósitos metalíferos en pórfidos y en skarns. Además, los recientes ajustes en la denominación y definición de los tipos y subtipos de depósitos epitermales (Einaudi et al., 2003; Sillitoe y Hedenquist, 2003), y la consiguiente definición de inclusividades y exclusividades entre ellos, va a ser tema de discusión durante un tiempo, pues cualquier modelo de nuevo cuño necesita ser completado con evidencias adicionales. Como esquema general, Sillitoe y Hedenquist (2003) enfatizaron la estrecha asociación entre depósitos en pórfidos y depósitos epitermales de sulfuración alta e intermedia y, además, señalaron que en ciertas áreas (como la Great Basin de Nevada) los depósitos de sulfuración intermedia y baja son mutualmente excluyentes en espacio y tiempo. En el caso de los depósitos epitermales de México, los tipos de depósitos epitermales de sulfuración intermedia y baja no son mutualmente exclusivos, antes bien, coexisten en las mismas regiones, se formaron durante los mismos rangos de tiempo, e inclusive se presentan juntos en un mismo depósito. Estos depósitos son enteramente de edad terciaria, entre el Luteciano y el Aquitaniano-Burdigaliano (o Eoceno medio a Mioceno temprano, con la sola excepción advertida de un depósito del Paleoceno), y su distribución espacial y temporal mimetiza la propia evolución del vulcanismo de arco continental de la Sierra Madre Occidental y la Sierra Madre del Sur. La inmensa mayoría de los depósitos epitermales de México pertenecen a los tipos de sulfuración intermedia (SI) o baja (BS), y sólo se han descrito algunos depósitos de alta sulfuración (AS) en la parte noroccidental del país (e. g. El Sauzal, Mulatos, Santo Niño, La Caridad Antigua, todos ellos en Sonora y Chihuahua). Dado que muchos depósitos epitermales en México exhiben características compuestas de estilos de mineralización tanto de SI como de BS (y ocasionalmente también de AS), éstos no pueden caracterizarse simplemente como depósitos de SI (depósitos polimetálicos asociados con las salmueras más salinas) o depósitos de BS (fundamentalmente depósitos de Ag y Au asociados con salmueras de más baja salinidad). Así, en el presente trabajo proponemos el uso de una clasificación empírica para depósitos de SI+BS (esto es, depósitos epitermales alcalinos/neutros) según tres tipos de mineralización, que denominamos A, B, y C. El tipo A (o tipo de SI) comprende los depósitos formados a mayores profundidades a partir de salmueras altamente salinas, casi en ausencia de evidencias de ebullición, y contiene exclusivamente mineralizaciones de SI, consistentemente de carácter polimetálico. El tipo B (o tipo de BS-SI) comprende los depósitos que exhiben predominantemente características de
\end{abstract}


BS pero que contienen raíces polimetálicas de SI ( $\mathrm{Zn}-\mathrm{Pb})$, y es el tipo de depósito epitermal más abundante en México. El tipo C (o tipo de BS) comprende los depósitos que sólo exhiben mineralizaciones de BS, se formaron generalmente a partir de ebullición en la parte superior de los depósitos a partir de salmueras de relativa baja salinidad, y son los que presentan contenidos más altos en metales preciosos y más bajos en metales básicos.

En este trabajo se efectúa una revisión completa del conocimiento acerca de los depósitos epitermales y las técnicas de estudio de empleo común (y no tan común) en los mismos, en primer lugar a nivel general y, en segundo lugar, restringiéndonos al ámbito de los depósitos mexicanos. Así, se contemplan aspectos como la mineralogía de menas y gangas, la estructura de los depósitos, los datos y el tipo de datos geotermométricos obtenidos en ellos, las composiciones en isótopos estables de los fluidos mineralizantes y otros componentes, la química de los fluidos y sus orígenes, y los mecanismos más plausibles para la movilización de salmueras profundas y para la formación de los depósitos en el ambiente epitermal. En la revisión sobre los depósitos epitermales mexicanos se trata de mostrar qué se conoce en la actualidad de los mismos, tanto como se trata de mostrar los numerosos huecos que permanecen sobre el tema. En México existen literalmente cientos de depósitos epitermales de cualquier tipo, pero se cuenta con estudios multidisciplinarios detallados sólo en un puñado de ellos, y todos estos depositos pueden potencialmente proveer de información valiosa sobre las provincias metalogenéticas que los contienen, así como también acerca del origen y evolución de estos depósitos como tipología. Así, no propiamente en el sentido de una revisión, el presente trabajo debe tomarse como una forma de estimular los muchos estudios aún por realizarse en los depósitos epitermales de México, y lo que se conoce de estos depósitos actualmente es sólo un ejemplo de lo que puede hacerse.

Palabras clave: Depósitos epitermales, México, vulcanismo de arco continental, Terciario, sulfuración intermedia, baja sulfuración, alta sulfuración, polimetálico, metales básicos, metales preciosos, Plata, Oro.

\begin{abstract}
Epithermal ore deposits have traditionally been the most economically important in Mexico, with renowned world-class deposits as those in the Pachuca - Real del Monte, Guanajuato, Fresnillo, Taxco, Tayoltita, and Zacatecas districts. It is also one of the most interesting topics for both scientific research and exploration on ore deposits, especially in the light of the genetic links with other deposit types such as metalliferous porphyries and skarns. Additionally, recent rearrangements of denominations and definitions for the types and subtypes of epithermal deposits (Einaudi et al., 2003; Sillitoe and Hedenquist, 2003), with consequent inclusivities and exclusivities between them, are going to be a matter of discussion for a while, as any newly set model needs to be completed with further evidence. Sillitoe and Hedenquist (2003) indicated a close association between porphyry and high and intermediate sulfidation deposits whereas, in certain areas (as the Great Basin in Nevada), intermediate and low sulfidation deposits have been found to be mutually exclusive in time and space. In the case of epithermal deposits in Mexico, the intermediate and low sulfidation types do not appear to be mutually exclusive and, to the contrary, they coexist in the same regions, formed during the same time spans, and even occur together within a single deposit. These deposits are all Tertiary in age, ranging from Middle Eocene to Early Miocene, with the possible sole exception of a Paleocene deposit, and their space and time distribution follows the evolution of the continental arc volcanism of the Sierra Madre Occidental and Sierra Madre del Sur. The vast majority of epithermal deposits in Mexico belong to the intermediate (IS) or low sulfidation (LS) types, and only a few high sulfidation (HS) deposits have been described in the NW part of the country (i.e. El Sauzal, Mulatos, Santo Niño, La Caridad Antigua, all of them in Sonora and Chihuahua). As most epithermal deposits in Mexico exhibit composite characteristics of both IS and LS mineralization styles (as well as scarce characteristics of HS), they can not be simply characterized as IS (polymetallic deposits associated with the most saline brines) or LS deposits (mainly Ag and Au deposits associated with lower salinity brines). Thus, in this paper we propose to use an empirical classification for IS $+L S$ deposits (that is, alkaline/neutral epithermal deposits) into four types of mineralization, namely A, B, and C. Type A (or IS type) comprises those deposits that generally formed at greater depths from highly saline but unsaturated brines, with or without evidence for boiling, and contain exclusively from top to bottom IS styles of mineralization with a consistent polymetallic character. Type B (or LS-IS type) comprises those deposits that exhibit dominant LS characteristics but have polymetallic IS roots ( $\mathrm{Zn}-\mathrm{Pb}-\mathrm{Cu})$, and is the most widespread type of epithermal mineralization in Mexico. Types A and B generally exhibit evidence for boiling. Type C (or LS type) comprises those deposits that exhibit only LS styles of mineralization, formed generally by shallow boiling of low salinity brines, and have the relatively highest precious metal and lowest base metal contents.

In this paper, although not necessarily as part of the above classification, we also review other known or attributable aspects of Mexican epithermal deposits, including ore and gangue mineralogy and their evolution in time and space, structure, geothermometry, stable isotopic composition of mineralizing fluids and other components of the deposits, chemistry and sources for mineralizing fluids, and the plausible mechanisms for the mobilization of deep fluid reservoirs
\end{abstract}


and for mineral deposition at the epithermal environment. In this review the intent is to show what is known today of epithermal deposits in Mexico, and to point out the gaps that remain in their knowledge. Detailed multidisciplinary studies are available only for a handful of literally hundreds of epithermal deposits in the country, whose study may potentially provide valuable information about the origin and evolution of these deposits as well as about the metallogenic provinces that contain them.

Key words: Epithermal deposits, Mexico, continental arc volcanism, Tertiary, intermediate sulfidation, low sulfidation, high sulfidation, polymetallic, base metals, precious metals, Silver, Gold.

\section{Introducción}

No hay duda que, en la actualidad, los depósitos epitermales se cuentan entre las tipologías de depósitos minerales de mayor interés, tanto a nivel económico como científico. Dicho interés se debe principalmente al hecho que estos yacimientos son portadores principales de oro y plata, además de otros elementos, como $\mathrm{Zn}, \mathrm{Pb}, \mathrm{Cu}, \mathrm{Cd}, \mathrm{As}, \mathrm{Sb}, \mathrm{Bi}$, Se, $\mathrm{Te}, \mathrm{Ga}, \mathrm{Ge}, \mathrm{In}, \mathrm{Tl}, \mathrm{Mo}$ y Sn. Con respecto al oro, si bien es cierto que estos depósitos no dejan de aportar cantidades relativamente accesorias al mercado mundial, frente a lo que son los depósitos de la cuenca de Witwatersrand o en los greenstone belts, van cobrando relevancia a medida que se ahonda en su conocimiento y que nuevas áreas son exploradas. Igualmente, la relación genética y temporal entre los depósitos epitermales y los depósitos metalíferos en pórfidos (Arribas et al., 1995; Hedenquist et al., 1998; Sillitoe, 1999; Brathwaite et al., 2001; Müller et al., 2002; Strashimirov et al., 2002; Einaudi et al., 2003; Sillitoe y Hedenquist, 2003; Simpson et al., 2004), representa un interés adicional para la exploración de ambas tipologías en regiones favorables. El conocimiento de los sistemas geotérmicos activos, que constituyen los análogos actuales de este tipo de depósitos, es una de las herramientas fundamentales para su conocimiento (Berger, 1991; White et al., 1995; Hedenquist, 1996; Einaudi et al., 2003). Con todo, es indudable que los depósitos epitermales (junto con los mesotermales) son los de mayor importancia global entre las diferentes tipologías de yacimientos de plata. Prueba de ello es que, países cuyos yacimientos epitermales tienen la peculiaridad de ser muy ricos en plata, como México y los E.U.A., han sido históricamente, y son actualmente, los mayores productores mundiales de este metal. Esto es especialmente significativo en el caso de México ya que, estando la minería para plata desarrollada mayormente en vetas epitermales, ocupa regularmente el primer lugar entre los países productores desde el año 1900 (González-Reyna, 1956; Craig et al., 1996). Asimismo, la producción total de plata en México desde el siglo XVI excede ampliamente en cantidad a la de cualquier otro país. En consecuencia, la investigación en este tipo de depósitos es de gran importancia económica para México.

\section{Concepto de depósito epitermal}

El ambiente epitermal, tal como indica la propia etimología de este término, se halla a escasa profundidad en referencia a la superfície terrestre y, en concreto, define la parte superior de los sistemas hidrotermales naturales. Lindgren $(1922,1933)$ definió el término "epitermal", caracterizando este tipo de depósitos minerales en función de la mineralogía de las menas y de sus características texturales, así como en sus propias reconstrucciones geológicas. En la definición que estableció para estos depósitos, Lindgren incluyó numerosos yacimientos minerales de metales preciosos (con presencia o no de telururos o seleniuros), metales básicos, mercurio y antimonio (con estibina como mineral principal). En tales trabajos ya se sugirió que se trataba de un tipo de depósitos metalíferos formados a partir de fluidos acuosos influenciados por emanaciones ígneas a temperaturas relativamente bajas $\left(<200^{\circ} \mathrm{C}\right)$ y en condiciones de presión "moderadas". En los numerosos estudios subsiguientes, a medida que el conocimiento de estos sistemas aumentaba, las condiciones de emplazamiento se han ido acotando y redefiniendo con el tiempo. Buddington (1935) indicó que, en ambientes próximos a la superfície, son posibles temperaturas mayores a las reportadas por Waldemar Lindgren, de modo que pronto el límite máximo de temperatura aceptado para sistemas epitermales "aumentó" hasta los $300^{\circ} \mathrm{C}$ (Panteleyev, 1988). Así, en la actualidad, se considera que las condiciones de formación de la mayoría de yacimientos epitermales comprenden temperaturas entre $<150$ y $\sim 300^{\circ} \mathrm{C}$ (y eventualmente mayores), y a profundidades desde la superfície hasta 1 ó $2 \mathrm{~km}$, con presiones de hasta varios centenares de bares (Berger y Eimon, 1983; Heald et al., 1987; Sillitoe, 1988; Reyes, 1990, 1991).

\section{Localización y relación con el vulcanismo}

Cuando Lindgren (1922) definió el término "epitermal", una de sus observaciones fue que la gran mayoría de los depósitos incluídos dentro de dicha tipología tienen como encajonante rocas volcánicas de edad terciaria y, por lo 
tanto, son de edad terciaria o posterior. Pero, a pesar de eso (más bien, precisamente por eso), también indicó que esa no es condición sine qua non para otorgar tal nombre a un depósito determinado, puesto que los depósitos epitermales no se encuentran encajonados únicamente en rocas de esa edad. Efectivamente, la mayoría de los depósitos epitermales conocidos hoy en día están situados alrededor del margen Circum-Pacífico (Figura 1), asociados al termalismo tardío de los sistemas volcánicos operantes en dicho margen desde el Terciario (White et al., 1995). En su totali- dad, los depósitos epitermales están asociados directamente a márgenes de subducción activos en diferentes épocas geológicas (Silberman et al., 1976; Sillitoe, 1977). Por ejemplo, en Europa la mayoría de depósitos epitermales de relevancia están ubicados en los Cárpatos, tectónicamente asociados al cierre del Tetis durante la orogénesis Alpina (Jankovic, 1997). En el márgen occidental del Pacífico (en contexto de arcos de islas), la mayoría de depósitos epitermales se formaron durante el Mioceno superior, el Paleoceno y el Cuaternario (White et al., 1995), mientras

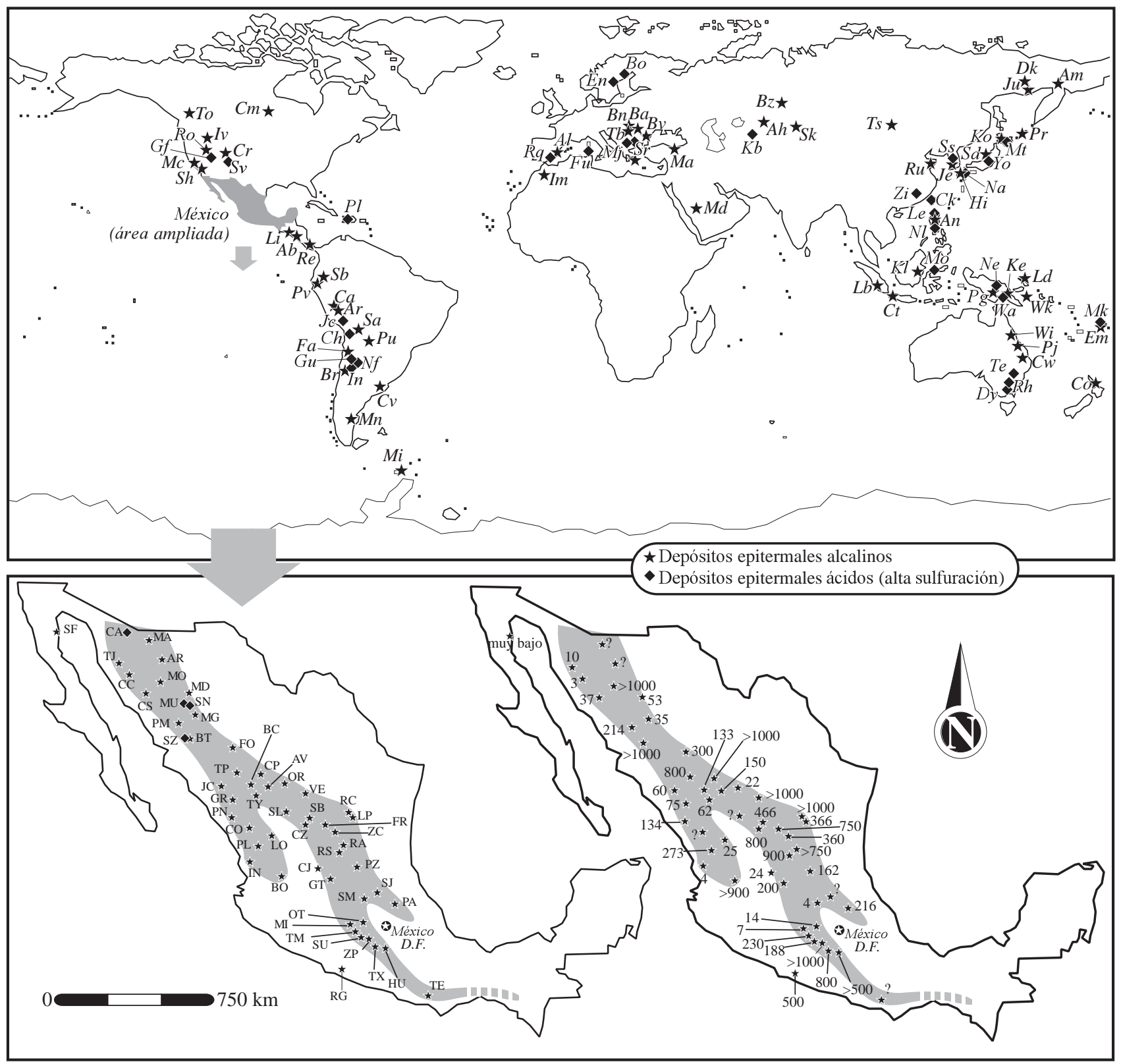

Figura. 1. Distribución geográfica de algunos depósitos epitermales ácidos (alta sulfuración) y alcalinos (baja e intermedia sulfuración) en el mundo y en México. El mapa de México de la derecha contiene las relaciones Ag/Au de cada de los depósitos de baja sulfuración en que esta información es disponible (referencias en Camprubí et al., 1999). La zona sombreada en el mapa de México define el área susceptible de contener depóstitos epitermales, según las zonaciones metálicas de $\mathrm{Pb}-\mathrm{Zn}-\mathrm{Ag}$, Au-Ag y Hg-Sb de Clark et al. (1982) y la distribución de los yacimientos de este tipo conocidos (Camprubí et al., 1999). Ver referencias acerca de la mayoría de depósitos en Arribas (1995), Simmons (1995), White et al. (1995), Camprubí (1999), Camprubí et al. (1999, 2003a), Hedenquist et al. (2000), Albinson et al. (2001). 
que en el márgen oriental del Pacífico y el Caribe (generalmente en contexto de arcos continentales), tienen edades entre el Cretácico y el Mioceno superior (Sillitoe, 1994). Esta diferencia de edades de los depósitos epitermales en una zona, la Circum-Pacífica, en cuyos márgenes se vienen produciendo grosso modo los mismos procesos desde el Cretácico, es debida a la gran diferencia de tasa de erosión entre los arcos de islas y los arcos continentales o andinos, de uno a dos órdenes de magnitud mayor en el primer caso que en el segundo (Sillitoe, 1994; Hedenquist et al., 1996). En Australia, abundan los casos de depósitos epitermales paleozoicos (Wake y Taylor, 1988; Wood et al., 1990; White et al., 1995), incluyendo los sínteres fósiles de Drummond Basin, los más antiguos conocidos (Cunneen y Sillitoe, 1989; White et al., 1989), junto con los de Rhynie, Escocia (Rice y Trewin, 1988). Pero los depósitos epitermales más antiguos que han sido descritos corresponden al Arqueano (Penczak y Mason, 1997), al Paleoproterozoico (Hallberg, 1994; Jacobi, 1999) y al Neoproterozoico (Huckerby et al., 1983; Cheilletz et al., 2002), aunque los depósitos pre-terciarios conocidos son aún comparativamente muy escasos (Buchanan, 1981; Mosier et al., 1986). Ello es debido a la erosión o a la presencia metamorfismo superpuesto que los haya podido desfigurar (Heald et al., 1987). En el caso de los greenstone belts, dada la diversidad de condiciones de emplazamiento y estilo de las mineralizaciones, algunos autores (Guha et al., 1988; Robert y Poulsen, 1996) pro- ponen que los tipos de depósitos previos al metamorfismo correspondieron primariamente a distintas tipologías, entre las cuales podrían incluirse también depósitos epitermales. En el caso de los depósitos epitermales mexicanos (todos ellos netamente terciarios) su edad disminuye, a grandes rasgos, hacia el sur y hacia el este, en relación con la migración general del vulcanismo ácido de la Sierra Madre Occidental y la Sierra Madre del Sur (e. g. Damon et al., 1981, 1983; Clark et al., 1982; Camprubí et al., 2003b).

La distribución de los depósitos epitermales coincide, no sólo con arcos volcánicos en márgenes convergentes (subducción de placa oceánica-continental u oceánicaoceánica), sino también con los rifts de tras-arco asociados, como en la zona del Basin-and-Range, en los Estados Unidos (White, 1982) o en la Isla Norte de Nueva Zelanda (Christie y Brathwaite, 1986; Hedenquist, 1986), con depósitos epitermales fósiles y sus equivalentes geotérmicos actuales. Las regiones con derrames basálticos continentales, tanto de carácter toleítico como alcalino, no contienen depósitos epitermales, y tampoco aparecen en rifts oceánicos, éstos últimos probablemente por ser típicamente submarinos (White y Hedenquist, 1990). Tradicionalmente, se ha considerado que en antiguos arcos de islas tampoco se han producido depósitos minerales, una idea que hoy en día ya está descartada (Sillitoe y Hedenquist, 2003). En el caso relativamente poco común en que los depósitos epitermales se hallan asociados a vulcanismo básico, éste es de afinidad

Figura 1 (Continuación). Depósitos epitermales en México: (AR) Arizpe, Sonora. (AV) Avino, Durango. (BC) Bacís, Durango. (BO) Bolaños y San Martín de Bolaños, Jalisco. (BT) Batopilas, Chihuahua. (CC) Cerro Colorado, Sonora. (CJ) Comanja de Corona, Jalisco. (CO) Copala, Sinaloa. (CP). Cerro Prieto y Mantos, Durango. (CS) Colorada, Sonora. (CZ) Colorada, Zacatecas. (FO) San Francisco del Oro y Santa Bárbara, Chihuahua. (FR) Fresnillo, Zacatecas. (GR) Guadalupe de los Reyes, Sinaloa. (GT) Guanajuato, Guanajuato. (HU) Huautla, Morelos. (IN) El Indio, Nayarit. (JC) San José del Cobre, Durango/Sinaloa. (LO) Lluvia de Oro, Durango. (LP) La Paz, San Luis Potosí. (MA) Magallanes, Sonora. (MD) Mineral de Dolores, Chihuahua. (MG) Maguaríchic, Chihuahua. (MI) Miahuatlán e Ixtapan del Oro, estado de México. (MO) Moctezuma, Sonora. (MU) Mulatos, Sonora. (OR) Orito, Durango. (OT) El Oro - Tlalpujahua, estado de México/Michoacán. (PA) Pachuca - Real del Monte, Hidalgo. (PL) Plomosas, Sinaloa. (PM) Palmarejo, Chihuahua. (PN) Pánuco, Sinaloa. (PZ) Pozos, Guanajuato. (RA) Real de Ángeles, Aguascalientes. (RC) Real de Catorce, San Luis Potosí. (RG) Real de Guadalupe, Guerrero. (RS) Real de Asientos, Aguascalientes. (SB) Sombrerete, Zacatecas. (SF) San Felipe, Baja California Norte. (SJ) San Joaquín, Querétaro. (SL) Saladillo, Durango. (SM) San Martín, Querétaro. (SN) Santo Niño, Chihuahua. (SU) Sultepec y Amatepec, estado de México. (SZ) El Sauzal, Chihuahua. (TE) Tejomulco, Oaxaca. (TJ) Tajitos, Sonora. (TM) Temascaltepec, estado de México. (TP) Topia, Durango. (TX) Taxco, Guerrero. (TY) Tayoltita, Durango. (VE) Velardeña, Durango. (ZC) Zacatecas, Zacatecas. (ZP) Zacualpan, estado de México.

Depósitos epitermales en el resto del mundo: (Ab) Abangares, Costa Rica. (Ah) Arharlik, Kazajstán. (AI) Almagrera, Mazarrón, España. (Am) Ametistovoye, Rusia. (An) Antamok - Acupan, Filipinas. (Ar) Arcata, Orcopampa, Caylloma, Perú. (Ba) Baia Sprie, Baia Mare, Rumanía. (Bn) Banská Hodrusa, Eslovaquia. (Bo) Boliden, Suecia. (Br) El Bronce, Chile. (Bv) Beregovo, Ucrania. (Bz) Bereznyakovskoye, Rusia. (Ca) Casapalca, Perú. (Ch) Choquelimpie, Chile. (Ck) Chinkuashih, Taiwan. (Cm) Campbell-Red Lake, Canadá. (Co) Coromandel, Golden Cross, Thames, Waihi, Nueva Zelanda. (Cr) Creede, E.U.A. (Ct) Cirotan, Gunung Pongkor, Indonesia. (Cv) Cerro Vanguardia, Argentina. (Cw) Cracow, Australia. (Dk) Dukat, Kubaka, Rusia. (Dy) Dobroyde, Australia. (Em) Emperor, Fiji. (En) Enåsen, Suecia. (Fa) Faride, Inca de Oro, Chile. (Fu) Furtei, Italia. (Gf) Goldfield, Paradise Peak, E.U.A. (Gu) Guanaco, Esperanza, La Coipa, El Hueso, Chile. (Hi) Hishikari, Japón. (Im) Imiter, Marruecos. (In) El Indio - Tambo, Chile. (Iv) Ivanhoe, Midas, E.U.A. (Jc) Julcani, Castrovirreyna, Ccahuarso, Cerro de Pasco, Colquijirca, Sucuitambo, Perú. (Je) Jeongju - Buan, Macizo de Ryeongnam, Corea del Sur. (Ju) Julietta, Rusia. (Kb) Kochbulak, Uzbekistán. (Ke) Kerimenge, Papúa-Nueva Guinea. (KI) Kelian, Indonesia. (Ko) Koryu, Japón. (Lb) Lebong Donok, Indonesia. (Ld) Ladolam, Papúa-Nueva Guinea. (Le) Lepanto, Filipinas. (Li) El Limón, La India, Nicaragua. (Ma) Mastra, Turquía. (Mc) McLaughlin, E.U.A. (Md) Mahd adh Dhahab, Arabia Saudita. (Me) Megala Therma, Profitis Ilias, Grecia. (Mi) Miers Bluff, Isla Livingston, Antártida. (Mj) Madjanpek, Bor, Serbia y Montenegro. (Mk) Mount Kasi, Fiji. (Mn) Manatial Espejo, Argentina. (Mo) Motomboto, Indonesia. (Mt) MitsumoriNukeishi, Japón. (Na) Nansatsu, Japón. (Ne) Nena, Papúa-Nueva Guinea. (Nf) La Mejicana - Nevados del Famatina, Argentina. (Nl) Nalesbitan, Filipinas. (Pg) Porgera, Papúa-Nueva Guinea. (Pj) Pajingo, Australia. (PI) Pueblo Viejo, Rep. Dominicana. (Pr) Prasolovskoye, Islas Kuriles, Rusia. (Pu) Pulacayo, Bolivia. (Pv) Portovelo, Ecuador. (Re) Remance - Alto la Mina, Panamá. (Rh) Rhyolite Creek, Australia. (Ro) Round Mountain, Comstock Lode, E.U.A. $(\boldsymbol{R} \boldsymbol{q})$ Rodalquilar, España. (Ru) Rushan, China. (Sa) Salinas de Garci Mendoza, Carangas, Bolivia. (Sb) San Bartolomé, Ecuador. (Sd) Sado, Japón. (Sh) Shumake, E.U.A. (Sk) Shkol'noe, Tadjikistán. (Sr) Srednogorie, Chelopech, Spahievo, Bulgaria. (Ss) Seongsan - Ogmaesan, Corea del Sur. (Sv) Summitville, E.U.A. (Tb) Telkibánya, Hungría. (Te) Temora, Australia. (To) Toodoggone, Freegold Mt., Canadá. (Ts) Tsagaan - Suvarga, Mongolia. (Wa) Wafi River, Papúa-Nueva Guinea. (Wi) Wirralie, Mt. Coolon, Australia. (Yo) Yoji, Japón. (Zi) Zijinshan, China. 
alcalina o shoshonítica, como es el caso de el yacimiento Emperor en Fiji (Anderson y Eaton, 1990), o bien se trata de vulcanismo bimodal basáltico-andesítico.

En la mayoría de los casos, los depósitos epitermales están relacionados de forma espacial y temporal con vulcanismo subaéreo, de carácter ácido a intermedio, y el subvolcanismo asociado, pudiendo el basamento ser de cualquier tipo. El encajonante volcánico suele ser del tipo central a proximal, muy típicamente con rocas efusivas o piroclásticas (Sillitoe y Bonham, 1984), aunque excepcionalmente puede ser del tipo distal (Wood et al., 1990).

Un gran número de depósitos epitermales están asociados a estructuras de origen volcánico, en especial calderas y complejos andesíticos, como es el caso de las San Juan Mountains de Colorado (Steven et al., 1977), en cuyo seno se hallan los conocidos distritos mineros de Creede y Summitville. Asimismo, existe un importante control de este tipo de depósitos por parte de fallas de escala regional en zonas de intensa fracturación tensional (Mitchell y Balce, 1990; Nesbitt, 1990; Staude, 1993; Ponce y Glen, 2002; Nieto-Samaniego et al., 2005). Dichas fallas determinan la localización de los depósitos y actúan como guía para el emplazamiento de la fuente de calor magmática necesaria para la subsiguiente actividad hidrotermal (Hedenquist, 1986; Fournier, 1987), que controla la duración de dicha actividad. Pero, aunque las fallas de orden mayor ejercen un control directo sobre el emplazamiento de la mineralización, se ha observado que ésta suele disponerse de forma preferencial en fallas subsidiarias (White y Hedenquist, 1990). El calor necesario para la circulación convectiva de los fluidos deriva tanto de cuerpos subvolcánicos enfriándose a profundidades relativamente cercanas a la superficie $(<2.5$ a $3.0 \mathrm{~km})$, como también de plutones emplazados a profundidades significativas $(>5 \mathrm{~km})$.

Los depósitos epitermales presentan un enriquecimiento general, en relación a las composiciones de los basaltos, en elementos como Ag, As, Au, B, Hg, S, Sb, Se, Te, Tl y U (Bornhorst et al., 1995), de hasta más de cinco órdenes de magnitud. Hay que destacar que este enriquecimiento se produce independientemente de la naturaleza de las rocas encajonantes, cuya abundancia en estos elementos suele ser siempre muy baja. Por lo tanto, estos elementos pueden ser útiles en prospección geoquímica.

\section{Factores de control de emplazamiento}

Según White y Hedenquist (1990), los principales factores que influencian las condiciones físicas del ambiente epitermal y que, en último término, determinan el carácter y la localización de la mineralización, son los siguientes:

1. la geología regional de la zona en la que se halla el depósito en cuestión, como su estructura, la estratigrafía, las intrusiones a las que se asocia la mineralización y la naturaleza de dichas rocas ígneas, factores éstos que controlan directamente el tipo y el grado de permeabilidad, así como la reactividad de la roca o rocas encajonantes;

2. las características hidrológicas de la zona, es decir, la relación existente entre la permeabilidad y la topografía que controla el movimiento de los fluidos, y las características de los fenómenos de recarga/descarga de fluidos, así como el acceso de aguas calentadas por vapor (steamheated waters);

3. las condiciones de presión y temperatura de los fluidos mineralizantes que, en lo que es el ambiente epitermal, se hallan estrechamente ligadas al punto de ebullición, determinado a su vez por la composición de los fluidos;

4. las características químicas y el contenido total en gas de los fluidos mineralizantes, que son los factores determinantes en su reactividad, en su capacidad para el transporte de metales y en la paragénesis mineral, tanto por lo que respecta a la alteración del encajonante como para la mineralización en si;

5. el posible desarrollo de permeabilidad contemporáneamente al hidrotermalismo y/o cambios en el gradiente hidráulico de la zona.

\section{Tipologías de los depósitos epitermales}

Las importantes diferencias en las características químicas de los fluidos mineralizantes, responsables de deposición mineral dentro del ambiente epitermal, son el criterio en base al cual se establecen los dos tipos principales de depósitos epitermales. En efecto, existen dos estilos contrastados de sistemas hidrotermales ubicados en el ambiente epitermal, según se desprende del estudio actualístico de ejemplos activos (e.g. Henley y Ellis, 1983; Reyes, 1990, 1991). En cuanto a la geoquímica de fluidos de estos dos estilos de sistemas, en un extremo se encuentra un conjunto de fluidos profundos reducidos y con $\mathrm{pH}$ cercanos a la neutralidad. Estos fluidos están esencialmente en equilibrio con las rocas encajonantes alteradas, debido a su ascenso relativamente lento, lo que resulta en un sistema dominado por dichas rocas (Giggenbach, 1992a). Los sistemas geotérmicos de este tipo se situan típicamente a una cierta distancia de los edificios volcánicos con los que pueden estar genéticamente asociados, aunque estos sistemas pueden encontrarse igualmente en zonas sin actividad volcánica contemporánea o alguna. En la mayoría de los casos, estos sistemas son activados por intrusiones situadas hasta 5 ó $6 \mathrm{~km}$ bajo la superficie.

En el extremo opuesto, se encuentran sistemas volcánico-hidrotermales en situación proximal a aberturas volcánicas por las que se canaliza la descarga de vapores a la superficie. La principal expresión en superficie de estos sistemas son fumarolas de alta temperatura, y sus condensados constituídos por aguas extremadamente ácidas. Estos fluidos, de carácter eminentemente ácido y oxidado, se encuentran notoriamente en desequilibrio con las rocas encajonantes, poniendo de manifiesto el carácter 
magmático de los mismos (Giggenbach, 1992c). El fuerte control estructural que existe sobre la canalización de estos fluidos es un factor determinante en su naturaleza altamente reactiva, y en el hecho que estos sistemas estén dominados por los fluidos (Giggenbach, 1992a). Las intrusiones generadoras de estos sistemas pueden ser muy próximas a la superficie e, inclusive, llegar a ser eruptivas.

Estos dos tipos de sistemas poseen características muy distintivas entre ellos, aunque ambos pueden coexistir uno al lado del otro (Hedenquist y Lowenstern, 1994; Hedenquist et al., 2000). En algunos casos, se puede identificar una transición entre ambos ambientes geoquímicos, a sólo 1 ó $2 \mathrm{~km}$ de profundidad, en la que los fluidos hipogénicos ácidos ascienden hasta sistemas de $\mathrm{pH}$ neutro (Reyes et al., 1993). Esta transición está típicamente representada por una zona de hidrólisis (Meyer y Hemley, 1967), denominada "neutralización primaria" (Giggenbach, 1981), ubicada debajo del ambiente epitermal (Figura 2).

\subsection{Terminología}

En la literatura tradicionalmente se ha distinguido entre dos tipos principales de depósitos epitermales: ácidos y alcalinos (Sillitoe, 1977). El primer tipo de depósito es el llamado de enargita-oro, alunita-caolinita, ácido-sulfato, o de alta sulfuración (high-sulfidation epithermal deposit). El segundo tipo recibe el nombre de depósito epitermal de adularia-sericita o de baja sufuración (low-sulfidation epithermal deposit). El término enargita-oro (Ashley, 1982), se definió según los dos minerales metálicos considerados como más característicos de esta tipología. La denominación de los términos ácido-sulfato y adularia-sericita fue propuesta por Hayba et al. (1985) y Heald et al. (1987) en base a la mineralogía y a los tipos de alteración de los depósitos epitermales. Posteriormente, Berger y Henley (1989) propusieron el término caolinita-alunita en lugar de ácido-sulfato para dar mayor relevancia a los minerales de alteración característicos de esta tipología. La denominación de los términos alta sulfuración y baja sulfuración fue propuesta por Hedenquist (1987) en base al estado de oxidación-reducción (o sulfuración) del azufre en los fluidos de sistemas geotérmicos actuales, equivalentes por origen a los depósitos fósiles de uno y otro tipo. El primer tipo se originaría a partir de fluidos de carácter oxidado y ácido (azufre en estado de oxidación +6 o +4, o sea, "alta sulfuración", en forma de $\mathrm{SO}_{4}^{2-}$ o $\mathrm{SO}_{2}$ ), típicos de fuentes termales ácidas próximas a volcanes; el otro tipo, en cambio, se originaría a partir de fluidos reducidos $\mathrm{y}$ de $\mathrm{pH}$ aproximadamente neutro (en los que el azufre se presenta con su estado de oxidación de -2, esto es, "baja sulfuración"), como los hallados en sistemas geotérmicos más o menos distales a la fuente de calor principal. Como es lógico, referida a depósitos epitermales, esta terminología se emplea para designar al estado de sulfuración de las asociaciones de sulfuros. Por su parte, Bonham $(1986,1988)$ también propuso los términos sulfuro alto y sulfuro bajo, referidos a la cantidad total de sulfuros en el depósito. Otra denominación que se ha empleado en numerosas ocasiones es la de depósitos "tipo manantial termal" (hot-spring type; Giles y Nelson, 1982), para designar depósitos similares a McLaughlin (California, E.U.A.), aunque no constituyen un estilo propio por tratarse de los rasgos someros o superficiales de depósitos de baja sulfuración. Recientemente, se han redefinido los tipos de depósitos epitermales, introduciéndose el término de sulfuración intermedia (Hedenquist et al., 2000; Einaudi et al., 2003; Sillitoe y Hedenquist, 2003). Los depósitos del subtipo de sulfuración intermedia son estructualmente muy similares a los de baja sulfuración, pues no en balde ambos conforman el conjunto de epitermales alcalinos según Sillitoe (1977), aunque las características geoquímicas de los fluidos mineralizantes asociados y de las mineralizaciones metálicas en sulfuración intermedia suele guardar una mayor afinidad con los depósitos de alta sulfuración (Einaudi et al., 2003; Sillitoe y Hedenquist, 2003). De hecho, inicialmente, fueron considerados como un tipo de depósito de baja sulfuración (Hedenquist et al., 2000). Así, según la terminología más reciente, el término de "estado de sulfuración" se emplea en el sentido que le otorgó Barton (1970), de forma análoga al de estado de oxidación, y se ha establecido un marco de referencia para el estado de sulfuración en función de la temperatura y la fugacidad de $\mathrm{S}_{2}$ gas (Einaudi et al., 2003). Los límites entre condiciones de sulfuración muy baja, baja, intermedia, alta y muy alta, según Einaudi et al. (2003), vienen determinadas factualmente por los campos de estabilidad de diversas especies de sulfuros (Figura 3). Huelga decir que, del paso del ambiente de los depósitos en pórfidos al de los epitermales, e incluso durante la formación de un solo depósito epitermal, pueden producirse transiciones entre un estado de sulfuración a otro, debido a disminución de temperatura, ebullición, a interacción agua-roca, etc. (Einaudi et al., 2003). Ver White y Hedenquist (1990) y Einaudi et al., (2003) para extensas discusiones acerca de la conveniencia de la terminología que se ha expuesto, los problemas que acarrea la misma, y la historia de los conceptos relacionados con el estado de sulfuración mismo.

En adelante, usaremos la nomenclatura de alta sulfuración (AS), sulfuración intermedia (SI) y baja sulfuración (BS), como referencia a los tipos genéricos de depósitos minerales. Con afán de clarificar la clasificación de los depósitos minerales entre sus tipos y subtipos, podemos usar el siguiente esquema:

\section{Epitermales ácidos \\ $\Rightarrow$ 1.1. Tipo de alta sulfuración (Figura 4)}

\section{Epitermales alcalinos neutros}

$\Rightarrow 2.1$. Tipo de sulfuración intermedia (Figura 5)

$\Rightarrow$ 2.2. Tipo de baja sulfuración

$\Rightarrow$ 2.2.1. Relacionados con magmas subalcalinos

$\Rightarrow$ 2.2.2. Relacionados con magmas alcalinos 
Camprubí y Albinson
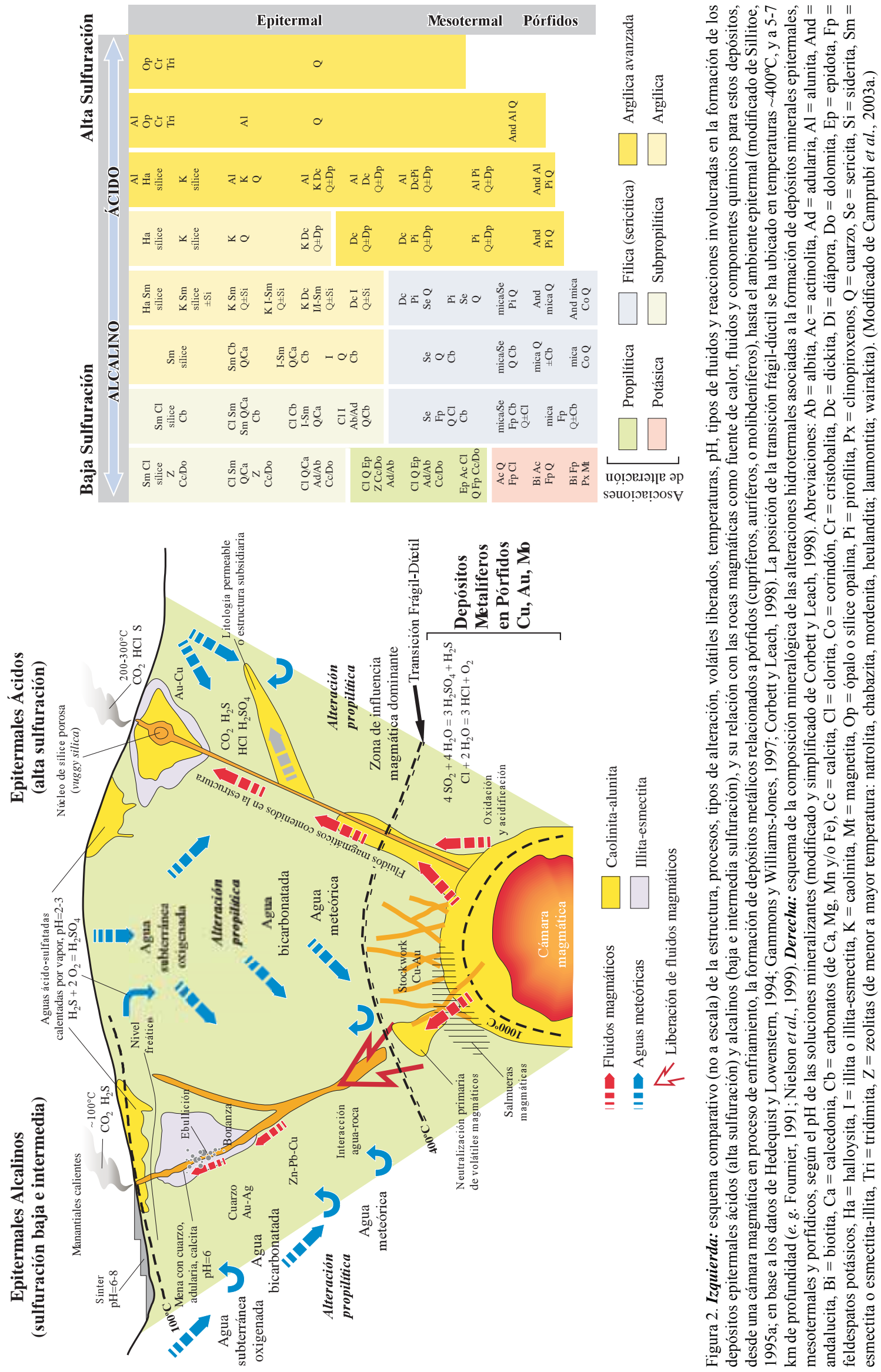
Ejemplos de dichos tipos y subtipos de depósitos son:

1.1. Srednogorie en Bulgaria (Bonev et al., 2002; Strashimirov et al., 2002), El Indio en Chile (Jannas et al., 1990, 1999); Summitville en E.U.A. (Stoffregen, 1987); Lepanto en Filipinas (Hedenquist et al., 1998), Mulatos y El Sauzal en México (Gray, 2001; Staude, 2001), Yanacocha en Perú (Harvey et al., 1999), Pueblo Viejo en Rep. Dominicana (Russell y Kesler, 1991). Ver la relación de Arribas (1995).

2.1. Creede y Comstock Lode en E.U.A. (Hayba et al., 1985; Plumlee y Rye, 1986; Vikre, 1989), Baguio en Filipinas (Cooke et al., 1996), Kelian en Indonesia (van Leeuwen et al., 1990), Pachuca-Real del Monte, Fresnillo, Tayoltita y Temascaltepec en México (Geyne et al., 1963; Gemmell et al., 1988; Ruvalcaba-Ruiz y Thompson, 1988; Simmons et al., 1988; Simmons, 1991; Camprubí et al., 2001a,b; Enriquez y Rivera, 2001a,b), Arcata en Perú (Ericksen y Cunningham, 1993). Ver relación de Simmons (1995).

2.2.1. Sleeper, Round Mountain y McLaughlin en E.U.A. (Sander y Einaudi, 1990; Sherlock et al., 1995), Waihi en Nueva Zelanda (Brathwaite y Faure, 2002), Hishikari en Japón (Izawa et al., 1990). Ver relación de Simmons (1995).

2.2.2. Cripple Creek en E.U.A. (Thompson et al., 1985), Emperor en Fiji (Ahmad et al., 1987; Anderson y Eaton, 1990; Kwak 1990), Antamok-Acupan en Filipinas (Cooke y Bloom, 1990; Cooke et al., 1996), Porgera y Ladolam en Papúa-Nueva Guinea (Richards, 1992, 1995; Richards y Kerrich, 1993; Richards et al., 1997).
Las características principales de los epitermales y alcalinos están resumidas en forma de tabla por Camprubí et al. (2003a) aunque, debido al cambio de denominación en sus tipos y subtipos, cabría substituir en dicha tabla "baja sulfuración" por "epitermales alcalinos" o "sulfuración baja+intermedia", que es el sentido en el cual dicha relación fue formulada, y en el cual es válida. En el presente trabajo se explicitan las principales características de los tres tipos de depósitos epitermales (BS, SI y AS) en la Tabla 1.

\section{Elementos de descripción de los depósitos epitermales}

\subsection{Contexto geológico}

Se pueden considerar cuatro contextos fundamentales (Figura 6) para depósitos epitermales en general, basados en la caracterización de sistemas hidrotermales activos (Bogie y Lawless, 1987; White et al., 1995), siempre dentro de un contexto geotectónico de subducción. Estos contextos son los siguientes:

1. Sistemas hidrotermales en depresiones estructurales asociadas a vulcanismo ácido (Figura 6A). Se emplazan en zonas con relieve bajo y poco variable $(0-300 \mathrm{~m})$. Las rocas volcánicas asociadas son lavas ácidas con depósitos piroclásticos y sedimentarios adyacentes; por lo común, en zonas con grandes calderas. Las aguas termales tienen $\mathrm{pH}$ neutro, forman sínteres y cráteres de explosión hidrotermal, y la separación de fases se produce en flujo vertical. Este

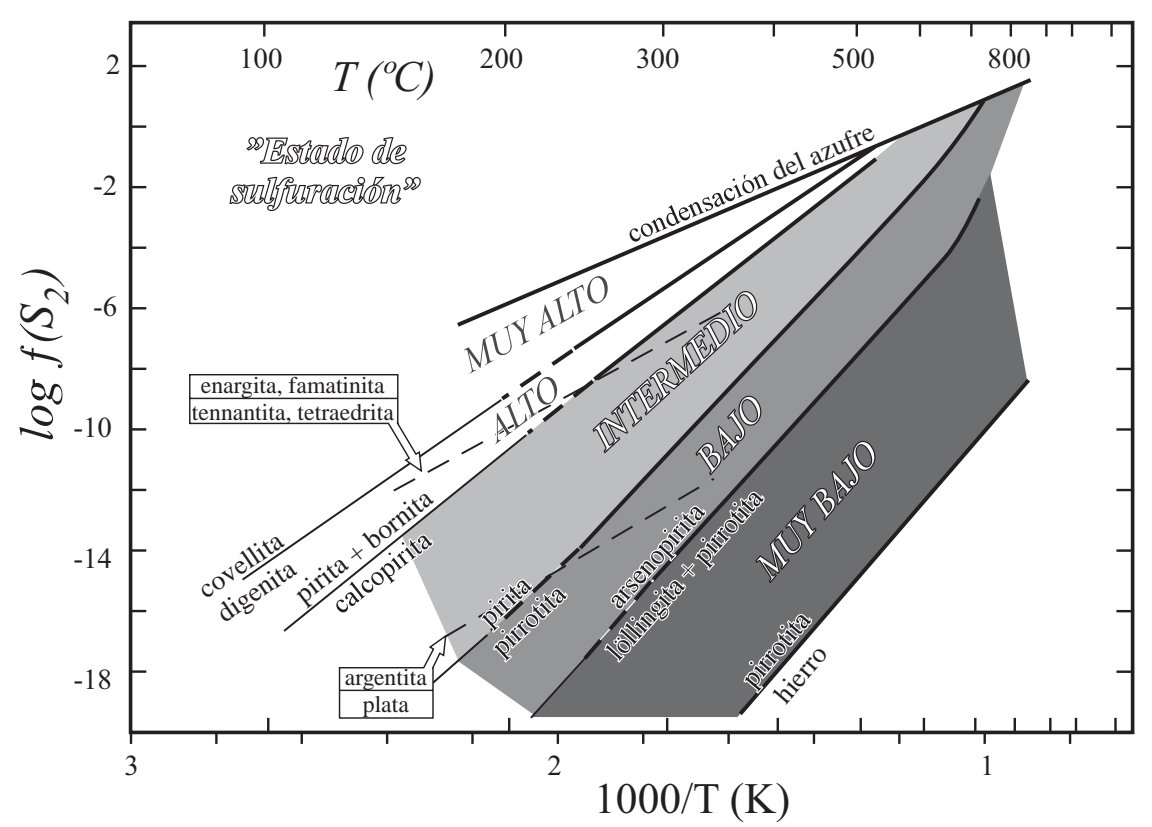

Figura 3. Diagrama de correlación entre temperatura y fugacidad de azufre para los estados de sulfuración relativos de los fluidos hidrotermales en el ámbito de depósitos metalíferos en pórfidos y epitermales, definidos según los campos de estabilidad de minerales clave. Adaptado de Einaudi et al. (2003). Las reacciones de sulfuración fueron tomadas de Barton y Skinner (1979). 


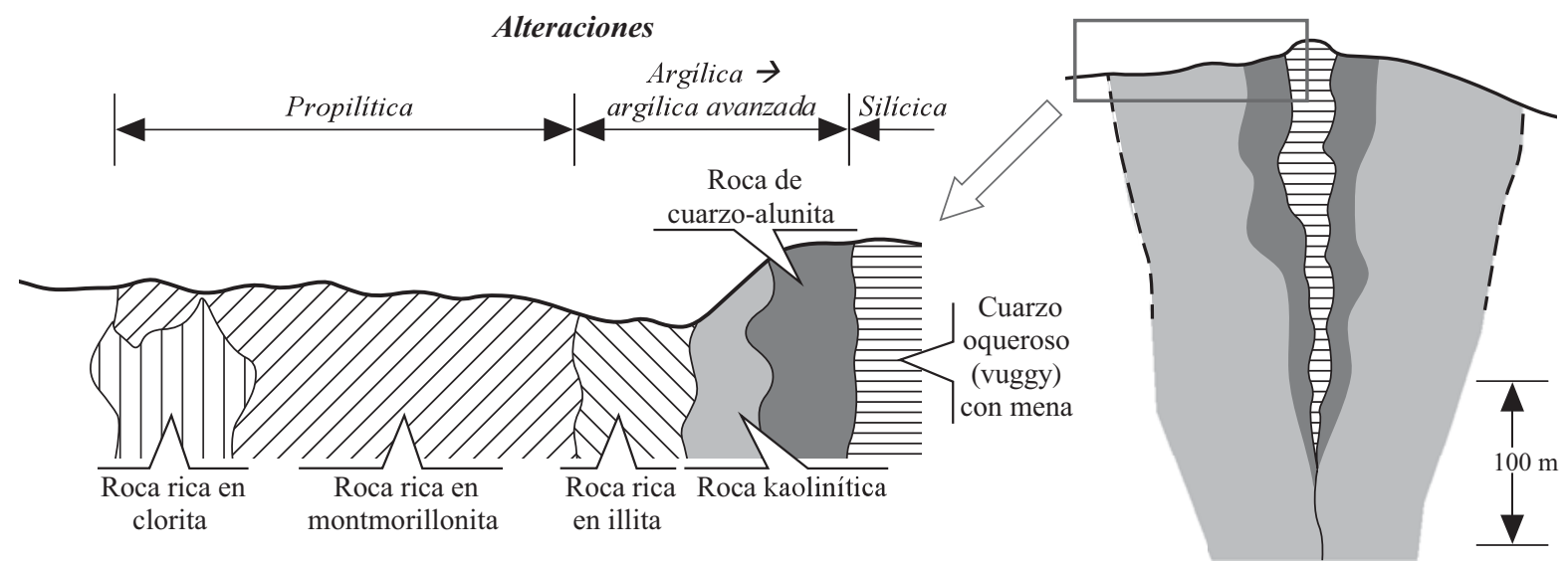

Figura 4. Esquema estructural de un cuerpo epitermal de alta sulfuración típico, basado en los depósitos de Summitville en Colorado (Stoffregen, 1987), mostrando la morfología de cuña del núcleo de sílice oquerosa (vuggy silica), con una ampliación que ilustra la zonación de alteraciones característica desde el núcleo de sílice a la roca encajonante inalterada (Steven y Ratté, 1960). El núcleo de sílice alberga la parte más importante de la mineralización económica, aunque algunas porciones de la zona con alteración argílica avanzada también pueden contener mineralización económica, particularmente donde el contenido en pirofilita es mayor que el de sílice (White, 1991). Cabe remarcar que los fluidos que originan el núcleo de sílice porosa por medio de lixiviación ácida no son los mismos a partir de los que precipitan las asociaciones de minerales metálicos. El núcleo de sílice, debido a su alta porosidad sirve de acuífero para fluidos posteriores (White, 1991). Los fluidos portadores de metales en solución son menos ácidos y oxidados, y relativamente más salinos (Hedenquist et al., 1998). La diferencia más evidente entre los dos subtipos de depósitos epitermales de AS es la presencia o ausencia de mineralizaciones metálicas, formadas con posterioridad al núcleo de sílice. En ausencia de las mismas, los depósitos resultantes se denominan "casquetes de cuarzo-alunita" (quartz-alunite lithocaps; Sillitoe, 1995b).

contexto carece de depósitos de AS, y la deposición en ambiente de BS se produce en stockwork, vetas y brechas, dándose estos dos últimos especialmente en profundidad. Los factores de localización son litologías permeables, fallas, fracturas y márgenes de caldera. Ejemplos de este contexto se encuentran en la zona volcánica central de Taupo y en Ohakuri Dam, Nueva Zelanda.

2. Sistemas hidrotermales en estratovolcanes andesíticos (Figura 6B). Se emplazan en zonas con relieve alto y variable $(500-2000 \mathrm{~m})$. Las rocas volcánicas asociadas son coladas andesíticas y brechas interestratificadas, normalmente con pendientes de deposición pronunciadas; comúnmente, en zonas con pequeñas calderas. $\mathrm{La}$ surgencia se produce a partir de fumarolas y solfataras, $o$ fuentes termales ácidas en los flancos y neutras a mayor distancia, raramente con sínteres. El flujo se produce vertical y lateralmente, con una alteración asociada muy extensa debida a los gases separados. En este contexto se hallan fundamentalmente depósitos metalíferos en pórfidos y epitermales de AS. Los depósitos de SI y BS se encuentran en vetas con un fuerte control estructural en litologías competentes. Ejemplos de este contexto se encuentran en Mount Ruapehu en Nueva Zelanda y Woodlark Island en Papúa-Nueva Guinea, dentro del contexto mayoritario en el SW del Pacífico.

3. Sistemas hidrotermales asociados a vulcanismo en contexto de Cordillera (Figura 6C). Se emplazan en zonas con relieve alto y variable (500-3000 m). Las rocas volcánicas asociadas constituyen centros andesíticos y domos dacíticos sobre un basamento deformado; no suele haber calderas. La surgencia se produce en fuentes termales con sínteres en depresiones, fuentes termales ácidas en los flancos, y neutras a mayor distancia, con presenica de cráteres de explosión hidrotermal. La separación de fases se produce en flujo vertical, con escasa alteración debida a los gases separados. En este contexto se hallan depósitos metalíferos en pórfidos y epitermales de AS. La deposición de SI y BS se produce en stockwork, vetas y brechas, estos dos últimos especialmente en profundidad. Ejemplos de este contexto se encuentran en Antamok-Acupan y Lepanto en Filipinas, así como la mayoría de epitermales de Canadá, E.U.A. y México (Berger y Henley, 1989).

4. Sistemas hidrotermales en islas con vulcanismo de tipo oceánico (Figura 6D). Se emplazan en zonas con relieve moderado y poco variable $(200-500 \mathrm{~m})$. Las rocas volcánicas asociadas son lavas basálticas y andesíticas; comúnmente con pequeñas calderas. Puede haber fuentes termales con sínteres en las calderas, y cráteres de explosión hidrotermal. La separación de fases se produce en flujo vertical, con escasa alteración debida a los gases separados. En este contexto se encuentran mayoritariamente depósitos de BS, aunque se han reconocido depósitos de AS asociados a depósitos metalíferos en pórfidos. La deposición se produce en zonas subsuperficiales de alta permeabilidad, fallas, fracturas y márgenes de caldera. Ejemplos de este contexto se encuentran en la isla Lihir, Papúa-Nueva Guinea, presentándose en el continente Americano en el arco volcánico de la parte sur de Centroamérica donde los depósitos se caracterizan por ser predominantemente auríferos y no argentíferos (Albinson et al., 2001). 


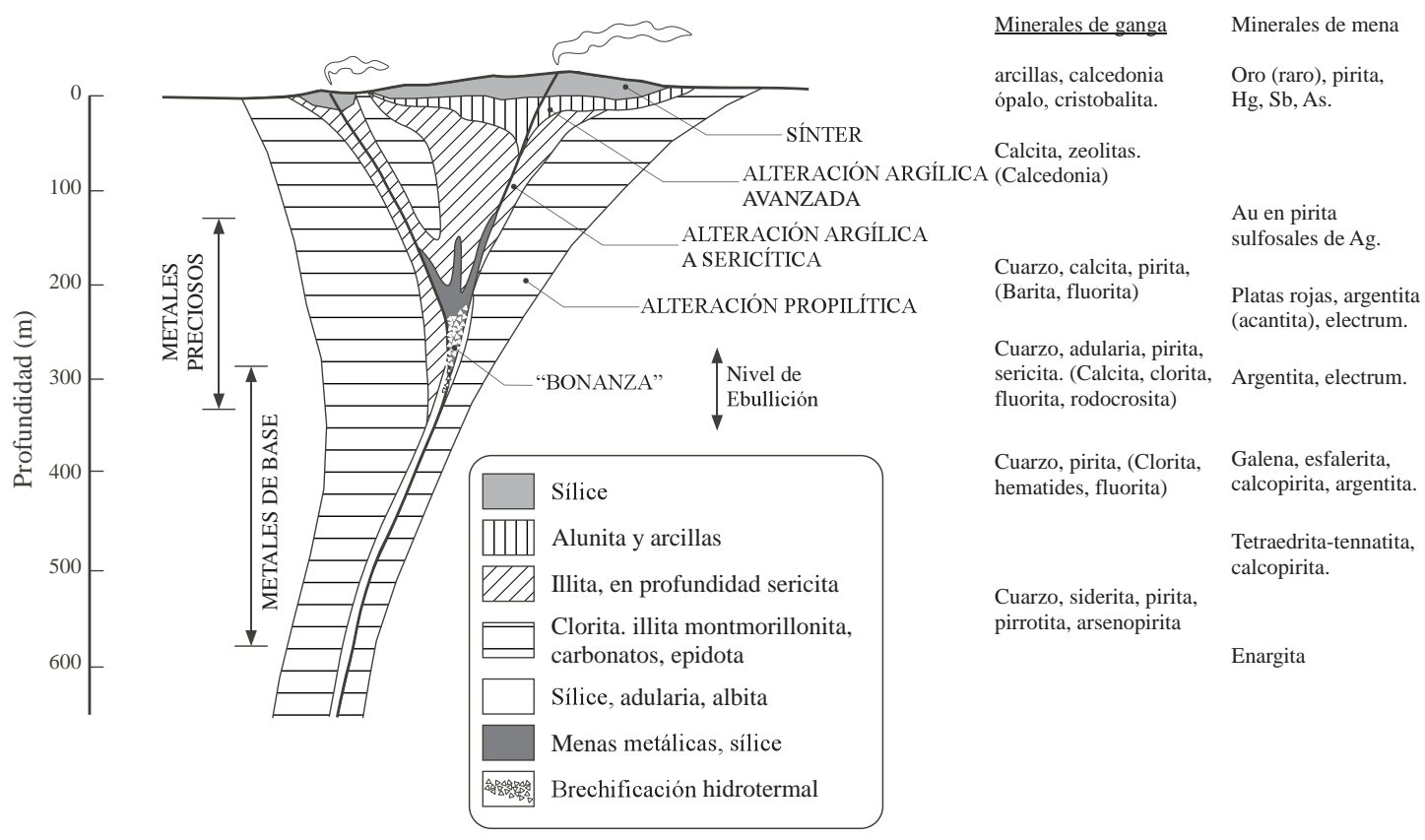

Figura 5. Esquema estructural general de los depósitos epitermales alcalinos (baja e intermedia sulfuración), modificado de Buchanan (1981), indicando la mineralogía de ganga, la generalización de los patrones de alteración típicos, y la variación en la mineralogía de mena típica en profundidad, y en la morfología de la mineralización. Ello incluye la distribución del sínter formado in situ, y la superposición de la alteración argílica avanzada derivada de vapores liberados por ebullición en profundidad. La extensión lateral y volumen de las aureolas de alteración depende, en gran manera, de la presencia de litologías permeables; debido a ello, la morfología y extensión de los halos puede variar desde el orden decimétrico hasta el hectométrico, inclusive dentro de un mismo depósito.

En este aspecto, Sillitoe y Hedenquist (2003) distinguen, a escala continental, numerosos contextos tectónicos favorables para los diversos tipos y subtipos de depósitos epitermales, durante una subducción o tras su término: (1) AS y SI en situación de neutralidad de esfuerzos a arco levemente extensional, con andesitas-dacitas \pm riolitas, (2) AS y SI durante vulcanismo de arco en situación de tras-arco compresional, con andesitas-dacitas \pm riolitas, (3) AS en arco compresional con vulcanismo de subducción, con riodacitas, (4) BS en arco extensional, con andesitasdacitas \pm riolitas o vulcanismo bimodal de basaltos-riolitas, (5) BS durante vulcanismo de arco en situación de tras-arco extensional, con vulcanismo bimodal de basaltos-riolitas, (6) BS en situación de tras-arco extensional durante una transición de magmatismo de subducción a magmatismo bimodal de rift, con vulcanismo alcalino, (7) BS en un margen continental extensional tras el cese de una subducción y relacionado al desarrollo de un margen de fallamiento lateral entre corteza oceánica y continental, con vulcanismo bimodal de basaltos-riolitas, (8) BS en situación de tectónica compresiva relacionada con un margen de fallamiento lateral, con vulcanismo bimodal de basaltosriolitas, (9) BS en situación de magmatismo postcolisional restringido durante compresión tectónica y el rompimiento de la placa subducida debido a la acreción continental, con vulcanismo alcalino, y (10) BS en contexto extensional debido a colapso tectónico tras una acreción continental, con vulcanismo bimodal de basaltos-riolitas.

\subsection{Estilo o forma de mineralización}

Posiblemente, esta es la forma más directa de clasificar a los depósitos epitermales. Ésta es una clasificación que nada dice sobre rocas encajonantes, texturas o génesis del depósito pero, al ser el resultado de la permeabilidad del encajonante durante la mineralización, dice mucho sobre sus condiciones de emplazamiento. Aunque muy pocos depósitos presentan un sólo estilo, bien pueden ponerse como ejemplo algunos depósitos en los que predomina un estilo en concreto. De esta forma, las mineralizaciones pueden diferenciarse según tres tipos de control (Sillitoe, 1993):

1. control estructural: vetas masivas o bien individualizadas (e. g. El Indio, Chile, o Pachuca-Real del Monte, México), "enjambres de vetas" (e.g. Hishikari, Japón), en stockwork (e. g. McLaughlin, E.U.A., o Chinkuashih, Taiwan), y vetas de bajo ángulo asociadas a fallas anulares (e. g. Emperor, Fiji);

2. control hidrotermal: brechas hidrotermales (e. g. Kerimenge, Papúa-Nueva Guinea), y cuerpos de sílice residual (típicos de AS, e. g. Kasuga, Japón);

3. control litológico: diseminaciones bajo acuitardos en ignimbritas o rocas sedimentarias clásticas (e.g. Round Mountain, E.U.A.), reemplazamientos ligados a contrastes de permeabilidad o de reactividad en el caso de rocas huéspez calcáreas (e.g. Taxco y San Francisco del Oro, México), y diseminaciones en brechas de diatrema (e.g. Montana Tunnels, E.U.A.). 
Tabla 1. Principales características de campo de los diferentes tipos de depósitos epitermales y sus subtipos. Adaptado de Sillitoe y Hedenquist (2003).

\begin{tabular}{|c|c|c|c|c|c|}
\hline & \multicolumn{2}{|c|}{$\begin{array}{l}\text { Baja sulfuración } \\
\text { (BS) }\end{array}$} & \multirow[t]{2}{*}{$\begin{array}{l}\text { Sulfuración intermedia } \\
\text { (SI) }\end{array}$} & \multicolumn{2}{|c|}{$\begin{array}{l}\text { Alta sulfuración } \\
\text { (AS) }\end{array}$} \\
\hline & Magma subalcalino & Magma alcalino & & Magma oxidado & Magma reducido \\
\hline Ejemplo tipo & Midas (Nev., EUA) & Emperor (Fiji) & $\begin{array}{l}\text { Rico en Au: Baguio } \\
\text { (Filipinas) } \\
\text { Rico en Ag: Fresnillo (Zac., } \\
\text { México) }\end{array}$ & $\begin{array}{l}\text { Diseminado: Yanacocha } \\
\text { (Perú) } \\
\text { Veta: E1 Indio (Chile) }\end{array}$ & Potosí (Bolivia) \\
\hline $\begin{array}{l}\text { Rocas } \\
\text { volcánicas } \\
\text { relacionadas }\end{array}$ & Basalto a riolita & $\begin{array}{l}\text { Basalto alcalino a } \\
\text { traquita }\end{array}$ & $\begin{array}{l}\text { Andesita a riodacita, } \\
\text { localmente riolita }\end{array}$ & Andesita a riodacita & Riodacita \\
\hline $\begin{array}{l}\text { Minerales clave } \\
\text { de alteración } \\
\text { proximal }\end{array}$ & Illita/smectita-adularia & $\begin{array}{l}\text { Roscoelita-illita- } \\
\text { adularia }\end{array}$ & $\begin{array}{l}\text { Sericita, adularia poco } \\
\text { común }\end{array}$ & $\begin{array}{l}\text { Cuarzo-alunita/ APS, } \\
\text { cuarzo-pirofilita/ dickita } \\
\text { en profundidad }\end{array}$ & $\begin{array}{l}\text { Cuarzo-alunita/ APS, } \\
\text { cuarzo-dickita en } \\
\text { profundidad }\end{array}$ \\
\hline Ganga de sílice & $\begin{array}{l}\text { Cuarzo y calcedonia } \\
\text { crustiforme y } \\
\text { coloforme rellenando } \\
\text { vetas; reempla- } \\
\text { zamiento de carbonatos }\end{array}$ & $\begin{array}{l}\text { Cuarzo y calcedonia } \\
\text { crustiforme y } \\
\text { coloforme rellenando } \\
\text { vetas; cuarzo escaso } \\
\text { en fases iniciales }\end{array}$ & $\begin{array}{l}\text { Cuarzo crustiforme } \\
\text { rellenando vetas y en peine }\end{array}$ & $\begin{array}{l}\text { Silicificación masiva de } \\
\text { residual oqueroso (vuggy }\end{array}$ & grano fino y cuarzo \\
\hline $\begin{array}{l}\text { Ganga de } \\
\text { carbonatos }\end{array}$ & $\begin{array}{l}\text { Presente, pero } \\
\text { típicamente tardía y } \\
\text { escasa }\end{array}$ & $\begin{array}{l}\text { Abundante, pero no } \\
\text { de Mn }\end{array}$ & $\begin{array}{l}\text { Común, típicamente } \\
\text { incluyendo variedades de } \\
\text { Mn }\end{array}$ & Ausente & \\
\hline $\begin{array}{l}\text { Otros minerales } \\
\text { de ganga }\end{array}$ & $\begin{array}{l}\text { Barita poco común, } \\
\text { fluorita localmente }\end{array}$ & $\begin{array}{l}\text { Barita, celestina y/o } \\
\text { fluorita común local- } \\
\text { mente }\end{array}$ & $\begin{array}{l}\text { Barita y silicatos de Mn } \\
\text { presentes localmente }\end{array}$ & Barita común, típicament & te tardía \\
\hline $\begin{array}{l}\text { Abundancia de } \\
\text { sulfuros }\end{array}$ & $\begin{array}{l}\text { Típicamente }<1 \text { a } 2 \% \\
\text { vol. (hasta } 20 \% \text { vol. } \\
\text { encajado en basaltos) }\end{array}$ & 2 a $10 \%$ vol. & 5 a $>20 \%$ vol. & 10 a $90 \%$ vol. & \\
\hline $\begin{array}{l}\text { Especies de } \\
\text { sulfuros clave }\end{array}$ & $\begin{array}{l}\text { Escasa a muy escasa ars } \\
\text { escasas esfalerita, galen } \\
\text { calcopirita }\end{array}$ & $\begin{array}{l}\text { enopirita } \pm \text { pirrotita; } \\
\text { tetraedrita-tennantita, }\end{array}$ & $\begin{array}{l}\text { Esfalerita, galena, } \\
\text { tetraedrita-tennantita, } \\
\text { calcopirita }\end{array}$ & $\begin{array}{l}\text { Enargita, luzonita, } \\
\text { famatinita, covellita }\end{array}$ & Acantita, estibina \\
\hline $\begin{array}{l}\text { Metales } \\
\text { principales }\end{array}$ & $\mathrm{Au} \pm \mathrm{Ag}$ & & $\mathrm{Au}-\mathrm{Ag}, \mathrm{Zn}, \mathrm{Pb}, \mathrm{Cu}$ & $\mathrm{Au}-\mathrm{Ag}, \mathrm{Cu}, \mathrm{As}-\mathrm{Sb}$ & $\mathrm{Ag}, \mathrm{Sb}, \mathrm{Sn}$ \\
\hline $\begin{array}{l}\text { Metales } \\
\text { menores }\end{array}$ & $\mathrm{Zn}, \mathrm{Pb}, \mathrm{Cu}, \mathrm{N}$ & $\mathrm{o}, \mathrm{As}, \mathrm{Sb}, \mathrm{Hg}$ & $\mathrm{Mo}, \mathrm{As}, \mathrm{Sb}$ & $\begin{array}{l}\mathrm{Zn}, \mathrm{Pb}, \mathrm{Bi}, \mathrm{W}, \mathrm{Mo} \text {, } \\
\mathrm{Sn}, \mathrm{Hg}\end{array}$ & $\mathrm{Bi}, \mathrm{W}$ \\
\hline $\begin{array}{l}\text { Especies de Se } \\
\text { y Te }\end{array}$ & $\begin{array}{l}\text { Seleniuros comunes, } \\
\text { localmente telururos }\end{array}$ & $\begin{array}{l}\text { Telururos abundantes, } \\
\text { seleniuros poco } \\
\text { comunes }\end{array}$ & $\begin{array}{l}\text { Telururos localmente } \\
\text { comunes, seleniuros poco } \\
\text { comunes }\end{array}$ & $\begin{array}{l}\text { Telururos comunes, } \\
\text { localmente seleniuros }\end{array}$ & $\begin{array}{l}\text { Desconocido, pocos } \\
\text { datos }\end{array}$ \\
\hline
\end{tabular}

\subsection{Modelo de deposición}

Este tipo de clasificación conecta con el anterior, en el sentido que tiene en cuenta la profundidad de formación. El segundo factor decisivo es el mecanismo a partir del cual se produjo la precipitación mineral, más en concreto, la existencia o no de ebullición. Así, se pueden definir tres tipos de depósitos epitermales de BS diferentes (Figura 7):

1. depósitos de "ebullición profunda" (o deep vein type), que son los más comunes dentro de los epitermales mexicanos (Albinson et al., 2001), como Fresnillo, Guanajuato, Pachuca-Real del Monte o Tayoltita. Suelen ser cuerpos minerales ciegos, es decir, que no afloran en superficie, relacionados con fluidos hidrotermales que inician la ebullición $\mathrm{a} \geq 300^{\circ} \mathrm{C}$ a profundidades de $\geq 1000$ $\mathrm{m}$ bajo la paleosuperfície, y se dispersan lateralmente en el sistema hidrológico;

2. depósitos de "ebullición somera" (o hot spring type), como McLaughlin en E.U.A., o San Martín en México. Se presentan a unos 300-400 m bajo la paleosuperfície, relacionados al "retraso" de la ebullición de los fluidos ascendentes en el sistema hidrotermal (Saunders, 1996);

3. depósitos "profundos sin ebullición", como Sombrerete en México. Éstos se caracterizan por hallarse dispuestos en zonas verticalmente extensas, relacionados con fluidos sobrepresionados, sin experimentar ebullición, que ascienden principalmente como líquidos (Albinson, 1988). 

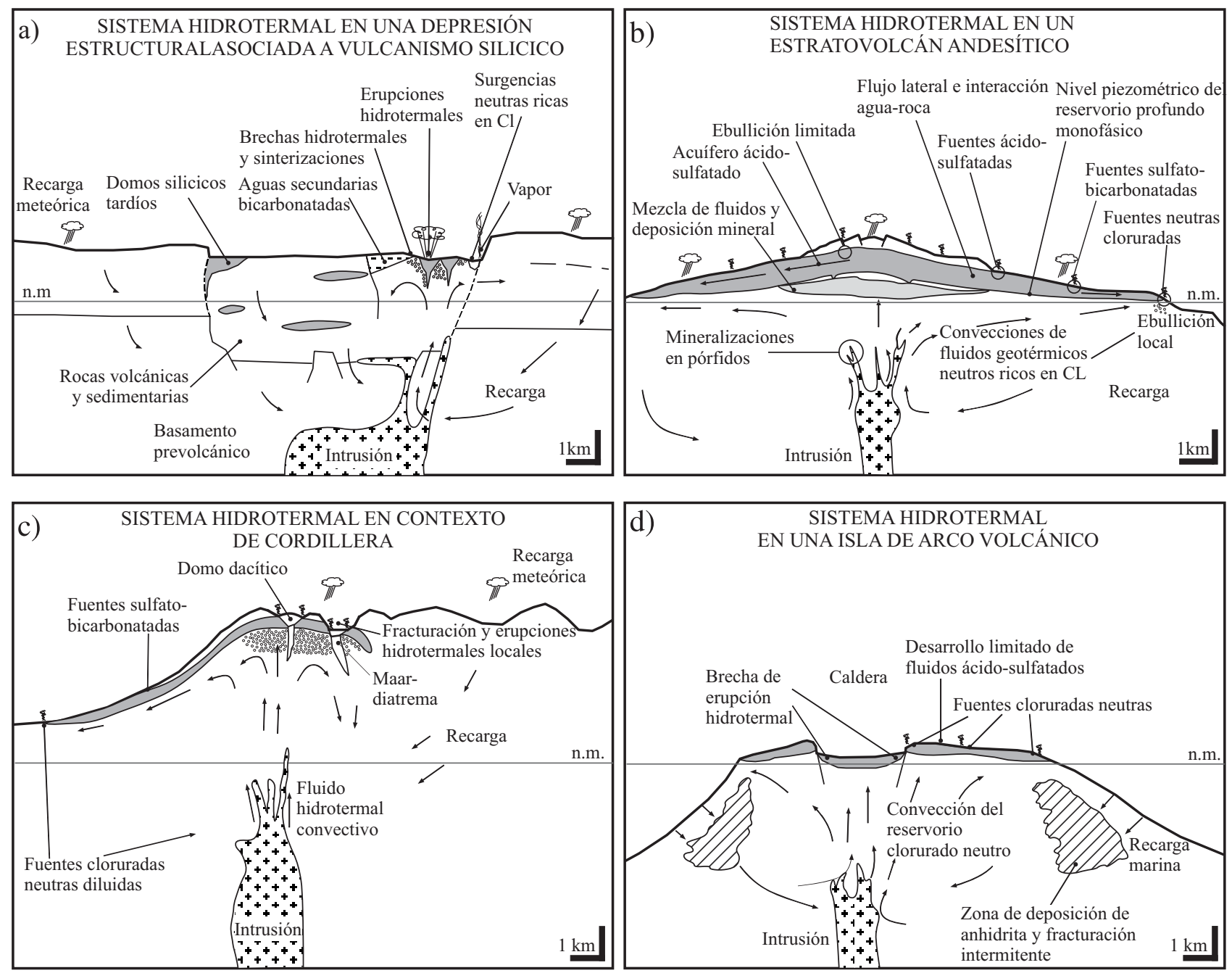

Figura 6. Esquemas de los diferentes contextos geológicos en que se producen depósitos epitermales, tanto ácidos (alta sulfuración) y alcalinos (baja e intermedia sulfuración). Simplificado de Bogie y Lawless, 1987, y de White et al., 1995). Clave: n.m. = nivel del mar.

\subsection{Profundidad de formación}

Esta clasificación (Tabla 2) permite explicar la variabilidad en las características específicas de los depósitos, según si su formación es "somera" (hasta unos $1000 \mathrm{~m}$ de profundidad) o "profunda" (hasta más de $2000 \mathrm{~m}$ de profundidad), puesto que los depósitos del suroeste del Pacífico se formaron generalmente a profundidades mayores que las reseñadas para los depósitos de Norteamérica (Sillitoe, 1988; Reyes, 1990, 1991), coincidiendo con las dos zonas de mayor abundancia areal de depósitos encajonados en estratovolcanes andesíticos y en contexto de Cordillera, respectivamente.

Los grandes depósitos epitermales de BS del suroeste del Pacífico también suelen presentar características ciertamente atípicas, si los comparamos con los más "clásicos" de Norteamérica, tales como: (1) depósitos con temperaturas relativamente mayores (e. g. Kelian, Indonesia), mineralizaciones diseminadas en brechas aparentemente relacio- nadas con alteraciones previas debidas a interacción con agua marina (e. g. Ladolam, Papúa-Nueva Guinea; White et al., 1995); (2) depósitos transicionales entre mesotermal y epitermal o "depósitos epitermales del tipo alcalino" o BSalcalinos (e. g. Porgera, Papúa-Nueva Guinea; Richards, 1992, 1995; Richards y Kerrich, 1993; Richards et al., 1997), etc. También en Norteamérica han sido descritos depósitos transicionales relacionados con pórfidos (modelo general de British Columbia, Canadá; Panteleyev, 1988), en contexto de Cordillera.

La presencia de enargita en algunos depósitos hasta ahora considerados de BS sugirió desde hace tiempo afinidades de algunos de éstos con los de AS. Buchanan (1981) contempló la presencia de enargita en profundidad, por debajo del nivel de ebullición, en su clásico modelo de los epitermales de alcalinos/neutros (Figura 5). Los depósitos epitermales de ese tipo en que se ha hallado enargita son: Tuscarora, E.U.A. (Buchanan, 1981), Ladolam, Papúa-Nueva Guinea (White et al., 


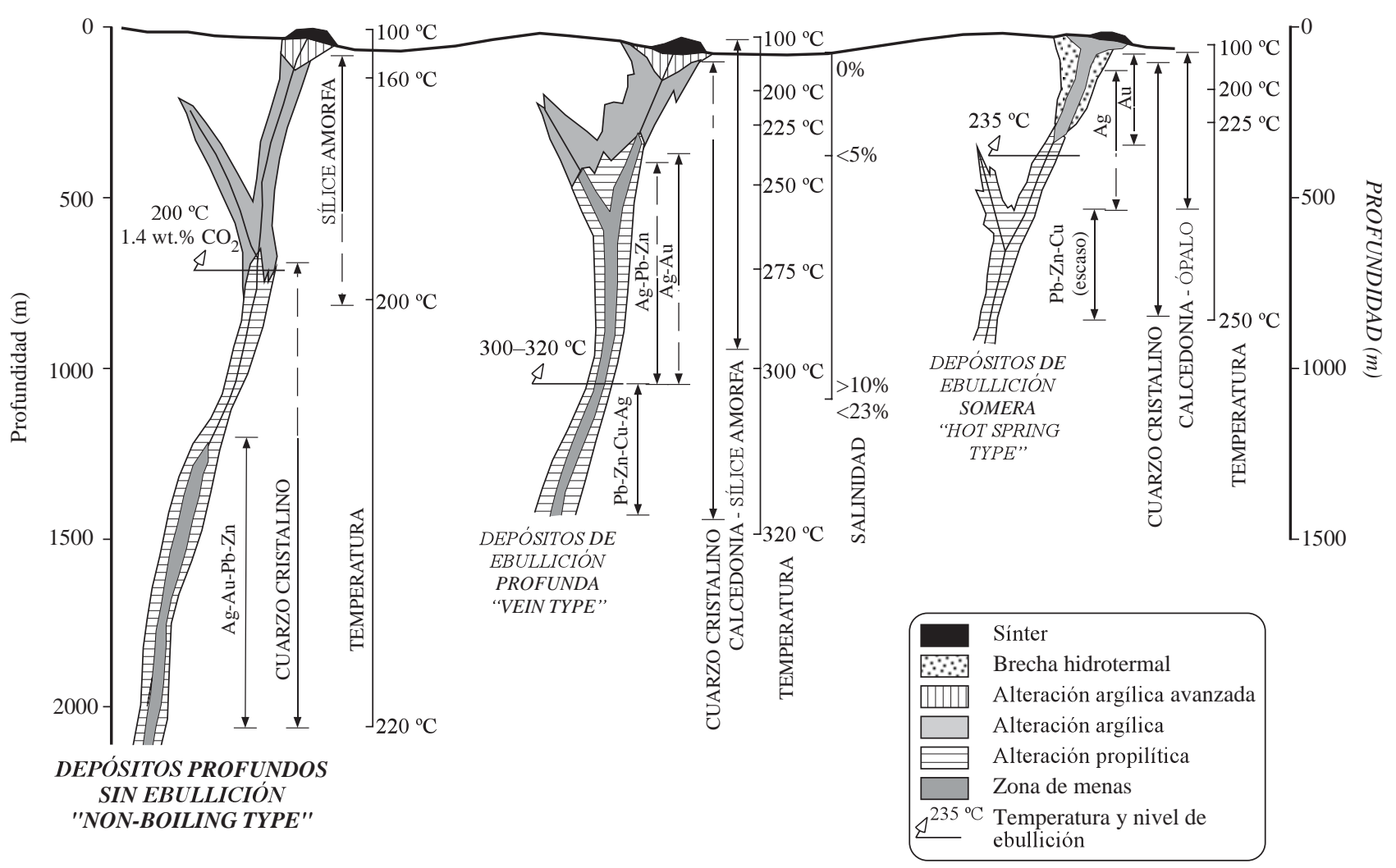

Figura 7. Tipos de depósitos epitermales alcalinos/neutros (baja e intermedia sulfuración) presentes en México, según su profundidad de formación relacionado al inicio del proceso de ebullición de fluidos sódico-clorurados ascendentes (simplificado de Albinson et al., 2001).

1995), Thames, Nueva Zelanda (Christie y Brathwaite, 1986), Orcopampa, Perú (Gibson et al., 1990), Faride, Chile (Camus y Skewes, 1991), Portovelo, Ecuador (van Thournout et al., 1996), Temascaltepec, México (Camprubí et al., 2001a), y San Felipe-Mexicali, México (Ibarra-Serrano, 1997). Esta característica de algunos depósitos epitermales alcalinos/neutros es uno de los elementos que llevó a la definición de los depósitos epitermales de SI dentro de los de BS por Hedenquist et al. (2000), y después como tipología independiente (Einaudi et al., 2003; Sillitoe y Hedenquist, 2003). De esta forma, al menos por el momento, puede considerarse que la presencia de enargita en depósitos epitermales alcalinos/ neutros es diagnóstica de que, al menos en alguna fase de formación del depósito, éste puede caracterizarse como de SI, o mixto de SI y BS.

Dentro de los epitermales de BS y SI "someros" o encajonados en un contexto de vulcanismo de Cordillera, pueden distinguirse características geoquímicas diferenciadas entre los depósitos ricos en plata y metales básicos, y los depósitos más ricos en oro. Los fluidos asociados a los primeros suelen presentar salinidades más altas y contenidos más bajos en $\mathrm{H}_{2} \mathrm{~S}$ que los segundos, en los que fue definido el término epitermal, con salinidades asociadas más bajas y más ricos en gases (Heald et al., 1987; Hedenquist y Lowenstern, 1994).

\subsection{Contenido relativo en metales básicos}

Este es un criterio puramente económico, en que los depósitos epitermales se definen como "ricos" y "pobres" en metales básicos (Heald et al., 1987; White et al., 1995), con ejemplos en Fresnillo y Tayoltita, respectivamente (ver Albinson et al., 2001), para SI. Del mismo modo pueden caracterizarse por su relación $\mathrm{Ag} / \mathrm{Au}$, en cuyo caso buena parte de los depósitos epitermales de BS y SI de México y del suroeste de los Estados Unidos se distinguen especialmente por su alto contenido en Ag.

\section{Relación con otros tipos de depósitos minerales}

La conexión genética de los depósitos epitermales con otras tipologías de depósitos minerales en contextos geotectónicos similares es uno de los temas de discusión más actuales acerca de estos depósitos. Existe una relación genética y temporal entre magmatismo y depósitos epitermales de SI y AS (McKee et al., 1992; Conrad et al., 1993; Simmons, 1995; Albinson et al., 2001; Enríquez y Rivera, 2001a; Camprubí et al., 2003b; Einaudi et al., 2003; Sillitoe y Hedenquist, 2003), así como también con depósitos metalíferos en pórfidos y skarns (Arribas et al., 1995; Hedenquist et al., 1996, 1998, 2000; Sillitoe, 1999; 
Müller y Groves, 2000; Brathwaite et al., 2001; Müller et al., 2002; Strashimirov et al., 2002; Einaudi et al., 2003; Morales-Ramírez et al., 2003; Sillitoe y Hedenquist, 2003; Simpson et al., 2004; Tritlla et al., 2004).

Lo que no ha sido tan evidente es la posible relación con otros tipos de depósitos. Aunque la definición estricta de depósito epitermal especifica que su ambiente de formación es subaéreo, recientemente se ha descrito la existencia de epitermales submarinos que, además, presentan afinidades genéticas con depósitos de sulfuros masivos vulcanogénicos (Herzig y Hannington, 1995; Herzig et al. 1999; Sillitoe et al., 1996; Petersen et al., 2002; Sillitoe y Hedenquist, 2003), y que Schwarz-Schampera et al. (2001) han calificado de depósitos transicionales entre epitermales y sistemas hidrotermales submarinos.

En el caso concreto de los depósitos submarinos de la costa de la isla Lihir, Papúa Nueva Guinea, es notable el hecho de que éstos son la continuación espacial directa bajo el mar de Ladolam, un conocido depósito epitermal de BS. Salvando las distancias, es posible que las vetas de calcitacuarzo-barita y los manantiales submarinos con cinabrio y sínteres en la Bahía de Concepción, Baja California Sur (Prol-Ledesma et al., 2004; Canet et al., 2005a,b) sean parte de un depósito análogo, a habidas cuentas que el ambiente geotectónico extensional actual es equivalente a los ambientes propicios para la formación de epitermales de BS según Sillitoe y Hedenquist (2003).

También se ha relacionado genéticamente a los depósitos epitermales proterozoicos de la zona del Tapajós en Brasil con depósitos de óxidos de hierro-Cu-Au o IOCG (Jacobi, 1999). En este sentido, cabría evaluar la posibilidad de que, al menos a escala de provincia y época metalogenética, pudieran relacionarse depósitos fanerozoicos equivalentes del tipo IOCG con depósitos del sistema

Tabla 2. Características de los depósitos epitermales ácidos (alta sulfuración) y alcalinos (baja e intermedia sulfuración), en función de la profundidad de formación en depósitos individuales; en ocasiones, también aproximables a variaciones dentro de un mismo depósito. Adaptado de Hedenquist et al. (2000).

\begin{tabular}{|c|c|c|c|c|c|}
\hline & \multicolumn{2}{|c|}{ Epitermales alcalinos (BS y SI) } & \multicolumn{3}{|c|}{ Epitermales ácidos (AS) } \\
\hline \multirow{2}{*}{$\begin{array}{l}\text { Rocas volcánicas } \\
\text { relacionadas }\end{array}$} & \multicolumn{2}{|c|}{$\begin{array}{l}\text { Andesitas-riodacitas (AR), riolitas-basaltos bimodales } \\
(\mathrm{RB}) \text {, alcalinas (A) }\end{array}$} & \multicolumn{3}{|c|}{ Andesitas-riodacitas, dominadas por magmas calcoalcalinos } \\
\hline & Somero & Profundo & Somero & Intermedio & Profundo \\
\hline $\begin{array}{l}\text { Profundidad de } \\
\text { formación }\end{array}$ & $0-300 \mathrm{~m}$ & $\begin{array}{l}300-800 \mathrm{~m} \text { (muy raro } \\
>1000 \mathrm{~m})\end{array}$ & $<500 \mathrm{~m}$ & $500-1000 \mathrm{~m}$ & $>1000 \mathrm{~m}$ \\
\hline $\begin{array}{l}\text { Contexto; roca de } \\
\text { caja típica }\end{array}$ & $\begin{array}{l}\text { Domos; rocas piroclásti- } \\
\text { cas y sedimentarias }\end{array}$ & $\begin{array}{l}\text { Domos, diatremas (AR, } \\
\text { A); rocas piroclásticas y } \\
\text { sedimentarias }\end{array}$ & $\begin{array}{l}\text { Domos, surgencia cen- } \\
\text { tral; rocas piroclásticas } \\
\text { y sedimentarias }\end{array}$ & $\begin{array}{l}\text { Domos, diatremas; } \\
\text { rocas volcánicas }\end{array}$ & $\begin{array}{l}\text { Domo-diatrema; pórfi- } \\
\text { dos, rocas volcánicas y } \\
\text { sedimentarias clásticas }\end{array}$ \\
\hline $\begin{array}{l}\text { Morfología del } \\
\text { depósito }\end{array}$ & $\begin{array}{l}\text { Vetas, enjambres de vetas, } \\
\text { stockwork, disemina- } \\
\text { ciones }\end{array}$ & $\begin{array}{l}\text { Vetas, cuerpos } \\
\text { brechificados, } \\
\text { diseminaciones }\end{array}$ & $\begin{array}{l}\text { Diseminaciones, } \\
\text { brechas y vetillas }\end{array}$ & $\begin{array}{l}\text { Vetas de sulfuros } \\
\text { masivos, brechas }\end{array}$ & $\begin{array}{l}\text { Diseminaciones, } \\
\text { vetillas, brechas }\end{array}$ \\
\hline $\begin{array}{l}\text { Texturas de las } \\
\text { menas }\end{array}$ & $\begin{array}{l}\text { Bandas delgadas, crusti- } \\
\text { formes, en peine, brechas }\end{array}$ & Bandas gruesas & $\begin{array}{l}\text { Cuarzo oqueroso de } \\
\text { reemplaza-miento }\end{array}$ & $\begin{array}{l}\text { Sulfuros masivos, ve- } \\
\text { tas o brechas tardías }\end{array}$ & Reemplaza-miento \\
\hline Alteración & $\begin{array}{l}\text { Capa de alunita-kaolinita, } \\
\text { halo de arcillas }\end{array}$ & $\begin{array}{l}\text { Arcillas, sericita, carbona- } \\
\text { tos; roscoelita, fluorita (A) }\end{array}$ & $\begin{array}{l}\text { Silícica (oquerosa), } \\
\text { cuarzo-alunita }\end{array}$ & $\begin{array}{l}\text { Silícica (oquero-sa), } \\
\text { cuarzo-alu-nita, pirofi- } \\
\text { lita-dickita-sericita }\end{array}$ & $\begin{array}{l}\text { Pirofilita-sericita, cu- } \\
\text { arzo-sericita }\end{array}$ \\
\hline $\begin{array}{l}\text { Minerales de } \\
\text { ganga }\end{array}$ & $\begin{array}{l}\text { Calcedonia-adularia-illita- } \\
\text { calcita }\end{array}$ & $\begin{array}{l}\text { Cuarzo-carbonatos-ser- } \\
\text { icita-adularia } \pm \text { barita } \pm \\
\text { anhidrita } \pm \text { hematites } \pm \\
\text { clorita (AR) }\end{array}$ & $\begin{array}{l}\text { Alunita, barita, } \\
\text { kaolinita }\end{array}$ & $\begin{array}{l}\text { Anhidrita, kaolinita, } \\
\text { dickita }\end{array}$ & Sericita, pirofilita \\
\hline Sulfuros & $\begin{array}{l}\text { Cinabrio, estibina; pirita/ } \\
\text { marcasita-arsenopirita, } \\
\text { seleniuros } \mathrm{Au}-\mathrm{Ag} \text {, } \\
\text { sulfosales } \mathrm{Se}, \text { pirrotita, } \\
\text { esfalerita-Fe }(\mathrm{RB})\end{array}$ & $\begin{array}{l}\text { Pirita-sulfuros/ sulfosales } \\
\text { Au-Ag, } \pm \text { esfalerita, } \\
\text { galena, calcopirita, } \\
\text { tetraedrita/ tennantita } \\
\text { (AR) }\end{array}$ & $\begin{array}{l}\text { Enargita/luzonita, } \\
\text { covellita, pirita }\end{array}$ & $\begin{array}{l}\text { Enargita/luzonita, } \\
\text { calcopirita, tetraedrita/ } \\
\text { tennantita, esfalerita, } \\
\text { covellita tardía, pirita }\end{array}$ & $\begin{array}{l}\text { Bornita, digenita, cal- } \\
\text { cocita, covellita }\end{array}$ \\
\hline Metales & $\begin{array}{l}\mathrm{Au}-\mathrm{Ag}-\mathrm{As}-\mathrm{Sb}-\mathrm{Se}-\mathrm{Hg}-\mathrm{Tl} \\
(\mathrm{RB}), \text { relación } \mathrm{Ag} / \mathrm{Au} \\
\text { baja; metales básicos } \\
<0.1-1 \%\end{array}$ & $\begin{array}{l}\mathrm{Ag}-\mathrm{Au}-\mathrm{Pb}-\mathrm{Zn}, \mathrm{Ba}, \mathrm{Mn}, \mathrm{Se} \\
(\mathrm{AR}) \text {, relación } \mathrm{Ag} / \mathrm{Au} \text { alta; } \\
\text { metales básicos }<2-10 \\
(20+) \%\end{array}$ & $\begin{array}{l}\mathrm{Au}-\mathrm{Ag}, \mathrm{Cu} \text { lixiviado } \\
\text { (Hg superpuesto) }\end{array}$ & $\mathrm{Cu}-\mathrm{Au}-\mathrm{Ag}-\mathrm{Bi}-\mathrm{Te}-\mathrm{Sn}$ & $\mathrm{Cu}-\mathrm{Au}$ \\
\hline $\begin{array}{l}\text { Características } \\
\text { notables }\end{array}$ & $\begin{array}{l}\text { Sínter, capa de calcedonia } \\
\text { (zona freática) }\end{array}$ & $\begin{array}{l}\text { Algunas vetas de sulfura- } \\
\text { ción intermedia, adyacen- } \\
\text { tes a depósitos de AS }\end{array}$ & $\begin{array}{l}\text { Capa de alteración } \\
\text { debida a aguas } \\
\text { calentadas por vapor }\end{array}$ & $\begin{array}{l}\text { Cuarzo oqueroso } \\
\text { (vuggy) }\end{array}$ & $\begin{array}{l}\text { Superpuesto a depósitos } \\
\text { metalíferos en pórfidos }\end{array}$ \\
\hline Fluidos & Incremento de salin & nidad y temperatura & Incremento de salin & idad y temperatura & Variable \\
\hline $\begin{array}{l}\text { Denominación de } \\
\text { tipo o subtipo }\end{array}$ & $\begin{array}{l}\text { Baja sulfuración (término } \\
\text { extremo) }\end{array}$ & Sulfuración intermedia & & & $\begin{array}{l}\text { Depósitos metalíferos } \\
\text { en pórfidos }\end{array}$ \\
\hline
\end{tabular}


pórfido-skarn-epitermal, en zonas propicias como los Andes o el suroeste de México.

\section{Origen de los componentes y concentración en los fluidos mineralizantes. Reacción con las rocas encajonantes}

El vulcanismo submarino que se produce en las dorsales centro-oceánicas y el hidrotermalismo asociado son responsables de la deposición de metales básicos en la corteza oceánica y de su alteración. Este proceso conlleva la hidratación de las rocas que constituyen la corteza en formación y la incorporación a ella de elementos tomados del agua marina, tales como azufre (en forma de sulfato) o cloro. La posterior deposición de sedimentos también incorpora a la corteza metales diversos, e igualmente atrapa agua marina. Durante el proceso de subducción (ver Hedenquist y Lowenstern, 1994) se produce la deshidratación de los sedimentos oceánicos incorporados y de las rocas hidratadas de la placa subducente (Figura 8). La liberación de agua durante este proceso metamórfico es la responsable de la fusión parcial del manto suprayacente a la zona de Wadati-Benioff (Stolper y Newman, 1994). Seguidamente, los magmas producidos por dicho mecanis- mo empiezan a ascender a través del manto, primero, y de la corteza, después, diferenciándose e interaccionando de diversas formas con las rocas encajonantes. Por lo tanto, hay una gran variedad de posibles fuentes de los componentes (metales, agua, halógenos, volátiles, sulfato, etc.) que luego serán fundamentales para la deposición mineral en la corteza continental (depósitos metalíferos en pórfidos, skarns, depósitos mesotermales, epitermales, etc.), incluyendo el agua marina, la corteza oceánica subducida y sus sedimentos, el manto y la propia corteza continental.

Los fluidos magmáticos derivados de cuerpos intrusivos someros relacionados con la formación de depósitos epitermales (AS, SI o BS) experimentan en profundidad una desmezcla (Figura 9; Hedenquist y Lowenstern, 1994; Gammons y Williams-Jones, 1997), durante la cual gran parte del agua y del $\mathrm{H}_{2} \mathrm{~S}$ migran a la fase vapor. Éste, al enfriarse, se recondensa en forma de aguas de naturaleza mixta magmática-meteórica, ricas en $\mathrm{H}_{2} \mathrm{~S}$ y, en consecuencia, con un alto potencial de disolución y removilización de cantidades significativas de oro en forma de complejos tiosulfurados (Gammons y Williams-Jones, 1997). Los fluidos resultantes originan depósitos de AS, SI o BS (ver Figura 10) en la parte superior de la corteza, según la capacidad de tamponamiento del $\mathrm{pH}$ por parte de las rocas encajonantes. En el caso de los de BS y SI se asume una

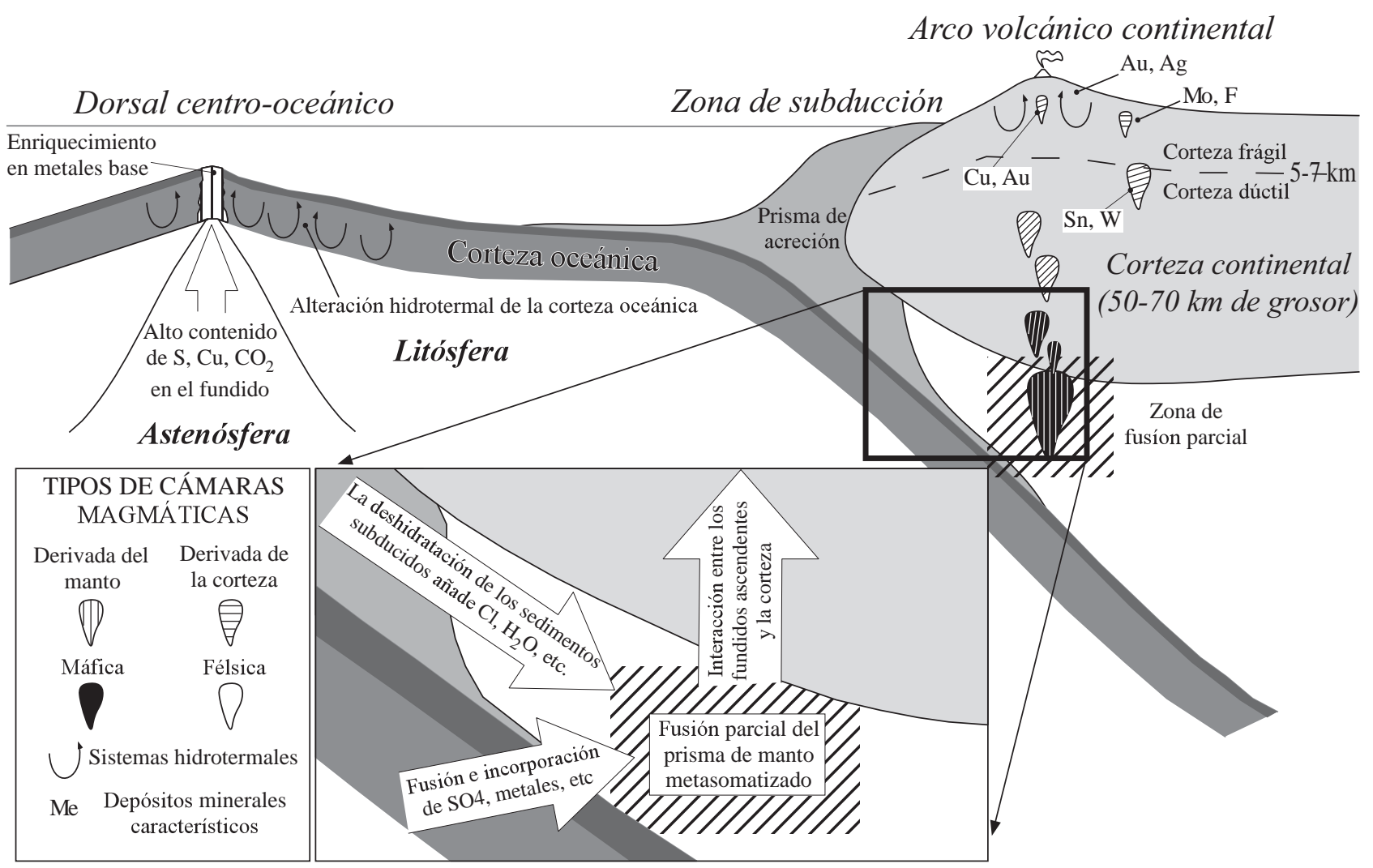

FUENTES DE METALES Y VOLÁTILES EN MAGMAS DE ARCO

Figura 8. Características de los depósitos epitermales ácidos (alta sulfuración) y alcalinos (baja e intermedia sulfuración), en función de la profundidad de formación en depósitos individuales; en ocasiones, también aproximables a variaciones dentro de un mismo depósito. Adaptado de Hedenquist et al. (2000). 
“neutralización primaria" durante la migración de los fluidos a través de la corteza, ya sea que dichos fluidos sean derivados de cuerpos intrusivos someros o profundos (Figura 11; Hedenquist y Lowenstern, 1994). Esta neutralización se traduce en las rocas encajonantes como alteraciones de varios tipos, incluyendo el tipo ácido-sulfato. Por lo tanto, resulta lógico pensar que al menos una cierta parte de los componentes químicos de dichos fluidos provienen de la lixiviación del encajonante. Como se verá más adelante, este hecho puede comprobarse mediante el estudio de la composición isotópica de algunos elementos, como el plomo (Hayba et al., 1985).

\section{Transporte de metales}

La especie $\mathrm{Au}(\mathrm{HS})_{2}^{-}$es muy estable a $\mathrm{pH}$ aproximadamente neutro, según la reacción

$$
\mathrm{Au}^{+}+\mathrm{H}_{2} \mathrm{~S}+\mathrm{HS}^{-} \leftrightarrow \mathrm{Au}(\mathrm{HS})_{2}^{-}+\mathrm{H}^{+}
$$

lo que indica que cantidades de oro geológicamente significativas, en cuanto a su capacidad de poder originar depósitos económicos, pueden ser transportadas por un fluido hidrotermal típico (Shenberger y Barnes 1989). En condiciones más ácidas, como las de los epitermales de AS o en las zonas "de raíz" de los fluidos ascendentes en epitermales de BS y SI, la especie $\mathrm{AuHS}^{0}$ es la dominante (Benning y Seward, 1996; Giggenbach, 1997), aunque los fluidos en los de AS estén relativamente oxidados y sean de salinidad ligeramente superior (Hedenquist et al., 1998) a la normal, según la reacción

$$
\mathrm{Au}^{+}+\mathrm{H}_{2} \mathrm{~S}+\leftrightarrow \mathrm{AuHS}^{0}+\mathrm{H}^{+}
$$

Sin embargo, en un rango de temperatura de 250 a $350^{\circ} \mathrm{C}$, condiciones muy comunes para la formación de depósitos epitermales, la especie portadora de oro dominante será $\mathrm{HAu}(\mathrm{HS})_{2}^{0}$ en la mayoría de condiciones de deposición mineral en que los fluidos se encuentran en equilibrio con pirita y/o pirrotita (Figura 12; Hayashi y Ohmoto, 1991). En el mismo rango de temperatura, la especie $\mathrm{Au}(\mathrm{HS})_{2}^{-}$será más importante para el transporte de oro que $\mathrm{HAu}(\mathrm{HS})_{2}^{0}$ a $\mathrm{pH}>5.5$. Sólo en un fluido rico en cloro, pobre en $\mathrm{H}_{2} \mathrm{~S}$ y con un $\mathrm{pH}$ ligeramente ácido $(<4.5)$ para un rango de temperatura de $250-350^{\circ} \mathrm{C}$, el oro será transportado como complejo clorurado (Hayashi y Ohmoto, 1991; Gammons y Williams-Jones, 1995), según la reacción,

$$
\mathrm{Au}_{(\text {aleación })}+2 \mathrm{Cl}^{-}+\mathrm{H}^{+}+\frac{1}{4} \mathrm{O}_{2 \text { (gas) }} \leftrightarrow \mathrm{AuCl}_{2}^{-}+\frac{1}{2} \mathrm{H}_{2} \mathrm{O}
$$

en cuyo caso se espera que el oro esté asociado con un alto contenido de plata y metales básicos, ya que se considera que $\mathrm{Ag}, \mathrm{Pb}, \mathrm{Cu}$ y $\mathrm{Zn}$ son transportados predominantemente como complejos moleculares clorurados (Barnes, 1979;

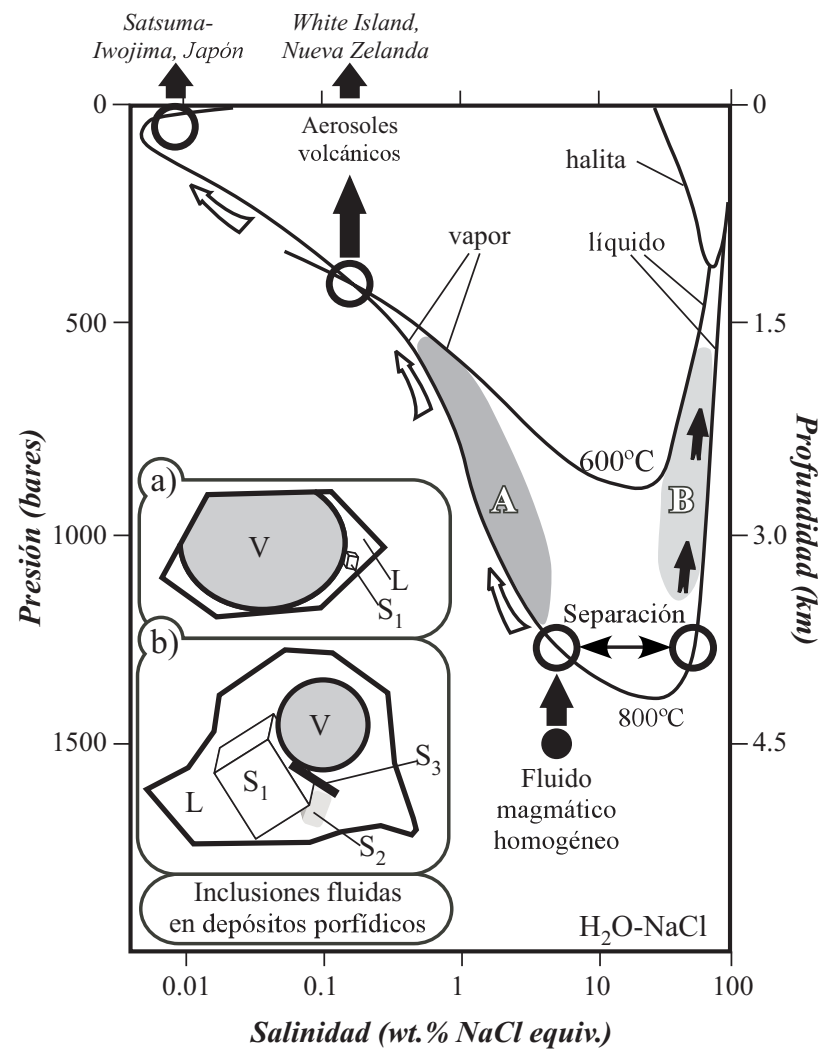

Figura 9. Composición de los fluidos inmiscibles en el sistema agua- $\mathrm{NaCl}$ (Pitzer y Pabalan, 1986) en función de la presión, a $800^{\circ}$ y $600^{\circ} \mathrm{C}$. La profundidad aproximada está considerada para un gradiente litostático. El fluido magmático hipotético considerado en el círculo negro tiene una salinidad de $\sim 5$ wt. \% NaCl equiv. y está a una presión de $\sim 1500$ bares. Este fluido se exsuelve del magma a $800^{\circ} \mathrm{C}$ y se descomprime isotérmicamente. De este fluido se separan un vapor y un líquido hipersalino. Los metales se fraccionan al líquido como complejos clorurados, mientras que los componentes volátiles se fraccionan preferencialmente a la fase vapor. Siguiendo una pauta de descompresión isotérmica (flechas blancas) el líquido progresivamente deviene más salino, y el vapor menos, debido a la condensación de líquido rico en $\mathrm{NaCl}$ a partir del vapor. Los vapores de alta temperatura en fumarolas volcánicas contienen $<100 \mathrm{ppm} \mathrm{NaCl}$ y son pobres en metales, mientras que los vapores a altas presiones que acompañan las erupciones volcánicas son relativamente ricos en $\mathrm{NaCl}$ y metales (por ejemplo, White Island; Hedenquist et al., 1993). Las zonas sombreadas indican las composiciones de inclusiones fluidas a temperaturas y presiones típicas de depósitos metalíferos en pórfidos. Los esquemas de inclusiones fluidas representan a las inclusiones que pueden encontrarse en esos campos: arriba, inclusión rica en vapor (V) con un líquido condensado de baja salinidad (L) y un sólido atrapado (S); abajo, inclusión hipersalina, con un líquido (L) sobresaturado en $\mathrm{NaCl}$ y tres critales hijos (S1, S2 y S3), el mayor de los cuales es halita. Adaptado de Hedenquist y Lowenstern (1994).

Ruaya y Seward, 1986; Seward, 1976 y 1984). Para los metales básicos en concreto, el tipo de complejo clorurado que los transporta depende decisivamente de la relación $\mathrm{Ca}^{2+} / \mathrm{Na}^{+}$que haya en el fluido (McKibben y Williams, 1989). Reed (1992) considera seis tipos de fluidos diferentes (definidos por sendos rangos de interacción con el encajonante) a partir de los cuales se puede originar deposición mineral en el ambiente epitermal mediante fenómenos de ebullición: tres de ellos formarían epitermales de BS y, otros 
tantos, epitermales de AS. Según este autor, el transporte de oro como complejo clorurado sólo es importante en dos de los tres fluidos que pueden originar epitermales de $\mathrm{AS}$, pero no en los otros fluidos considerados. A $500^{\circ} \mathrm{C} \mathrm{y} 1 \mathrm{kbar}$ de presión, en un modelo isobárico, la solubilidad del oro está dominada efectivamente por la especie $\mathrm{AuCl}_{2}^{-}$(Gammons y Williams-Jones, 1997). Durante el ascenso y el consecuente enfriamiento conductivo de estos fluidos, según su contenido de $\mathrm{H}_{2} \mathrm{~S}$ puede que éstos se encuentren, bien dentro del campo de estabilidad de la pirita, o bien dentro del de la magnetita. En el primero de estos casos, el complejo portador de oro que será predominante en la solución ya no será $\mathrm{AuCl}_{2}^{-}$, sino $\mathrm{Au}(\mathrm{HS})_{2}^{-}$(Hayashi y Ohmoto, 1991; Gammons y Williams-Jones, 1997), siguiendo su camino ascendente hacia el ambiente epitermal. En el segundo caso, la solubilidad del oro disminuirá de forma constante hasta una temperatura alrededor de $300^{\circ} \mathrm{C}$, por lo que su precipitación se producirá en profundidad (Gammons y Williams-Jones, 1997). Así pues, no parece posible que, en los epitermales de BS o SI dominados por Ag- $\mathrm{Pb}-\mathrm{Zn}$, el oro pueda ser transportado mediante el mismo tipo de complejos que estos metales hasta el ambiente epitermal.

Un $\mathrm{pH}$ de los fluidos mineralizantes cercano a la neutralidad y contenidos en cloro como los reseñados arriba se corresponden con muchos de los epitermales de BS y SI de México (Hedenquist, 1991), en los que la mineralización está además asociada a fluidos con salinidades de hasta el 23 wt.\% $\mathrm{NaCl}$ equiv., bastante superiores por lo común a las establecidas típicamente en epitermales de estos tipos (Hedenquist y Henley, 1985a; Simmons, 1995; Albinson et al., 2001).

\section{Mecanismos de precipitación mineral y cómo reconocerlos}

Por lo común se consideran dos mecanismos físicos principales para la precipitación mineral en depósitos epitermales: ebullición y mezcla de fluidos (Giggenbach y Stewart, 1982). Estos mecanismos no suelen presentarse desligados, sino que se complementan produciendo la deposición mineral (Plumlee, 1994). Por mezlca de fluidos en cuanto a la precipitación mineral dentro del ambiente epitermal debe entenderse una mezcla dentro del ambiente epitermal entre aguas meteóricas descendentes y unos fluidos hidrotermales ascendentes, sea cual sea el origen de estos últimos. Los fluidos hidrotermales puede ser en sí mismos el resultado de la mezcla en profundidad de aguas meteóricas y magmáticas (ver Hedenquist y Lowenstern, 1994; Simmons, 1995; Gammons y Williams-Jones, 1997).

\subsection{Ebullición}

En base a estudios termodinámicos y al conocimiento de los sistemas geotérmicos actuales, se considera que existen cuatro evidencias mineralógicas y texturales principales que son indicativas de ebullición (Browne y Ellis, 1970; Browne, 1978; Henley, 1985; Hedenquist, 1986, 1991; Cathles, 1991; Simmons y Christenson, 1994; Hedenquist et al., 2000):

1. Presencia de calcita hojosa, generalmente reemplazada por cuarzo: indica que ha ocurrido ebullición, que resultó en la pérdida de $\mathrm{CO}_{2}$, y la subsiguiente saturación en calcita, según la reacción

$$
\begin{aligned}
& 2 \mathrm{HCO}_{3}^{-}+\mathrm{Ca}^{2+} \rightarrow \mathrm{CaCO}_{3} \text { (calcita) }+\mathrm{H}_{2} \mathrm{CO}_{3} \rightarrow \\
& \mathrm{CaCO}_{3}+\mathrm{H}_{2} \mathrm{O}+\mathrm{CO}_{2}
\end{aligned}
$$

2. Presencia de adularia: indica que ha ocurrido ebullición, causando un aumento de $\mathrm{pH}$ debido a la pérdida de $\mathrm{CO}_{2}$, pasando del campo de estabilidad de la illita al de la adularia (Figura 13), según la reacción

$$
\begin{aligned}
& \mathrm{KAl}_{3} \mathrm{Si}_{3} \mathrm{O}_{10}(\mathrm{OH})_{2} \text { (illita) }+6 \mathrm{H}_{4} \mathrm{SiO}_{4}+2 \mathrm{~K}+\rightarrow \\
& 3 \mathrm{KAlSi}_{3} \mathrm{O}_{8} \text { (adularia) }+12 \mathrm{H}_{2} \mathrm{O}+2 \mathrm{H}
\end{aligned} ;
$$

sin embargo, según aseguran Dong y Morrison (1995), la sola presencia de adularia en un depósito epitermal de BS no asegura automáticamente que se haya producido ebullición, ya que algunos tipos morfológicos de adularia pueden haberse producido bajo condiciones de cristalización lenta, lo cual invalidaría la existencia de ebullición. Por ello, no basta la identificación de este mineral para deducir la existencia de ebullición, sino que se precisa de su identificación morfológica. Según Dong y Morrison (1995), las morfologías de adularia aptas para inferir la existencia de ebullición son la pseudoromboédrica y la pseudoacicular.

3. Presencia de truscottita (silicato de $\mathrm{Ca}$ y Al hidratado): este mineral se ha hallado asociado con menas de oro de alta ley, y es estable sólo cuando la concentración de sílice excede la saturación en cuarzo, lo cual constituye otra evidencia indirecta de ebullición (Izawa y Yamashita, 1995);

4. Presencia de sílice amorfa o de calcedonia: indica que se ha producido un enfriamiento brusco del fluido, a temperaturas de deposición entre 100 y $190^{\circ} \mathrm{C}$ (White y Hedenquist, 1990), y una sobresaturación de sílice en el fluido que también puede indicar ebullición. La presencia de texturas de cuarzo heredadas de geles de sílice puede ser buena indicadora de ebullición en el ambiente epitermal (Dong et al., 1995), aunque lo más adecuado es que esta evidencia esté en consonancia con otras evidencias mineralógicas para mayor confiabilidad.

Cabe resaltar que la presencia de adularia suele notarse por encima de la de calcita hojosa, o de sus fantasmas (e. g. Camprubí et al., 2001b), lo que es consistente con el consumo del ácido carbónico del líquido durante la precipitación de la calcita hojosa, que provoca el desplazamiento efectivo de las condiciones de estabilidad mineral desde el campo de estabilidad de la illita al de la adularia (Figura 13; Browne y Ellis, 1970; Hedenquist, 

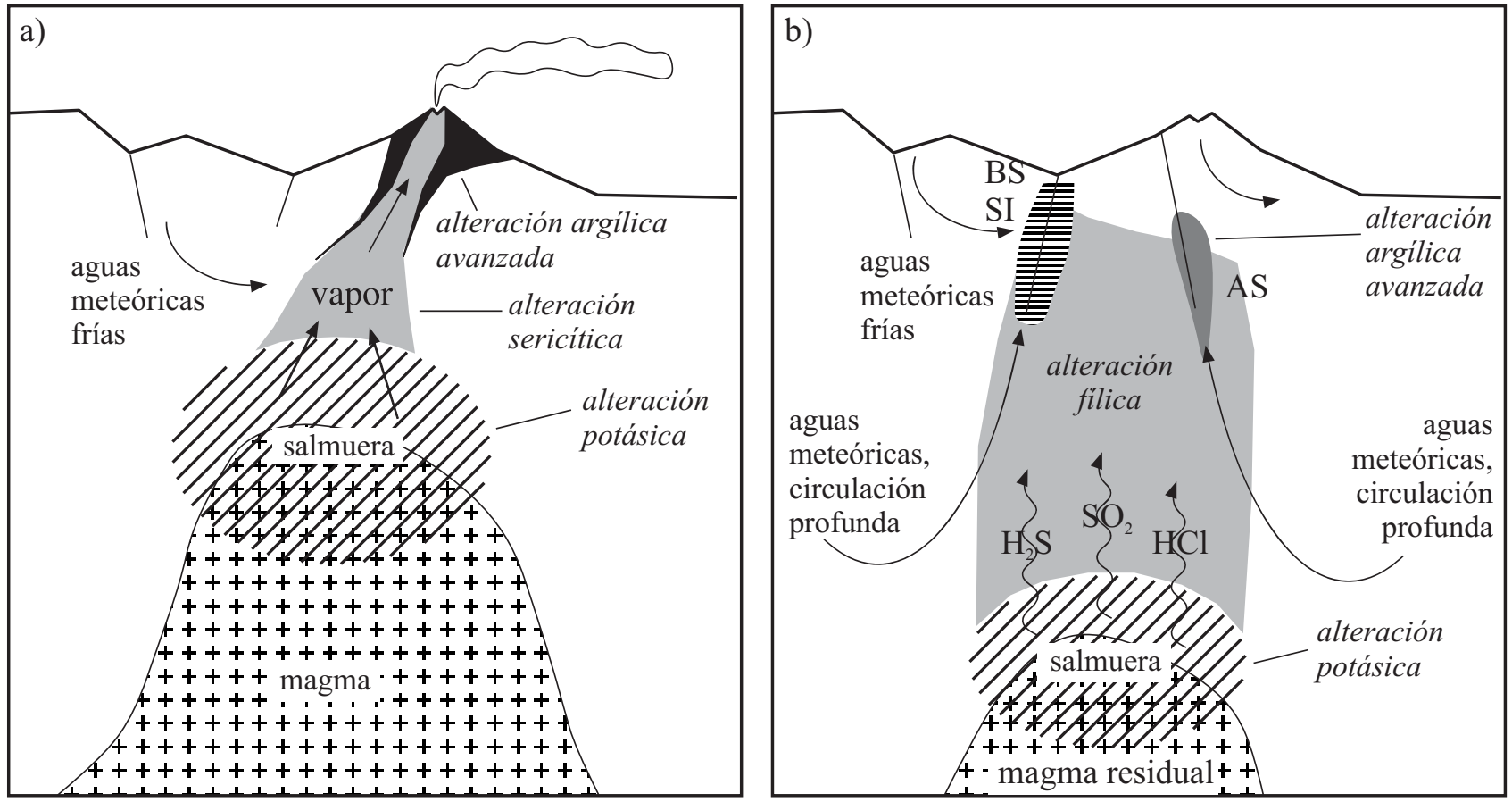

Figura 10. Sumario de los dos principales estadios de evolución de un sistema porfídico-epitermal. A: Intrusión de magma a escasa profundidad ( 4 km?), que se traduce en superficie como actividad fumarólica y erupciones volcánicas intermitentes. Los fluidos magmáticos se exsuelven durante la cristalización del fundido y emergen a partir de la zona de alteración potásica y desmezcla. El oro se fracciona a la salmuera como $\mathrm{AuCl}_{2}-, \mathrm{y}_{\mathrm{fuede}}$ precipitar en en la zona de alteración potásica por pérdida conductiva de calor (enfriamiento conductivo), mezcla de aguas y/o ebullición. Al mismo tiempo, el ascenso de vapor rico en $\mathrm{H}_{2} \mathrm{~S}$ provoca la alteración fílica en las rocas encajonantes, así como la sulfuración del hierro férrico transformándolo en pirita. A niveles someros, la mezcla con aguas meteóricas frías provoca la condensación del vapor, formando aureolas de alteración argílica avanzada. B: El fundido saturado en agua se ha retraído a mayor profundidad, permitiendo así la invasión del sistema por aguas meteóricas calentadas (de cirdulación profunda o "evolucionadas"), lo cual provoca la superposición de la alteración filítica sobre la zona de alteración potásica anterior (A). El $\mathrm{H}_{2} \mathrm{~S}$ y otros volátiles magmáticos ya no llegan a la superficie por ser condensados mediante su mezcla con aguas meteóricas, aumentando la capacidad de éstas para removilizar el oro depositado en la zona potásica (A). La migración de las aguas meteóricas enriquecidas en metales y $\mathrm{H}_{2} \mathrm{~S}$ acaba formando depósitos epitermales alcalinos (baja e intermedia sulfuración) o ácidos (alta sulfuración), según si los fluidos y las rocas encajonantes tienen o no capacidad suficiente para neutralizar los volátiles ácidos, como $\mathrm{HCl}$ y SO 2 (Gammons y Williams-Jones, 1997).

1986). También pueden encontrarse íntimamente asociadas (Etoh et al., 2002). En base a estudios experimentales y la comparación de éstos con las evidencias en sistemas naturales (Sakharova et al., 1994), se ha indicado que la asociación de cuarzo-adularia puede ejercer además de "trampa química" para la precipitación de oro en el ambiente epitermal.

En los depósitos epitermales de AS, en la zona de mena debida a ebullición, en cuanto pueden formarse silicatos se depositan típicamente sericita, dickita y/o kaolinita junto con el cuarzo poroso que contiene típicamente la mena (Hedenquist et al., 2000), constituyendo una asociación mineral diagnóstica.

Otras evidencias indirectas de ebullición durante la deposición mineral son la presencia de horizontes de alteración ácida debidos a aguas calentadas por vapor (Buchanan, 1981) y, hasta cierto punto, la presencia de brechas de fracturación hidráulica (Hedenquist y Henley, 1985b). En depósitos que hayan experimentado poca erosión, pueden reconocerse alteraciones ácidas (kaolinita-alunita) en superficie, como expresión de ebullición en profundidad, tanto en depósitos epitermales de AS como de SI o BS. Ello es debido a que el $\mathrm{H}_{2} \mathrm{~S}$ liberado en la ebullición migra con la fase vapor hacia la superficie, oxidándose para producir $\mathrm{H}_{2} \mathrm{SO}_{4}$ (ácido sulfúrico) en la zona de vadosa (Schoen et al., 1974) y dando lugar a aguas ácido-sulfatadas calentadas por vapor. Esta alteración suele mimetizar la distribución de la zona de vadosa, formando un cuerpo tabular subhorizontal (Schoen et al., 1974; Buchanan, 1981; Sillitoe, 1993; Hedenquist et al., 2000), cuya distinción de los halos de alteración ácido-sulfatados alrededor de cuerpos mineralizados en epitermales de AS es crucial para la localización de cuerpos mineralizados.

Aparte de las evidencias mineralógicas y texturales, la ebullición puede ponerse igualmente de manifiesto mediante el estudio petrográfico y microtermométrico de inclusiones fluidas o a partir de las relaciones entre los gases contenidos en ellas. Si en las zonas de ebullición se produce el atrapamiento de inclusiones fluidas, en éstas se presentará un amplio rango de variación de las relaciones líquido/vapor (Hayba et al., 1985). Cabe destacar que, de hallarse sólo inclusiones muy ricas en vapor e inclusiones 
muy ricas en líquido, sin inclusiones con relaciones líquido/ vapor intermedias, es más posible que nos encontremos en una situación que refleja más bien un proceso de estrangulamiento de las inclusiones fluidas (o necking). En un caso similar es preferible optar por la cautela y no deducir que constituye evidencia de ebullición. La presencia de agrupaciones de inclusiones fluidas todas ellas ricas en vapor, en cambio, sí constituye una mejor evidencia de ebullición. No siempre es posible encontrar inclusiones fluidas dentro de la propia zona de ebullición, pero pueden hallarse formas indirectas para evidenciar la existencia de este mecanismo de precipitación. Puesto que durante la ebullición se produce la separación de una fase vapor, hacia la cual se fraccionarán mayoritariamente los componentes más volátiles, y de una fase líquida, que resultará más salina, cabe esperar encontrar inclusiones líquidas relativamente salinas en minerales precipitados con posterioridad en la secuencia paragenética a inclusiones líquidas menos salinas, sin que haya necesariamente variaciones significativas en sus temperaturas de homogeneización. La existencia de una sucesión como la expuesta también puede implicar la entrada de fluidos en un nuevo pulso hidrotermal sin relación alguna con la ebullición, con lo que el estudio de inclusiones fluidas tiene que apoyarse generalmente en otros métodos de análisis geoquímico (estudio de isótopos estables, geoquímica de gases, etc.).

Si se ha producido la ebullición de un fluido hidrotermal, el fraccionamiento isotópico entre las fases líquida y vapor separadas inducirá a cambios en la composición isotópica de los fluidos resultantes. La magnitud del cambio isotópico del fluido hidrotermal depende de la temperatura a la cual se produce la ebullición, así como de la relación líquido/vapor en el sistema. La relación líquido/vapor, a su vez, depende esencialmente de la entalpía del fluido inicial, del intérvalo de temperaturas en que ocurre la ebullición y del mecanismo de separación del vapor (Matsuhisa, 1986). Dichos mecanismos de separación pueden resumirse en (1) separación monoepisódica, (2) separación contínua, y (3) separación multiepisódica (Truesdell et al., 1977). La separación monoepisódica se produce cuando líquido y vapor coexisten, separándose a una cierta temperatura y produciendo un fraccionamiento isotópico considerable (Truesdell et al., 1977; Giggenbach y Stewart, 1982). Este es el caso más común en depósitos epitermales. La separación contínua se produce cuando el vapor migra contínuamente a medida que se va formando, de forma que los fluidos evolucionan siguiendo la curva de ebullición determinada por su composición (Figura 14), en cual caso

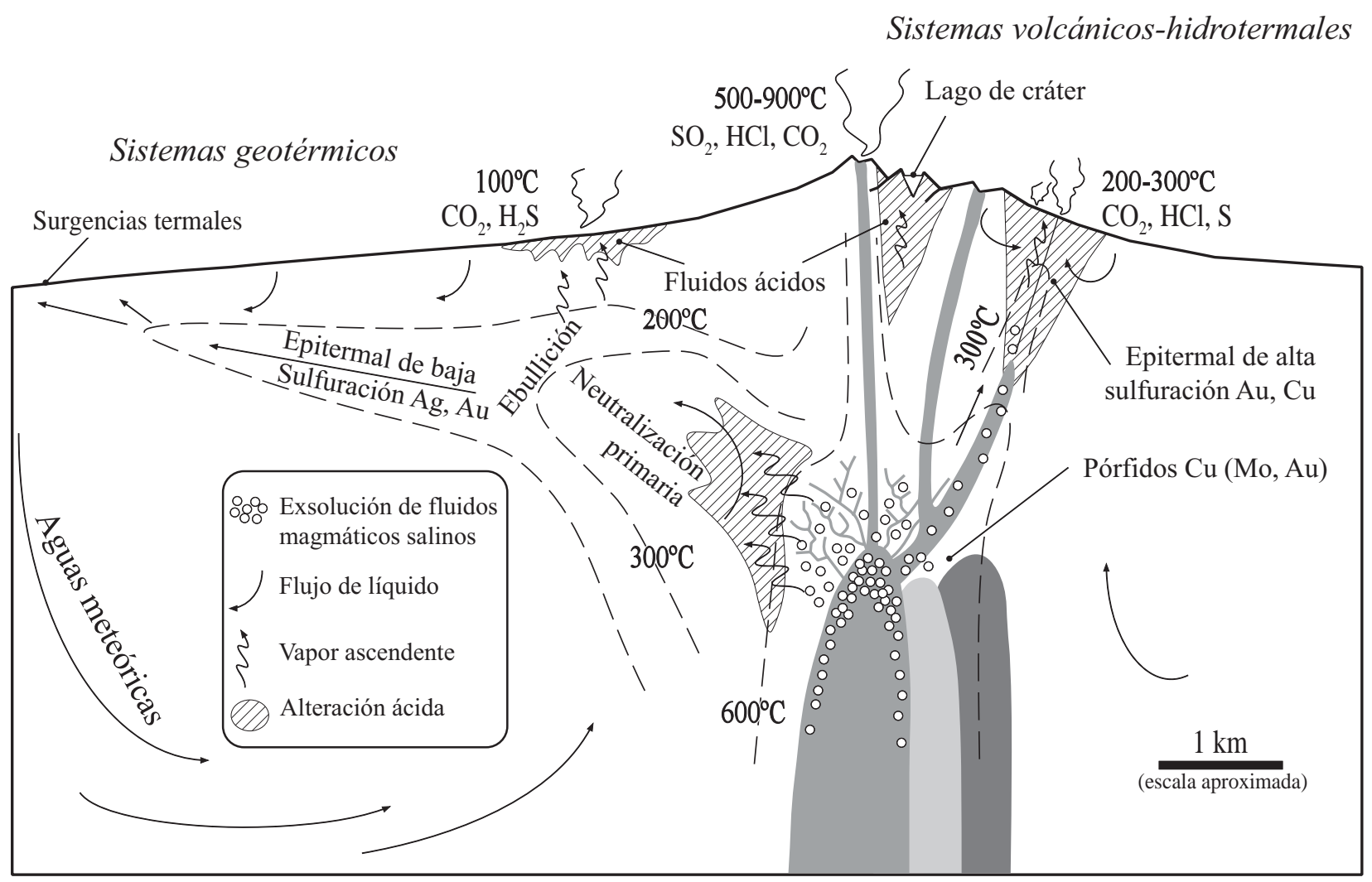

Figura 11. Esquema geológico mostrando las intrusiones sub-volcánicas someras, un estratovolcán asociado, y los ambiente inferidos para la formación de depósitos metalíferos en pórfidos y de depósitos epitermales. Los sistemas volcánicos-hidrotermales activos se extienden desde la exsolución de fluidos en los magmas hasta las fumarolas y las surgencias ácidas, e incluyen los ambientes de formación de los depósitos metalíferos en pórfidos y/o los depósitos epitermales de alta sulfuración. En cambio, los depósitos epitermales de baja sulfuración se forman a partir de sistemas geotérmicos, que se caracterizan por presentar fuentes termales y géiseres de pH neutro, como los de Yellowstone (Hedenquist y Lowenstern, 1994; Hedenquist, 1996). 
los efectos de fraccionamiento isotópico son mínimos. La separación multiepisódica es un mecanismo "intermedio" entre los dos anteriores, y también lo son los efectos que produce. Sin embargo, según Truesdell et al. (1977), el cambio en la composición isotópica del oxígeno del fluido producido por ebullición no es mayor del $2 \%$ a temperaturas superiores a $100^{\circ} \mathrm{C}$.

El fluido hidrotermal es reducido en profundidad y, dado su carácter prácticamente neutro, su salinidad relativamente baja y su contenido relativamente alto en $\mathrm{H}_{2} \mathrm{~S}$ gas, el oro se encontrará en solución como complejos tiosulfurados (Henley, 1985; Gammons y Williams-Jones, 1997). La "liberación episódica de presión" (Buchanan, 1981) conlleva un proceso de ebullición, que se traduce en un enfriamiento, una pérdida de gases que migran con el vapor de agua y un aumento en el pH de la solución. También se ha descrito la posible existencia de ebullición debida a la caída de la presión hasta condiciones hidrostáticas, asociada a un descenso del nivel de aguas freáticas (Fournier, 1987). De este modo, la curva de ebullición para una salinidad concreta se sitúa a mayor profundidad con lo que, un fluido situado por debajo de la curva de ebullición original puede encontrarse por encima de la nueva curva, produciéndose una repentina y vigorosa ebullición.

La pérdida de $\mathrm{H}_{2} \mathrm{~S}$ gas subsiguiente al fenómeno de ebullición será la causa de la saturación del oro y su precipitación (Reed y Spycher, 1985; Seward, 1989; Shenberger y Barnes, 1989; Cooke y Simmons, 2000; Hedenquist et al., 2000), según la reacción

$$
\mathrm{Au}+\mathrm{H}_{2} \mathrm{~S}+\mathrm{HS}-\leftrightarrow \mathrm{Au}(\mathrm{HS})_{2}^{-}+\frac{1}{2} \mathrm{H}_{2} .
$$

La predicción de la precipitación de oro a partir de ebullición se confirma en sistemas geotérmicos activos (Hedenquist, 1991; Simmons y Christenson, 1994). Sin embargo, el aumento de $\mathrm{pH}$ debido a la pérdida de $\mathrm{CO}_{2}$ provoca un incremento en la solubilidad del oro, lo cual explicaría el porqué de la ausencia de oro a la profundidad en que se produce la inmiscibilidad entre los fluidos ascendentes. Este proceso continua hasta que la pérdida de $\mathrm{H}_{2} \mathrm{~S}$ se convierte en el control principal de la solubilidad del oro (Seward, 1989), aunque la ebullición está condicionada al sellado del sistema. Dado este caso, vuelve a aumentar la presión, inhibiéndose el proceso de ebullición (Dong et al., 1995). Ésta también puede terminar cuando el enfriamiento conductivo del sistema y el aumento de salinidad del fluido acuoso remanente conllevan la aparición de una nueva curva de ebullición (Fournier, 1987).

\subsection{Mezcla de fluidos}

La mezcla de los fluidos profundos con aguas frías marginales o con aguas freáticas calentadas por vapor, tanto si son de carácter ácido-sulfatado como carbonatado (ricas en $\mathrm{CO}_{2}$ ), también puede provocar la saturación del oro. Sin embargo, si los fluidos ascendentes ya han experimentado un proceso de ebullición más o menos extenso antes de su dilución por parte de aguas superficiales, dichos fluidos pueden haber perdido ya su potencial mineralizante (Hedenquist, 1991). Esta sucesión de procesos se ha propuesto como explicación para la común incidencia de mineralización económica de metales preciosos y básicos en las "vetas profundas en estado de ebullición" en México, y la notable escasez o ausencia de contenidos metálicos en las incidencias de epitermalismo somero tipo hot spring (Albinson et al., 2001).

Existen modelos experimentales (Brown, 1989; Spycher y Reed, 1989) en los que se indica que la mezcla de fluidos ascendentes clorurados, de $\mathrm{pH}$ aproximadamente neutro (carácter de los fluidos que originan los epitermales de BS), que contengan oro, con aguas freáticas ácidas y sulfatadas, constituye un mecanismo muy eficiente para la precipitación de oro. Esta mezcla resulta en el desarrollo de alteración argílica avanzada, que puede incluir la presencia de alunita (Hedenquist, 1991). A pesar de todo, contrariamente al caso de epitermales de AS, es muy poco frecuente encontrar este tipo de alteración en asociación directa con mineralizaciones económicas en epitermales de BS o SI, como se evidencia en las relaciones sobre la mineralogía de las gangas y de las alteraciones asociadas a la precipitación mineral. La presencia de alteraciones del tipo ácido-sulfato en epitermales de BS y SI se asocia comúnmente, bien a aguas freáticas ácidas y sulfatadas calentadas por vapor a niveles muy someros, sin mineralización asociada, o bien se trata de una superposición tardía asociada al colapso de las aguas calentadas por vapor durante hiatos en el hidrotermalismo ascendente $\mathrm{y} / \mathrm{o}$, especialmente, cuando cesa y colapsa al final el sistema hidrotermal. La presencia de etapas estériles con calcita cristalina (no hojosa) en fases de formación tardías y entre etapas productivas, como se observa en Fresnillo, podría interpretarse precisamente como influjos de aguas carbonatadas descendentes durante hiatos del hidrotermalismo de fluidos clorurados ascendentes (Simmons, 1991).

En contraste con la existencia de múltiples indicadores mineralógicos de ebullición, especialmente en depósitos de BS y SI, no hay tales indicadores para la existencia de mezcla. Aún así, se han reportado en numerosas ocasiones evidencias de mezcla de fluidos tanto en depósitos de BS como de SI o AS en base a datos microtermométricos de inclusiones fluidas e isotópicos de $\mathrm{O}$ y $\mathrm{H}$ (e. g. Deen et al., 1994; Arribas, 1995; Mancano y Campbell, 1995; Camprubí et al., 2001b), como factor posible para la precipitación mineral. La mezcla de fluidos en la zona de menas se encuentra generalmente restringida a fases tardías durante el colapso del sistema hidrotermal, lo que permite el descenso y percolación de aguas calentadas por vapor, y la producción de ganga de carbonatos o sulfatos (Cooke y Simmons, 2000). Sin embargo, sigue sin poderse determinar con claridad si la mezcla de fluidos es responsable de la deposición de menas, de la deposición 


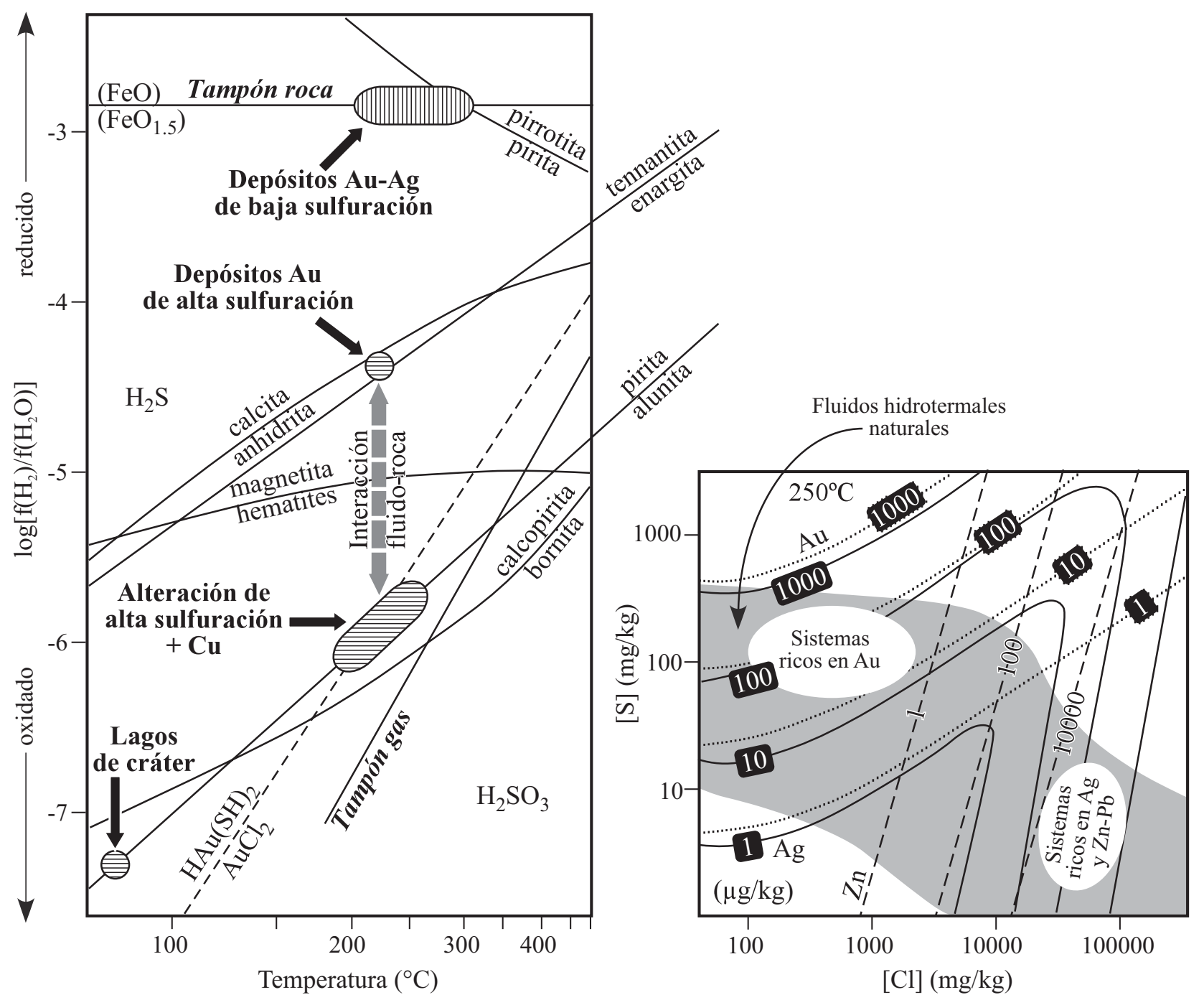

Figura 12. Izquierda: Diagrama temperatura-potencial redox para los fluidos limitados entre el tampón oxidado de gases volcánicos y el tampón de rocas reductor (Giggenbach, 1992b; Hedenquist et al., 1994b; Hedenquist et al., 1996). El lixiviado de alta sulfuración y la alteración alunita-pirita tienen lugar bajo condiciones oxidantes; la precipitación de enargita también se produce en condiciones relativamente oxidantes. La precipitación de oro se produce típicamente de forma tardía en muchos depósitos epitermales de alta sulfuración, asociada a condiciones relativamente reductoras (próximas al campo de estabilidad de la tennantita), posiblemente debido al cese de aporte de fluidos oxidantes y ácidos de origen magmático y/o debido a interacción fluido-roca. Los fluidos de baja e intermedia sulfuración, en cambio, son reductores; los componentes magmáticos oxidantes reaccionan con las rocas encajonantes, siendo neutralizados por debajo del ambiente epitermal (Giggenbach, 1992b). El oro se transporta mediante complejos tiosulfurados bajo condiciones relativamente reductoras (por encima de la línea discontínua); bajo condiciones relativamente oxidantes (o en pH bajos o salinidades altas), los complejos clorurados de oro son los dominantes. Derecha: Solubilidades de Au, Ag y $\mathrm{Zn}$ en función de las concentraciones de cloro y azufre, bajo condiciones redox y de pH de baja sulfuración (Henley, 1991). Las soluciones pobres en Cl típicas de depósitos epitermales de baja sulfuración ricos en $\mathrm{Au}$ (Hedenquist y Henley, 1985a) transportan Au como complejos tiosulfurados, pero no tienen capacidad para transportar muchos metales básicos, que se transportan mediante complejos clorurados.

de minerales de ganga, o del enriquecimiento en metales en aguas subterráneas.

La mezcla de los fluidos ascendentes con aguas calentadas por vapor ricas en $\mathrm{CO}_{2}$ o bien aguas freáticas frías suele provocar la precipitación de los metales remanentes en solución, distribuyéndose en halos marginales o por debajo de la zona de formación de las aguas ácidas y sulfatadas. Estos halos suelen ser de carácter subeconómico, pero llegan a tener contenidos de metales preciosos que pueden ser económicos sólo que, en este caso, y como se ha explicado anteriormente, se asocian directamente a ebullición de fluidos clorurados ascendentes (Schoen et al., 1974; Buchanan, 1981; Sillitoe, 1993; y otros autores en Hedenquist, 1991). La mezcla de fluidos, en definitiva, sí puede tener un papel importante en la precipitación mineral, aunque tal vez restringido a las partes más someras de un sistema epitermal, excepto en zonas con relieves pronunciados, en los que estas aguas pueden penetrar hasta grandes profundidades a lo largo de fracturas (Reyes, 1990, 1991; Hedenquist et al., 1992). 


\section{El problema de las formaciones silíceas y las alteraciones ácidas superficiales y subsuperficiales}

La presencia de formaciones silícicas estructural y texturalmente similares a las que se forman en superfície en zonas de descarga hidrotermal actuales y recientes $(e$. g. Yellowstone, E.U.A., o la zona volcánica de Taupo, Nueva Zelanda) se ha venido utilizando como criterio de prospección para depósitos epitermales. La adscripción de zonas de silicificación a la categoría de sínteres es controvertida en muchos casos, debido a factores intrínsecos de su naturaleza, como son la fragilidad y alta susceptibilidad a la erosión de estas estructuras, de lo que deriva su relativa escasez o su registro parcial o, inclusive, su no adscripción a todos contextos volcánicos en que se producen depósitos epitermales. Es por ello que sólo una detallada descripción de las características morfológicas y texturales de cuerpos de sílice atribuibles a dicho origen puede realmente permitir el uso del témino "sínter", con las implicaciones que éste tiene.

Clásicamente se ha definido como "sínter" un conjunto de rocas o formaciones de de origen químico o bioquímico formadas por la precipitación en superficie de sílice amorfa (geiserita) y/o carbonatos (travertino o toba hidrotermal), a partir de soluciones hidrotermales saturadas en sílice que descargan fluidos de carácter neutro o ácido, tanto en la surgencia de las mismas como en sus cercanías. La formación de estos depósitos suele tener un carácter estacional, dependiendo de las variaciones de profundidad del nivel freático según el régimen hidrológico al que se halla sometido, así como del propio régimen pulsátil del sistema hidrotermal. Pueden tener asociados sulfuros de metales básicos ( $\mathrm{Fe}, \mathrm{Pb}, \mathrm{Zn}, \mathrm{Cu})$, contenidos anómalos en metales preciosos (Sherlock et al., 1995) y suelen presentar fuertes anomalías en $\mathrm{Hg}$, As y Sb. En las fuentes termales el tipo de sílice dominante es ópalo-A, amorfo e hidratado con cantidades variables de agua. Su precipitación se produce cuando los fluidos hidrotermales saturados en sílice surgen en superficie a partir de géiseres o fuentes termales, se enfrían y se evaporan con la consiguiente sobresaturación en sílice amorfa (White et al., 1965). Otros factores, como cambios de $\mathrm{pH}$ en los fluidos, la presencia de otros compuestos minerales en solución, de materia orgánica, o bien la mediación de organismos vivos como algas o cianobacterias pueden provocar su precipitación (Walter et al., 1972; Jones et al., 2001a; Konhauser et al., 2001; Yee et al., 2003; Canet et al., 2005b).

Los sínteres presentan morfologías muy variadas dependiendo del tipo de surgencia y de la topografía de la zona (White et al., 1989), desde masas bulbosas hasta terrazas con frentes estalagtíticos. En general, se trata de depósitos lenticulares con zonas de reemplazamiento planar de las rocas encajonantes, extendiéndose hasta cientos de metros horizontalmente y decenas de metros verticalmente (Panteleyev, 1996). Bajo estos depósitos se encuentran los sistemas alimentadores, en forma de cono o prisma, constituidos por stockworks y vetas de cuarzo centrados en zonas de fractura (Figura 5). En las rocas encajonantes, las alteraciones hidrotermales asociadas a este tipo de sistemas suelen ser múltiples episodios de silicificación, alteración argílica y, menos comúnmente, asociaciones de alteración argílica avanzada con cuarzo, caolinita y, raramente, alunita (Panteleyev, 1996). Hacia los flancos de estos sistemas, o en profundidad, se encuentra alteración propilítica con clorita, óxidos de Fe, zeolitas y escasa adularia. Cerca de la superfície, puede haber importantes acumulaciones locales de selenita, alunita y otros sulfatos, junto con azufre nativo. Los sínteres suelen presentar marcadas laminaciones y una gran variedad de estructuras a microescala. Dado que la precipitación de sílice para formar sínteres se produce bajo una delgada lámina de agua de grosor variable, es muy común hallar una gran variedad de restos vegetales, coprolitos, oncoides y "huevos de géiser" (Renaut et al., 1996; Jones et al., 2001b), bioturbaciones, laminaciones algales, evidencias de oleaje, grietas de desecación y otras estructuras sedimentarias (Vikre, 1985; Camprubí et al., 2001c; Morales-Ramírez et al., 2003; Canet et al., 2005b). Igualmente, son comunes las estructuras geopetales. Asimismo, suelen aparecer brechificaciones locales de dimensiones variables, debidas a erupciones hidrotermales, posteriormente recementadas por la descarga de nuevas surgencias hidrotermales.

Con el tiempo y durante el eventual enterramiento del sínter, el ópalo-A cambia su estructura gradualmente a fases de sílice más estables y ordenadas, siendo reemplazado por ópalo-CT o cristobalita (ópalo-C) hasta cuarzo (Williams et al., 1985). Durante la transformación diagenética de los sínteres puede producirse igualmente la precipitación de cuarzo como cemento, a partir de fluidos percolantes saturados en sílice, modificando la fábrica original del sínter y sellando la porosidad remanente.

En los depósitos epitermales de BS y SI, y en los sistemas hidrotermales actuales análogos a éstos, las estructuras de tipo sínter corresponden a los depósitos característicos más superficiales de dicho hidrotermalismo. Por ello, aunque estas estructuras no son exclusivas de los depósitos epitermales, su hallazgo en el contexto adecuado es de gran utilidad en la exploración para los mismos. En la prospección de estos depósitos, uno de los problemas que se presentan es reconocer entre sínteres silíceos "verdaderos" y "falsos". Este último caso puede corresponder a depósitos de sílice de diferentes orígenes. En la Tabla 3 se enumeran todos los tipos diferentes de alteraciones o depósitos silícicos que pueden hallarse en depósitos epitermales. Un caso particular son los resíduos de sílice (Sillitoe, 1993; Hedenquist et al., 2000; Herdianita et al., 2000), que consisten en niveles opalinos derivados de la lixiviación ácida de las rocas encajonantes debido a la condensación en la zona freática de vapores derivados de ebullición, tanto en depósitos epiermales de AS como de BS y SI. Como el único metal que se transporta de esa manera es $\mathrm{Hg}$, estos depósitos no tienen interés económico y, además, el hecho 


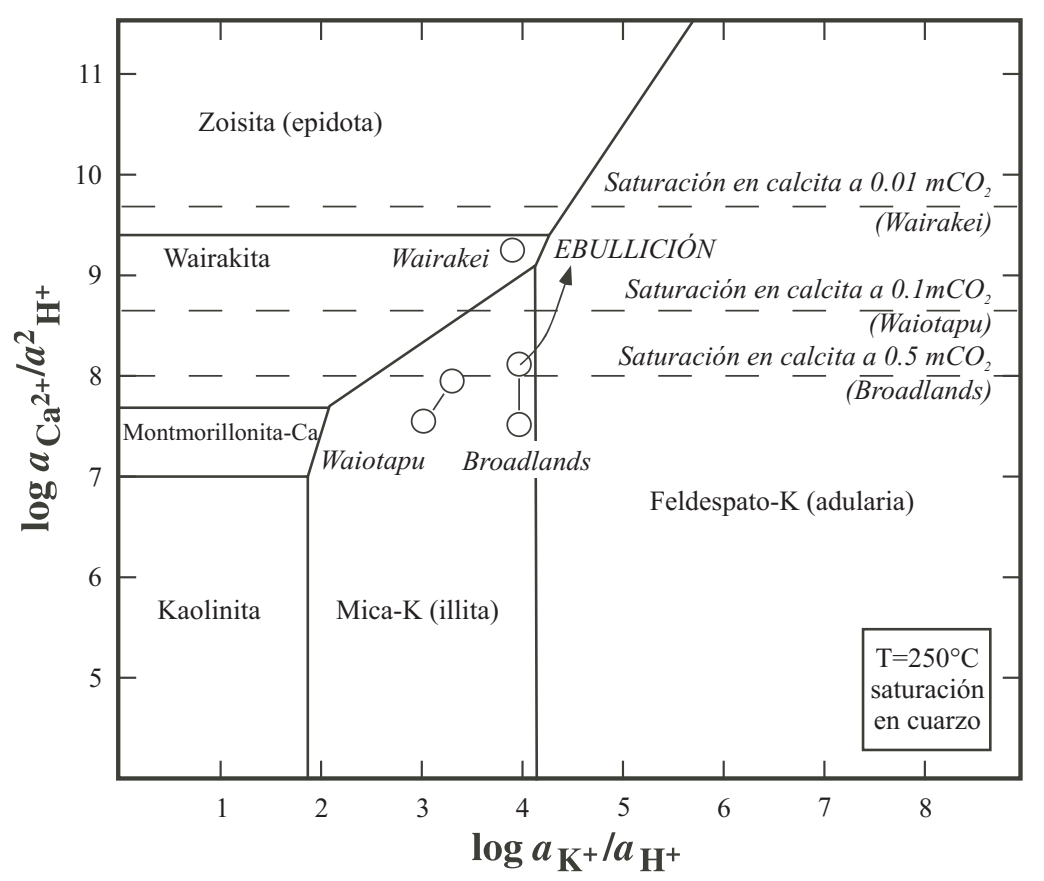

Figura 13. Relaciones de equilibrio entre minerales de alteración en sistemas geotérmicos actuales y depósitos epitermales de baja sulfuración (Hedenquist, 1986), según el diagrama de actividades del sistema $\mathrm{CaO}-\mathrm{K}_{2} \mathrm{O}-\mathrm{Al}_{2} \mathrm{O}_{3}-\mathrm{SiO}_{2}-\mathrm{H}_{2} \mathrm{O}$ (Henley y Brown, 1985).

de ser identificados como sínteres lleva a interpretaciones incorrectas sobre las características paleohidrológicas de un depósito epitermal.

Otro tipo común de depósitos de sílice amorfa (no contemplado en la Tabla 3) son rocas de láminas muy delgadas, comúnmente sedimentos lacustres, derivados de silicificación penetrativa (Sillitoe, 1993). En muchos casos, estos depósitos son difícilmente distinguibles de laminaciones de sílice similares formadas en sínteres, aunque carecen de características de sínter tales como la presencia de tapices algales, estructuras de escape de líquidos, etc. La identificación de sínteres in situ también puede ser obstaculizada por los "sínteres transportados", que se forman lejos de las surgencias hidrotermales debido a un relieve irregular o pronunciado. Para el caso, la presencia de brechificaciones de láminas de sílice recementadas por vetas o matriz de sílice tardías es una característica diagnóstica de sínter in situ. También se puede producir localmente una silicificación masiva de niveles porosos (Sillitoe, 1993). Por todo ello, es necesario realizar un reconocimiento morfológico y textural exhaustivo de cuerpos laminares de sílice parecidos a sínteres antes de poder utilizar tal denominación con propiedad, puesto que las implicaciones genéticas derivables de los diferentes tipos de cuerpos de sílice pueden ser muy diversas.

Debido a la alta susceptibilidad de los sínteres a la erosión en cuanto cesa la actividad hidrotermal, especialmente en lugares con un alto relieve topográfico o en ambientes áridos en el que el ópalo se deshidrata y se quiebra, estas estructuras no se conservan con facilidad. En el caso de sistemas hidrotermales asociados a estratovolcanes andesíticos, debido a la variabilidad del relieve original en que se produce la actividad hidrotermal, la propia formación de sínteres suele ser excepcional (Bogie y Lawless, 1987; White et al., 1995). La mayoría de los depósitos epitermales conocidos hoy en día están situados alrededor del márgen Circum-Pacífico, asociados al termalismo tardío de los sistemas volcánicos félsicos e intermedios o bimodales (Mitchell y Garson, 1981) operantes en la región desde el Terciario (White y Hedenquist, 1990). A pesar de la relativa abundancia de depósitos epitermales en dicha región, no es común la presencia de estructuras de tipo sínter o similares a no ser que los depósitos sean relativamente recientes, que hayan sido sepultados rápidamente por rocas sedimentarias o volcánicas, o bien que la zona tenga un bajo contraste de relieve topográfico o una baja tasa de erosión. La explicación del sepultamiento sería el caso, por ejemplo, de algunas áreas con epitermalismo de nivel alto en el Altiplano de México, con silicificaciones característicamente correspondientes a raíces de sínteres, que fueron sepultadas por rocas piroclásticas cuya distribución areal es del orden de decenas de km (Albinson, 1998).

De forma análoga a los depósitos superficiales y subsuperficiales de sílice, los cuerpos superficiales o subsuperficiales de alteración ácida compuestos por kaolinita y alunita (alteración argílica avanzada) pueden tener origenes diversos, y su distinción es importante para la exploración de depósitos epitermales. Los tres principales origenes de asociaciones de este tipo son (Sillitoe, 1993): (1) por condensación o disolución de volátiles magmáticos, forma- 


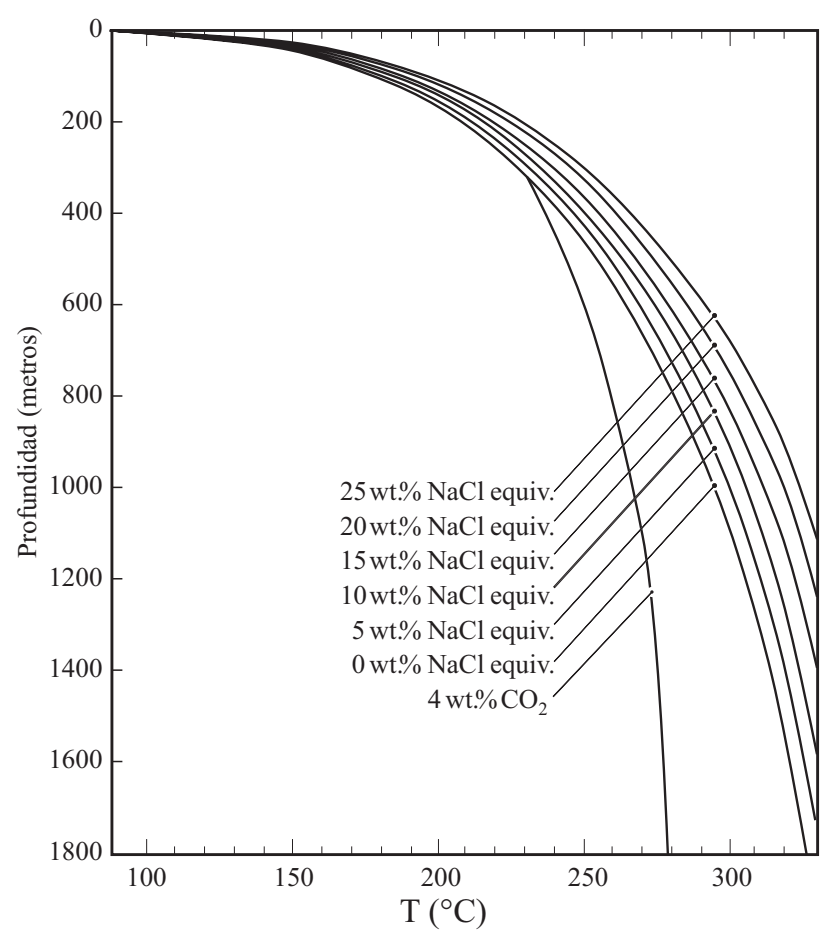

Figura 14. Curvas de ebullición del agua con diferentes contenidos de $\mathrm{NaCl}$ (Haas, 1971) y una curva de referencia al efecto producido por la presencia de $\mathrm{CO}_{2}$ en los fluidos (Henley et al., 1984).

das muy por debajo del nivel freático, (2) por lixiviación ácida somera, formadas por encima del nivel freático, y (3) mediante oxidación supergénica. Las asociaciones de este tipo formadas bajo el nivel freático en sistemas de alta sulfuración pueden contener mineralizaciones económicas $\mathrm{o}$, más frecuentemente, disponerse en forma de halos alrededor de la mena. Las asociaciones de este tipo formadas por encima del nivel freático, tanto en sistemas de alta como de baja sulfuración, son estériles, aunque pueden estar asociadas a menas infrayacentes. En cambio, la formación de alteración argílica avanzada mediante alteración supergénica no necesariamente puede estar asociada con menas epitermales, aunque pueden contener mineralizaciones económicas, dependiendo de la posición de la mena respecto a la posición de la pirita que se ha oxidado. En la Tabla 4 se lista un compendio de las características distintivas entre las tres diferentes asociaciones de alteración argílica avanzada según su origen.

\section{Origen de los fluidos mineralizantes}

Los fluidos mineralizantes en los depósitos epitermales de BS son, por lo general, originados mayoritariamente a partir de aguas meteóricas. La química de los fluidos en campos geotérmicos actuales, de $\mathrm{pH}$ aproximadamente neutro, está determinada por la interacción de las celdas de convección del agua meteórica con las rocas encajonan- tes a niveles intermedios, aunque normalmente se infiere una componente indeterminada de fluidos magmáticos en profundidad. En contraste, los fluidos mineralizantes en epitermales de AS son de origen mayoritariamente magmático, pudiéndose mezclar con aguas meteóricas a diferentes profundidades. En el caso de los depósitos epitermales de SI, la composición de los fluidos a partir de los cuales se formaron es también intermedia, entre magmáticos y meteóricos (Albinson et al., 2001; Einaudi et al., 2003; Sillitoe y Hedenquist, 2003). Los fluidos formadores de depósitos epitermales pueden evolucionar desde un fluido temprano súmamente reactivo, que interacciona fuertemente con las rocas encajonantes en profundidad, hasta un fluido más reducido, eventualmente de carácter más bien correspondiente a BS, que puede originar la mineralización. En ambos casos, los principales fluidos involucrados en la formación de los depósitos son, bien de origen magmático, bien de origen meteórico, aunque en algunos casos se han hallado contribuciones de agua marina, sea en depósitos epitermales o en sus análogos geotérmicos actuales (Bogie y Lawless, 1987; Müller et al., 2002). Uno de los principales problemas en el estudio de depósitos epitermales es la dificultad que entraña la detección de la componente magmática en los fluidos mineralizantes, debido a la escasez de evidencias diagnósticas de su intervención. Ello se debe a tres procesos geológicos principales (Simmons, 1995):

1. Las composiciones geoquímicas magmáticas pueden verse enmascaradas por la interacción agua/roca desde la separación de los fluidos magmáticos, en su camino desde el magma hasta el ambiente epitermal.

2. Las contribuciones magmáticas se debilitan con el tiempo, produciéndose a veces como pulsos, de tal forma que su preservación en la mineralización queda circunscrita a complejos bandeados interminerales y/o zonaciones intraminerales, de escala centrimétrica a micrométrica.

3. Durante el cese de la actividad hidrotermal se puede "diluir" o borrar por completo las evidencias geoquímicas de las aportaciones magmáticas.

Para el caso, llega a darse la paradoja que, donde el magmatismo es más voluminoso, es también donde la preponderancia de las aguas meteóricas es más obvia. Ello es debido a que la existencia de una gran fuente magmática de calor provoca la formación de celdas de convección de agua meteórica con mayor recorrido y de funcionamiento más prolongado, que pueden llegar a borrar toda evidencia temprana que pudiera haber sobre la contribución de fluidos magmáticos (Hedenquist y Lowenstern, 1994).

A pesar de los problemas que conlleva la interpretación de los datos procedentes de los depósitos epitermales de AS, BS y SI, derivados en parte de los procesos geológicos a los que se ven sometidos los fluidos mineralizantes, es posible dilucidar el origen u orígenes de los fluidos mineralizantes. Dicha determinación puede realizarse a partir del análisis de los siguientes relaciones isótopicas y componentes químicos (Simmons, 1995): ${ }^{3} \mathrm{He} /{ }^{4} \mathrm{He}, \mathrm{N}_{2}-\mathrm{Ar}-\mathrm{He}, \delta^{18} \mathrm{O}, \delta \mathrm{D}$ y la concentración total de $\mathrm{Cl}$ en los fluidos mineralizantes. El 
Tabla 3. Tipos de depósitos y alteraciones de sílice en depósitos epitermales (Hedenquist et al., 2000)

\begin{tabular}{|c|c|c|c|c|c|}
\hline Tipo & Formación & Ubicación & Significado & Metales & AS o BIS \\
\hline Sínter & $\begin{array}{l}\text { En fuentes termales } \\
\text { con } \mathrm{pH} \sim \text { neutro }\end{array}$ & Sólo en superficie & $\begin{array}{l}\text { Paleosuperficie, depresión topográfica } \\
\text { (hidrológica), centrado en el flujo }\end{array}$ & $\begin{array}{l}\mathrm{As}, \mathrm{Sb}, \mathrm{Hg}, \mathrm{Tl}(\mathrm{Au}, \\
\mathrm{Ag})\end{array}$ & Sólo BIS \\
\hline $\begin{array}{l}\text { Sílice residual } \\
\text { (opalina) }\end{array}$ & $\begin{array}{l}\text { Lixiviación } \\
\text { moderada, } \mathrm{pH} \sim 2-3\end{array}$ & Zona de vadosa & $\begin{array}{l}\text { Zona calentada por vapor sobre el nivel } \\
\text { freático }\end{array}$ & $\begin{array}{l}\mathrm{Hg} \text { salvo en } \\
\text { sobreimposiciones }\end{array}$ & AS o BIS \\
\hline $\begin{array}{l}\text { Horizonte de } \\
\text { calcedonia }\end{array}$ & $\begin{array}{l}\text { Sílice removilizada } \\
\text { de zona calentada por } \\
\text { vapor }\end{array}$ & Nivel freático & $\begin{array}{l}\text { Paleonivel freático, puede ser distal a } \\
\text { fuente }\end{array}$ & $\begin{array}{l}\mathrm{Hg} ; \mathrm{o} \mathrm{As}, \mathrm{Sb}, \mathrm{Au} \\
\mathrm{Ag}^{(1)}\end{array}$ & AS o BIS \\
\hline $\begin{array}{l}\text { Vetas de } \\
\text { calcedonia, bandas } \\
\text { coloformes; vetas } \\
\text { cripto-cristalinas }\end{array}$ & $\begin{array}{l}\text { Fluido de baja } \\
\text { T, coloides; } \\
\text { recristalizado de } \\
\text { un gel }\end{array}$ & Someras, $<150 \mathrm{~m}$ & $\begin{array}{l}<200^{\circ} \mathrm{C} \text {, enfriamiento rápido del } \\
\text { fluido, ebullición en profundidad; } \\
\text { criptocristalino a } \sim 200^{\circ} \mathrm{C}\end{array}$ & $\mathrm{As}, \mathrm{Sb}, \mathrm{Se}, \mathrm{Au}, \mathrm{Ag}$ & $\begin{array}{l}\text { BIS o AS } \\
\text { tardío }\end{array}$ \\
\hline Vetas de cuarzo & $\begin{array}{l}\text { A partir de } \\
\text { enfriamiento de una } \\
\text { solución }\end{array}$ & Profundidad $>150 \mathrm{~m}$ & $>200^{\circ} \mathrm{C}$ & $\begin{array}{l}\mathrm{Au}, \mathrm{Ag}, \text { metales } \\
\text { básicos }\end{array}$ & $\begin{array}{l}\text { BIS o AS } \\
\text { tardío }\end{array}$ \\
\hline $\begin{array}{l}\text { Sílice residual } \\
\text { (cuarzo oqueroso) }\end{array}$ & $\begin{array}{l}\text { Lixiviación extrema } \\
\text { a } \mathrm{pH}<2\end{array}$ & $\begin{array}{l}\text { Núcleo de sistema } \\
\text { volcánico-hidrotermal }\end{array}$ & $\begin{array}{l}\text { Núcleo permeable, principal zona de } \\
\text { deposición de menas de AS }\end{array}$ & $\begin{array}{l}\text { estéril, o Cu, As, } \\
\mathrm{Au}, \mathrm{Ag}\end{array}$ & Sólo AS \\
\hline Silicificación & $\begin{array}{l}\text { A partir de } \\
\text { enfriamiento de agua }\end{array}$ & $\begin{array}{l}\text { De la superficie a } \\
500 \mathrm{~m} \text {, masiva a } \\
\text { profundidad }<150 \mathrm{~m}\end{array}$ & $\begin{array}{l}\text { Porción somera del sistema, flujo } \\
\text { penetrativo }\end{array}$ & $\mathrm{Au}, \mathrm{Ag}$ (trazas) & $\begin{array}{l}\text { BIS, AS } \\
\text { intermedio- } \\
\text { tardío }\end{array}$ \\
\hline
\end{tabular}

(1) $\mathrm{Hg}$ si está en una zona calentada por vapor; $\mathrm{As}, \mathrm{Sb}, \mathrm{Au}, \mathrm{Ag}$ si es debido a fluidos profundos. AS = alta sulfuraciópn. BIS = sulfuración baja o intermedia.

uso de todos estos métodos está invariablemente ligado al estudio de las paragénesis minerales y de las inclusiones fluidas.

\subsection{Composiciones isotópicas de $\mathrm{O}$ y $\mathrm{H}$}

Las composiciones isotópicas de $\mathrm{O}$ y $\mathrm{H}$ en aguas de los campos geotérmicos suelen ser muy cercanas a las de las aguas meteóricas regionales, indicando que ése es su origen primario. La variación registrada en las composiciones isotópicas de $\mathrm{O}$ y $\mathrm{H}$ se debe a tres procesos principales y a sus combinaciones: (1) pérdida de vapor por ebullición, (2) mezcla de fluidos, y (3) interacción agua/roca. Dado que las rocas encajonantes inalteradas contienen gran cantidad de oxígeno pero comparativamente poca cantidad de hidrógeno, la $\delta^{18} \mathrm{O}$ tanto de la roca como del fluido cambia con suma facilidad, al contrario de lo que sucede con la $\delta \mathrm{D}$ en un clásico proceso de interacción agua-roca.

Los datos de $\delta \mathrm{D}$ son difícilmente interpretables sin conocer la composición del agua meteórica en la época en que tuvo lugar la mineralización, pero puede inferirse a partir de las tendencias marcadas por la combinación de $\delta^{18} \mathrm{O}-\delta \mathrm{D}$ y, en depósitos muy recientes, puede utilizarse la composición del agua meteórica regional actual. El principal objeto de discusión en los últimos tiempos ha sido la redefinición del campo composicional de las aguas magmáticas. En los datos obtenidos de fumarolas en volcanes de Japón, Alaska y la Península de Kamchatka (Sakai y Matsubaya, 1977; Viglino et al., 1985; Taran et al., 1989), se pone de manifiesto que el conjunto de las composiciones isotópicas más altas muestran valores muy homogéneos alrededor de $\delta^{18} \mathrm{O}=10 \%$ y $\delta \mathrm{D}=-20 \%$. Las composiciones isotópicas de las "aguas magmáticas primarias" (Sheppard et al., 1969; Sheppard, 1986; Taylor, 1986), con $\delta^{18} \mathrm{O}$ entre 6 y $10 \%$ y $\delta \mathrm{D}$ entre -50 y $-80 \%$, difícilmente pueden explicar las composiciones referidas arriba. Por este motivo, Giggenbach (1992b,c), defino el campo de las "aguas andesíticas", con composiciones isotópicas que esencialmente reflejan la de aguas marinas recicladas, llevadas en la porosidad de los sedimentos pelágicos de la corteza oceánica subducida hasta la zona de producción de magma (Peacock, 1990; Hedenquist y Lowenstern, 1994). Estas aguas tienen una $\delta \mathrm{D} \approx-30 \%$ (Liu y Epstein, 1984), debido al fraccionamiento isotópico existente entre el agua marina y los sedimentos pelágicos. Por lo tanto, un valor de $\delta \mathrm{D} \approx-20 \%$, característico de las "aguas andesíticas", puede representar la mezcla en profundidad de estas aguas con otras de origen meteórico.

De todos modos, el valor de $\delta \mathrm{D}$ considerado como magmático, basado en el análisis isotópico de rocas magmáticas y de arcillas generadas hidrotermalmente en depósitos metalíferos en pórfidos, no representa con precisión la composición del agua magmática previa a su migración desde el magma saturado, cuyo rango de variación es más restringido. Efectivamente, en base a análisis de obsidianas en numerosos complejos volcánicos (Taylor, 1992) se han hallado valores de $\delta \mathrm{D}$, alrededor de $-40 \%$, más similares a los de las aguas andesíticas que a los de las "aguas magmáticas primarias".

En el estudio de seis grandes depósitos epitermales de BS y SI (Antamok-Acupan en Filipinas, Comstock en E.U.A., Emperor en Fiji, Hishikari en Japón, Fresnillo y Tayoltita en México), se halló que la distribución de los 
Tabla 4. Características de campo de los tres principales contextos de alteración argílica avanzada relacionados con depósitos epitermales (adaptado de Sillitoe, 1993).

\begin{tabular}{|c|c|c|c|}
\hline Origen & Hipogénico profundo & Hipogénico somero & Oxidación supergénica \\
\hline $\begin{array}{l}\text { Terminología genética } \\
\text { (Rye et al., 1992) }\end{array}$ & Magmática-hidrotermal & Calentada por vapor & Supergénica \\
\hline Formación & $\begin{array}{l}\text { Condensación de vapores magmáticos } \\
\text { ascendentes de alta } \mathrm{T} \text { con } \mathrm{HCl} \text { y } \mathrm{SO}_{2}\end{array}$ & $\begin{array}{l}\text { Oxidación atmosférica de } \mathrm{H}_{2} \mathrm{~S} \text { en la } \\
\text { zona freática }\end{array}$ & $\begin{array}{l}\text { Oxidación atmosférica de sulfuros de } \\
\text { grano fino en zona de meteorización } \\
\text { superficial }\end{array}$ \\
\hline $\begin{array}{l}\text { Textura de la alunita y } \\
\text { hábito cristalino }\end{array}$ & $\begin{array}{l}\text { Agregados de cristales de grano grueso } \\
\text { o fino; cristales tabulares u hojosos }\end{array}$ & $\begin{array}{l}\text { Agregados pulverulentos (cristales }<20 \text { - } \\
50 \mu \mathrm{m} \text { ), masas gredosas o porcelanosas; } \\
\text { cristales romboédricos }\end{array}$ & $\begin{array}{l}\text { Masas gredosas o porcelanosas, } \\
\text { agregados pulverulentos (cristales }<20 \text { - } \\
50 \mu \mathrm{m} \text { ); cristales romboédricos }\end{array}$ \\
\hline Color & Incoloro, blanco, rosado, amarillo, pardo & Generalmente blanco & $\begin{array}{l}\text { Blanco, crema, amarillo-pardo } \\
\text { (manchado de jarosita) }\end{array}$ \\
\hline Disposición típica & $\begin{array}{l}\text { Reemplazamiento de fenocristales de } \\
\text { feldespato, litoclastos, etc.; relleno de } \\
\text { cavidades }\end{array}$ & $\begin{array}{l}\text { Reemplazamiento penetrante, } \\
\text { especialmente de feldespatos }\end{array}$ & $\begin{array}{l}\text { Vetillas irregulares, masas nodulares; } \\
\text { reemplazamiento penetrante local }\end{array}$ \\
\hline $\begin{array}{l}\text { Minerales de alteración } \\
\text { asociados }\end{array}$ & $\begin{array}{l}\text { Cuarzo, kaolinita, alunita, dickita, } \\
\text { diáspora, pirofilita }\end{array}$ & Cristobalita, ópalo, kaolinita, alunita & Kaolinita, alunita \\
\hline $\begin{array}{l}\text { Disposición respecto a } \\
\text { los sulfuros }\end{array}$ & $\begin{array}{l}\text { Junto con sulfuros, excepto sujetos a } \\
\text { oxidación supergénica }\end{array}$ & $\begin{array}{l}\text { Normalmente junto con sulfuros, } \\
\text { excepto sujetos a oxidación supergénica, } \\
\text { localmente con limonita hipogénica } \\
\text { (hematites) }\end{array}$ & $\begin{array}{l}\text { Normalmente con limonita, pero } \\
\text { pueden recubrir una zona de sulfuros } \\
\text { infrayacente }\end{array}$ \\
\hline Relación con la mena & $\begin{array}{l}\text { Potencialmente puede incluir mena, } \\
\text { típicamente como envoltura de la mena }\end{array}$ & $\begin{array}{l}\text { Estéril; sobreyace a la mena o está } \\
\text { superpuesta a ella }\end{array}$ & $\begin{array}{l}\text { Sin relación inequívoca con la mena de } \\
\text { sulfuros, puede estar relacionada con } \\
\text { ella o no }\end{array}$ \\
\hline $\begin{array}{l}\text { Temperatura de } \\
\text { formación }\left({ }^{\circ} \mathrm{C}\right)\end{array}$ & $\begin{array}{l}300^{\circ}-350^{\circ} \text { a } 100^{\circ} \text {; fluidos hipogénicos } \\
\text { ascendentes }\end{array}$ & $\begin{array}{l}100^{\circ}-120^{\circ}, \text { hasta } 150^{\circ}+\text {; fluidos } \\
\text { descendentes }\end{array}$ & $\begin{array}{l}20^{\circ}-40^{\circ} ; \text { superposición por fluidos } \\
\text { descendentes }\end{array}$ \\
\hline $\begin{array}{l}\text { Composición isotópica } \\
\text { de la alunita }\end{array}$ & $\delta^{34} \mathrm{~S}$ alunita $\gg \delta^{34} \mathrm{~S}$ sulfuro asociado & $\delta^{34} \mathrm{~S}$ alunita $\sim \delta^{34} \mathrm{~S}$ sulfuro asociado & $\delta^{34} \mathrm{~S}$ alunita $=\delta^{34} \mathrm{~S}$ sulfuro precursor \\
\hline
\end{tabular}

valores de $\delta^{18} \mathrm{O}$ y temperatura de fluidos obtenidas en dichos depositos (1) define un campo intermedio entre la curva que determinan las aguas magmáticas y la de las aguas meteóricas, o (2) se solapa a la curva de las aguas magmáticas, con enriquecimientos positivos máximos relativos a las aguas meteóricas de $\delta^{18} \mathrm{O}$ entre 7 y $20 \%$ (Figura 15). Aceptando un valor de $\delta^{18} \mathrm{O}=9 \%$ o como el máximo posible para el enriquecimiento isotópico de las aguas meteóricas debido a la interacción agua/roca, se sugiere que los fluidos en los depósitos de Comstock, Emperor y Fresnillo tuvieron un aporte de fluidos magmáticos cuanto menos del 50\%, y que los de Antamok-Acupan, Hishikari y Tayoltita no tuvieron aportes de fluidos magmáticos. Por otro lado, asumiendo un intercambio isotópico nulo durante la interacción agua/roca, resultaría que todos estos depósitos se formaron a partir de fluidos magmáticos, en proporciones que varían del 10 al 90\% (Simmons, 1995). Estos dos casos acotan condiciones extremas, en las que la interacción agua/roca se revela como un elemento determinante para discernir el origen último de los fluidos, e ineludible en la interpretación de datos de isótopos estables de $\mathrm{O}$ y $\mathrm{H}$.

\subsection{Composición isotópica de $\mathrm{S}$}

Mediante el estudio de la composición isotópica del azufre de sulfuros y sulfatos en depósitos epitermales es posible discernir diferentes fuentes de dicho elemento. En este tipo de depósitos generalmente se ha propuesto comúnmente un origen magmático dominante del azufre presente como sulfuros o sulfatos (Rye y Ohmoto, 1974; Rye y Sawkins, 1974; Hayba et al., 1985; Sherlock et al., 1995; Willan y Spiro, 1996; Mulshaw et al., 1997; Castor et al., 2003; John et al., 2003). Cabe subrayar que estas composiciones magmáticas no implican que haya existido una contribución en azufre magmática "directa", sino que por lo general se ha argumentado que más bien reflejan una incorporación de azufre a partir de la lixiviación de rocas magmáticas por parte de los fluidos mineralizantes. Para poder argüir sobre contribuciones magmáticas directas de azufre no basta con estudiar su composición isotópica, sino que hay que apoyarse en otras evidencias. En depósitos epitermales de BS y SI, sin embargo, en que las rocas encajonantes o circundantes pueden no ser dominantemente magmáticas, la composición isotópica de los sulfuros registra en parte también la composición isotópica de rocas sedimentarias o metasedimentarias (Gross, 1975; Pearson et al., 1988; Ruvalcaba-Ruiz y Thompson, 1988; Thiersch et al., 1997; Camprubí et al., 2001b). En otros casos, habiéndose registrado composiciones isotópicas muy o extremadamente negativas, también se ha invocado la presencia de azufre derivado de sulfatorreducción bacteriana.

Igualmente, no sólo es posible deducir las fuentes más probables del azufre, sino también los posibles mecanismos de precipitación mineral. Según Ohmoto (1972), la composición isotópica de azufre en sulfuros depende de la tempe- 

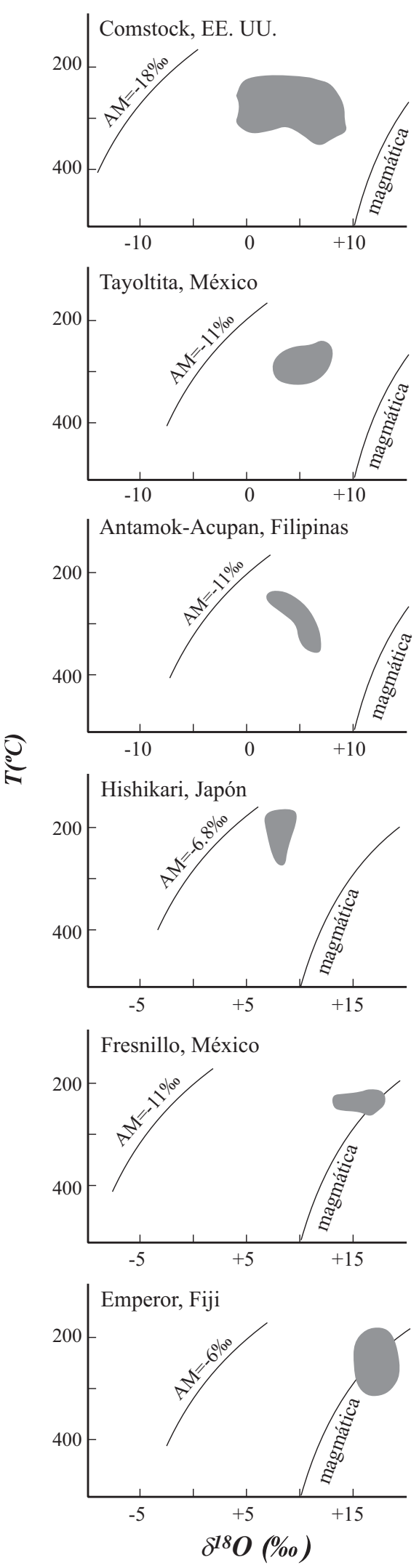

Figura 15. Correlación entre la temperatura y la composición isotópica del oxígeno del agua en equilibrio con los minerales analizados en seis grandes depósitos epitermales de baja e intermedia sulfuración (Simmons, 1995). AM = composición isotópica del oxígeno de las aguas meteóricas locales. ratura, el $\mathrm{pH}$, la fugacidad de oxígeno y la fuerza iónica de la solución durante la deposición mineral. Los cambios en estas variables pueden producir grandes desplazamientos de la composición isotópica del azufre de los sulfuros que están precipitando. En depósitos epitermales, un proceso que comúnmente conlleva cambios en la fugacidad de oxígeno puede ser la mezcla entre fluidos reducidos de origen o circulación profunda y aguas superficiales oxidantes. Otro mecanismo que provoca tal cambio es la ebullición, dado que la pérdida de $\mathrm{H}_{2} \mathrm{y} \mathrm{H}_{2} \mathrm{~S}$ al incorporarse preferentemente de la solución a la fase vapor, que migra hacia la superficie, causa un aumento en el estado de oxidación del fluido residual (Drummond y Ohmoto, 1985). Mientras que el primer proceso ha sido documentado ámpliamente, el segundo ha sido reconocido sólo en algunos depósitos (e. g. Creede, Colorado, E.U.A.; Plumlee y Rye, 1986). Sólo con el uso de técnicas de análisis in situ mediante microsonda iónica (McKibben y Eldridge, 1990) se ha puesto de manifiesto la presencia de fuertes zonaciones isotópicas a escala de cristal, lo cual es atribuible a la oxidación de los fluidos mineralizantes debida a ebullición.

\subsection{Concentraciones de cloro}

Las concentraciones de cloro en aguas geotérmicas de sistemas asociados a magmatismo de arco de islas, aislados de recargas de agua marina y en ausencia de evaporitas o salmueras connatas, son típicamente de unas 500-2500 ppm para sistemas relacionados con riolitas, y de 6000 a $12000 \mathrm{ppm}$ para sistemas relacionados con andesitas (Hedenquist y Henley, 1985a). Estas concentraciones pueden variar debido a los mismos procesos que afectan a la composición de los isótopos estables, ya descritos. Debido a que la recarga meteórica en sistemas convectivos profundos empieza a partir de agua prácticamente pura, las concentraciones de cloruros medidas en aguas geotérmicas son debidas necesariamente a procesos diferentes de la ebullición. Es posible calcular la concentración de cloro en el fluido pre-ebullición, para el rango de temperaturas determinado dentro del cual se produce la ebullición (Henley et al., 1984; Simmons, 1995). Según estudios experimentales, hasta varios centenares de ppm de cloro en solución pueden ser derivados de la lixiviación de rocas de la corteza por parte de agua pura. De forma alternativa, las contribuciones magmáticas también pueden ser decisivas, aunque la transferencia de cloro magmático a las celdas convectivas no está todavía bien tipificado y se contempla como un proceso más complejo de lo que sería una simple mezcla (ver Fournier, 1987). De todas formas, en los casos en que la concentración de cloro es mayor de la que puede obtenerse por lixiviación del encajonante, puede inferirse una fuente magmática (Simmons, 1995). Dado que los fluidos ricos en cloro y elementos alcalinos y los ricos en agua pueden exsolverse simultáneamente, como resultado de la evolución magmática y la desgasificación (Kilinc y 
Burnham, 1972; Shinohara et al., 1989; Webster, 1997), pueden evolucionar a través de la corteza conjuntamente hasta mezclarse con otros fluidos y formar mayores volúmenes de fluido susceptibles de provocar deposición mineral. En cuanto al origen "primario" de este cloro, tanto puede provenir del manto como derivar del reciclaje del cloro en solución contenido en la porosidad de los sedimentos pelágicos de la corteza oceánica subducida (Hedenquist y Lowenstern, 1994).

Los contenidos de cloro pueden utilizarse con una cierta fiabilidad como indicadores sólo en salinidades superiores al $2.5 \mathrm{wt} \% \% \mathrm{NaCl}$ equiv. Esto se debe a que las temperaturas de fusión del hielo correspondientes a esa salinidad en el sistema $\mathrm{H}_{2} \mathrm{O}-\mathrm{NaCl}$, entre 0 y $-1.5^{\circ} \mathrm{C}$, pueden ser debidas, no sólo al contenido en sales sino también a la presencia de clatratos durante los ensayos microtermométricos a baja temperatura (Hedenquist y Henley, 1985a; Hedenquist et al., 1992). En el caso de los depósitos del distrito de Fresnillo, las salinidades más altas están estrechamente relacionadas con la deposición de sulfuros, lo cual es congruente con la capacidad de transporte de Ag- $\mathrm{Pb}-\mathrm{Zn}$ por parte de complejos moleculares clorurados (Helgeson, 1964; Candela y Piccoli, 1995). La inyección recurrente de fluidos de este tipo se ha interpretado como indicación de la existencia en profundidad de un reservorio de salmueras de origen magmático, por debajo de las celdas de convección de aguas mucho más diluidas, siempre y cuando las litologías de la zona no sean favorables para la presencia de evaporitas o salmueras connatas (Simmons et al., 1988; Loucks et al., 1988; Simmons, 1991; Simmons y Browne, 1997; Camprubí et al., 2001b). En este caso, la existencia regionalmente de otras mineralizaciones (Clark et al., 1982), de tipología diferente pero de la misma edad, cuyas características apuntan a un origen netamente magmático (tales como depósitos metalíferos en pórfidos, skarns o depósitos de óxidos de hierro tipo IOCG), supone un elemento más de apoyo para proponer un origen magmático de buena parte de los fluidos mineralizantes.

Según estudios sobre relaciones $\mathrm{Br} / \mathrm{Cl}$ (Giggenbach, 1995) e isótopos de cloro (Hedenquist et al., 1990), realizados a lo largo del campo geotérmico de la zona volcánica de Taupo en Nueva Zelanda, también se pudo comprobar la presencia de cloro de origen magmático.

\subsection{Composición de gases en inclusiones fluidas}

Los fluidos mineralizantes pueden clasificarse según su diferente origen: fluidos magmáticos, aguas meteóricas de circulación profunda (o "evolucionadas"), salmueras de origen sedimentario y aguas meteóricas superficiales. Entre los fluidos magmáticos, también pueden distinguirse los fluidos procedentes de riolitas o de basaltos centrooceánicos. Cada uno de estos tipos de fluidos contiene gases que ocupan regiones características en un diagrama triangular $\mathrm{N}_{2}-\mathrm{He}-\mathrm{Ar}$ (Giggenbach, 1986; Giggenbach y
Matsuo, 1991; Giggenbach y Glover, 1992; Norman y Musgrave, 1994), lo mismo que sus mezclas (Figura 16). Así, las aguas meteóricas que han experimentado una cierta circulación en profundidad tienen composiciones de gases que ocupan una región comprendida entre la composición de las aguas saturadas en aire y las corticales. Del mismo modo, las aguas meteóricas que han adquirido volátiles de un intrusivo tendrán composiciones entre las características de las aguas saturadas en aire y las del campo de aguas magmáticas. Dado que las aguas meteóricas de circulación profunda (también llamadas de cuenca, "evolucionadas", con contaminación cortical o "corticales") y los fluidos de origen riolítico y basáltico ocupan típicamente la misma región dentro del diagrama $\mathrm{N}_{2}-\mathrm{He}-\mathrm{Ar}$ (Figura 16), se hace necesario otro tipo de discriminación. Por este motivo, también se utiliza el diagrama $\mathrm{N}_{2}-\mathrm{CH}_{4}-\mathrm{Ar}$, en el que la zona cercana al ápice de $\mathrm{CH}_{4}$ está ocupada únicamente por las aguas meteóricas de circulación profunda.

Las concentraciones relativas de $\mathrm{N}_{2}$-Ar-He en muestras de gases de volcanes activos asociados a hot spots, dorsales y bordes convergentes de placa definen dos tendencias diferenciadas de mezcla entre aguas basálticas y andesíticas con aguas meteóricas (Giggenbach, 1992a). Las aguas andesíticas se caracterizan por valores de $\mathrm{N}_{2} / \mathrm{He}$ entre 1700 y 5000 , y las basálticas por valores entre 10 y 220 (Simmons, 1995). Los valores de $\mathrm{He} / \mathrm{Ar}$ de los gases de origen basáltico y andesítico son cercanos al valor "mantélico", $\approx 3$. Las aguas meteóricas saturadas en aire, con relaciones $\mathrm{N}_{2} / \mathrm{Ar}$ entre 36 y 50, reflejando la influencia atmosférica $\left(\mathrm{N}_{2} / \mathrm{Ar}=84\right)$ en la composición de los gases, suelen constituir el extremo tanto de las aguas basálticas como las andesíticas. Los fluidos de recarga de un sistema hidrotermal activo pueden tener contenidos variables de aire, y los procesos de ebullición pueden alterar de alguna forma la relación $\mathrm{N}_{2} / \mathrm{Ar}$. Como ninguno de los tres gases considerados $\left(\mathrm{N}_{2}, \mathrm{He}, \mathrm{Ar}\right)$ es reactivo dentro de los fluidos geotérmicos, sus concentraciones relativas pueden servir para complementar las relaciones isotópicas de He como trazadores potenciales de la intervención de fluidos profundos de origen magmático (Giggenbach, 1986 y 1992a; Hedenquist et al., 1992; Norman y Musgrave, 1994; Simmons, 1995). Los valores obtenidos de gases de volcanes félsicos (Giggenbach, 1992b), en inclusiones de vidrio magmático (Norman et al., 1997a) e inclusiones fluidas procedentes de depósitos metalíferos en pórfidos (Norman y Musgrave, 1994), indican que los volátiles de origen magmático se caracterizan por relaciones $\mathrm{N}_{2} / \mathrm{Ar}$ significativamente mayores que la del aire.

En los depósitos epitermales (Benton, 1991; Norman y Musgrave, 1994; Simmons 1995; Albinson et al., 2001; Camprubí et al., 2003c), las composiciones de los gases contenidos en inclusiones fluidas se encuentran mayoritariamente dentro del campo delimitado por los miembros extremos de las aguas meteóricas y las magmáticas (andesíticas) en el diagrama $\mathrm{N}_{2}-\mathrm{He}-\mathrm{Ar}$. Esto sugiere una importante contribución de fluidos magmáticos, aunque 
bajo la influencia no menos importante de aguas meteóricas. En el estudio sistemático de los gases contenidos en inclusiones fluidas procedentes de 29 depósitos epitermales de baja sulfuración de México (Norman et al., 1997b; Albinson et al., 2001) se sugiere que (1) la presencia de aguas magmáticas es evidente en la gran mayoría de ellos; (2) los análisis en las menas metálicas muestran un mayor contenido en aguas magmáticas que en los minerales de ganga; y (3) la contribución en azufre, en forma de $\mathrm{H}_{2} \mathrm{~S}$, por parte de dichas aguas es decisiva para la existencia de mineralización metálica. De todos modos, sin el apoyo de datos obtenidos mediante otras técnicas (isótopos estables de $\mathrm{O}$ y $\mathrm{H}$, isótopos de helio, etc.), puede ser difícil determinar de forma definitiva los orígenes de los fluidos involucrados en sistemas o depósitos hidrotermales (Norman y Musgrave, 1994). Este es el caso de las aguas metamórficas, cuyas relaciones "típicas" de $\mathrm{N}_{2}-\mathrm{He}-\mathrm{Ar}$ o $\mathrm{N}_{2}-\mathrm{CH}_{4}-\mathrm{Ar}$ no están claramente tipificadas todavía.
También se ha demostrado la utilidad de la cuantificación de los gases contenidos en inclusiones fluidas naturales como indicadora de los posibles mecanismos de precipitación mineral (ebullición y/o mezcla de fluidos), así como el origen común de algunos componentes químicos en sistemas epitermales (Norman et al., 1991, 1997a,b; Albinson et al., 2001; Camprubí et al. 2003c). Además, la correlación positiva entre las relaciones $\mathrm{N}_{2}$ /Ar y valores de isótopos estables con firma magmática, indica un origen magmático para el $\mathrm{N}_{2}$ (Hedenquist y Aoki, 1991).

\subsection{Composición isotópica de helio}

Las diferencias existentes entre las composiciones de isótopos de He en la atmósfera, el manto superior, la corteza continental, y las fuentes radiogénicas, permite el uso de las relaciones de estos isótopos como trazadoras inequí-
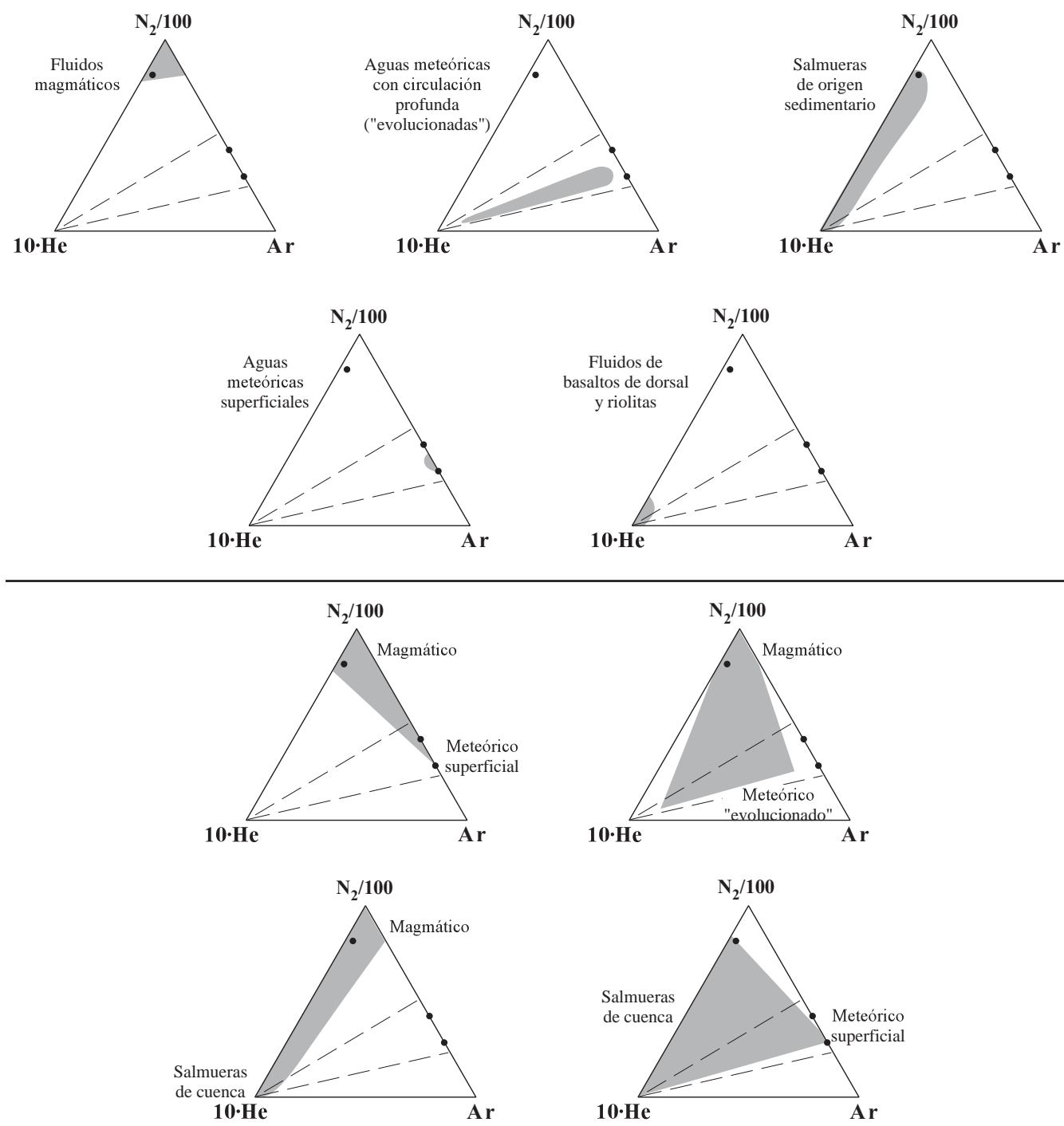

Figura. 16. Campos composicionales característicos de fluidos de diversos orígenes, según el diagrama triangular $\mathrm{N}_{2}$-Ar-He, y de sus mezclas (Norman y Musgrave, 1994). 
vocas de los posibles orígenes de los volátiles volcánicos y geotérmicos (Giggenbach y Poreda, 1993; Giggenbach et al., 1994; Simmons, 1995). La relación ${ }^{3} \mathrm{He} /{ }^{4} \mathrm{He}$ en la atmósfera es de 1.39 \pm 0.01 (Clarke et al., 1969; Mamyrin et al., 1969). Esta relación es convencionalmente denominada $R a$ y constituye la referencia estándard utilizada. Las comparaciones entre esta referencia y los análisis de las muestras problema se expresan como una relación $R / R a$, en la cual el valor $R$ corresponde a la relación ${ }^{3} \mathrm{He} /{ }^{4} \mathrm{He}$ de la muestra problema. La relación $R / R a$ es de aproximadamente 8-9 en basaltos de dorsal centro-oceánica, 15-30 en el manto profundo, $\mathrm{y}<0.1$ en la corteza continental, debida a la desintegración radiactiva de $\mathrm{U}$ y Th.

Por otro lado, el helio que aportan los magmas ascendentes hacia la corteza tiene relaciones $R / R a>6$ (Craig et al., 1978; Lupton, 1983). Los volátiles en sistemas geotérmicos del arco Circum-Pacífico muestran relaciones $R / R a$ entre 4.3 y 8.2 , lo cual indica la existencia de importantes contribuciones de helio derivado del manto (Torgersen et al., 1982; Sano y Wakita, 1985; Poreda y Craig, 1989; Giggenbach y Poreda, 1993; Giggenbach et al., 1994; Giggenbach, 1995; Patterson et al., 1997). Estas relaciones son muy parecidas a las halladas en fenocristales y xenolitos procedentes de lavas en contexto de arcos volcánicos, con relaciones $R / R a$ entre $<1$ y 8.5 (Tolstikhin et al., 1972, 1974; Hilton y Craig, 1989; Poreda y Craig, 1989; Hilton et al., 1993; Gasparon et al., 1994; Patterson et al., 1997).

En los depósitos epitermales de baja sulfuración de Antamok-Acupan en Filipinas y Fresnillo en México se obtuvieron relaciones $R / R a$ de 6-7 y 1-2, respectivamente (Simmons et al., 1988; Cooke y Bloom, 1990). Dichos análisis ponen de manifiesto la presencia de helio derivado del manto que, aunque "diluido", se ha interpretado que fue transportado a la corteza probablemente por medio de los magmas ascendentes, migrando a la corteza superior en las aguas hidrotermales.

Una relación ${ }^{3} \mathrm{He} /{ }^{4} \mathrm{He}$ típicamente mantélica puede ser modificada mediante diversos mecamismos. La acumulación de ${ }^{4} \mathrm{He}$ radiogénico en un magma ascendente se asocia generalmente a un largo periodo de residencia de dicho magma en la corteza continental (Simmons, 1995). El resultado es la "contaminación" por parte de helio de origen cortical, cuya $R / R a$ es de $\sim 0.1$. Ésta hipótesis se ha considerado como la más probable en Fresnillo, teniendo en cuenta que la corteza continental en la zona de la Sierra Madre Occidental es relativamente gruesa (e. g. Aiken et al., 1988; Gomberg et al., 1988; Schellhorn et al., 1991; Morán-Zenteno et al., 1996; Nieto-Samaniego et al., 2005). $\mathrm{El}{ }^{4} \mathrm{He}$ también puede ser añadido a los fluidos hidrotermales a partir de la lixiviación de rocas de la corteza, como parte del ciclo hidrológico. También la mezcla de fluidos de origen mantélico con aguas meteóricas puede ser otro posible mecanismo de dilución de la composición isotópica del helio magmático. En este caso, hay que destacar que la relación ${ }^{3} \mathrm{He} /{ }^{4} \mathrm{He}$ de los fluidos en campos geotérmicos actuales disminuye a medida que aumenta la distancia desde los centros volcánicos, como función del aumento de la interacción agua/roca (Hilton et al., 1993), teniendo también en cuenta la mayor incorporación potencial de aguas meteóricas a las células de convección hidrotermal, con helio de composición isotópica atmosférica. Los valores $R / R a$ sensiblemente inferiores a los considerados como mantélicos pueden ser explicados mediante (1) una contribución de componentes corticales, bien por asimilación por parte del magma, bien por la interacción agua/roca en profundidad, y (2) una mezcla con aguas meteóricas saturadas en aire. Otro proceso que puede enmascarar el helio mantélico puede ser el fraccionamiento de ${ }^{3} \mathrm{He}$ a la fase vapor durante la ebullición, con lo cual es importante poner un especial cuidado en el estudio petrográfico para detectar este factor.

\subsection{Composición isotópica de plomo}

Los isótopos de plomo han sido utilizados en sistemas geotérmicos activos para evaluar la posible fuente magmática de los metales en los fluidos mineralizantes, tanto en sistemas con un cierto potencial económico como en sistemas cuyas concentraciones metálicas no favorecen su explotación minera (Hedenquist y Gulson, 1992). De estos estudios se ha deducido que el aporte magmático favorece la presencia de mineralización económica. Contrariamente, en los sistemas geotérmicos cuyas composiciones isotópicas de plomo sugieren que este metal deriva de la lixiviación de las rocas encajonantes, los contenidos en metales preciosos son subeconómicos. Este modelo es aplicable únicamente en sistemas hidrotermales de muy baja salinidad, inferior al 2 wt.\% $\mathrm{NaCl}$ equiv., incluyendo los depósitos epitermales. Estas salinidades son insuficientes para la lixiviación efectiva de componentes a partir de las rocas encajonantes (Hedenquist y Henley, 1985a). A pesar de esto, en el estudio de isótopos de plomo en depósitos epitermales de BS y SI de México y los Estados Unidos (Zartman, 1974; Cumming et al., 1979; Doe et al., 1979; Foley y Ayuso, 1994; Keppie y Ortega-Gutiérrez, 1995; John et al., 2003) se sugiere que una parte significativa del plomo deriva de las rocas precámbricas o fanerozoicas subyacentes al vulcanismo de edad Terciaria. De este modo, se ha interpretado que buena parte de los componentes de las menas derivan de la lixiviación de las rocas encajonantes en profundidad (Hayba et al., 1985; Foley y Ayuso, 1994).

\subsection{Contenido de FeS en esfalerita}

En algunos depósitos se han hallado altos contenidos, hasta el 0.24 molar, de FeS en esfalerita, que se han atribuido como derivados del fluido ascendente sin interacción alguna con aguas superficiales, asumiendo en ello una cierta contribución de fluidos reducidos de origen magmático (Hayba et al., 1985; Gemmell et al., 1988; Loucks et al., 
1988; Camprubí et al., 2001a; Einaudi et al., 2003). En estos casos y en otros, incluyendo algunos campos geotérmicos actuales, esta componente ha sido demostrada mediante geoquímica de isótopos estables (Hayba et al., 1985), y se considera que la presencia de fluidos reducidos magmáticos ha ejercido un papel decisivo en la deposición mineral.

\section{Los depósitos epitermales en México}

\subsection{Distribución espacial y temporal}

Como ya se ha señalado anteriormente, los depósitos epitermales conocidos hasta la fecha en México son de edad Terciaria (desde el Luteciano hasta el Aquitaniano; Camprubí et al., 2003b), y su distribución espacial coincide con la distribución espacial determinada por la evolución del vulcanismo de la Sierra Madre Occidental y de la Sierra Madre del Sur (ver Damon et al., 1981; Clark et al., 1982; Camprubí et al., 2003b). Según esto, la distribución de depósitos epitermales en México (Figura 17) puede definirse según tres rangos de edades principales (Camprubí et al., 2003b):

1. Más antiguos de $\sim 40 \mathrm{Ma}$ : este rango está ejemplificado por los depósitos de Batopilas, Topia y La Caridad Antigua, aunque la edad absoluta más antigua reportada hasta el momento para depósitos epitermales en México (58 Ma, correspondiente al Paleoceno) corresponde a los depósitos de El Barqueño, Jalisco (Camprubí et al., 2006). Este rango de edades se corresponde con la orogenia Larámide en el norte de México. Estos depósitos están localizados al este o al oeste de la Sierra Madre Occidental (e. g. Real de Ángeles), por lo que Staude y Barton (2001) sugieren que depósitos similares pueden estar cubiertos bajo la Serie Volcánica Superior de la Sierra Madre Occidental.

2. Entre $\sim 40$ y $\sim 27 \mathrm{Ma}$ : la mayoría de depósitos epitermales de México se formó en este periodo, y se disponen según un cinturón NW-SE desde Chihuahua al Estado de México, a una distancia de hasta $\sim 250 \mathrm{~km}$ de la costa Pacífica. Este intervalo de tiempo se corresponde con el primer episodio volcánico bimodal andesítico-riolítico de la Serie Volcánica Inferior de la Sierra Madre Occidental (Fredrickson, 1974; McDowell y Keizer, 1977). La Serie Volcánica Inferior está constituida, en gran medida, por andesitas que, en forma más local, exhiben centros de vulcanismo riolítico, donde generalmente se presentan yacimientos epitermales importantes, como San Dimas (Tayoltita) en Durango y Pánuco en Sinaloa. Albinson (1988) indicó un rango de tiempo preferencial entre 35 y 30 Ma para la formación de depósitos epitermales en la parte central del Altiplano Mexicano, lo que se corresponde con el clímax del vulcanismo predominantemente de composición intermedia.

3. Más recientes de $\sim 23 \mathrm{Ma}$ : estos depósitos se encuentran en la parte sur de la Sierra Madre Occidental, al norte de la Faja Volcánica Mexicana. Éstos definen una tendencia WNW-ESE, que se corresponde con el último episodio netamente ignimbrítico de la Sierra Madre Occidental, conocido como Serie Volcánica Superior (Fredrickson, 1974; McDowell y Keizer, 1977; Ferrari et al., 2002). Esta tendencia coincide con un cambio en la orientación del arco volcánico, siguiendo la apertura de la nueva trinchera al sur de México (Ferrari et al., 1999). Sin embargo, hay evidencias cuanto menos de una distribución "bipolar" de estos depósitos, teniendo en cuenta que la presencia de Pachuca-Real del Monte, Hidalgo, e Ixtacamaxtitlán, Puebla, constituyen evidencia de la presencia de depósitos del Mioceno al este de la Faja Volcánica Mexicana (Tritlla et al., 2004).

\subsection{Tipos de depósitos epitermales en México}

En función de los contenidos relativos en metales (Ag/Au y metales nobles/metales básicos) y la salinidad aparente de las inclusiones fluidas, Albinson et al. (2001) distinguen entre depósitos epitermales de baja sulfuración de $\mathrm{Zn}-\mathrm{Pb}-\mathrm{Ag}$, Ag-Zn-Pb, Ag+Au+Pb+Zn+Cu, Ag-Au, y Au-Ag o, más genéricamente, entre depósitos polimetálicos y depósitos de metales preciosos. A primera vista, estas dos categorías se corresponden grosso modo con los subtipos de SI y BS, respectivamente, según los criterios de Hedenquist et al. (2000), Einaudi et al. (2003), y Sillitoe y Hedenquist (2003). En detalle, la relación entre los dos tipos de depósitos es quizás más estrecha de lo que se ha sospechado y, como se verá subsecuentemente, numerosos depósitos exhiben una franca coexistencia entre ambos estilos de mineralización. Aunque Simmons (1991) utilizó los términos "heavy sulfide" y "light sulfide" en Fresnillo en otro sentido, éstos pueden usarse también como equivalentes a estilos de mineralización de IS y LS, respectivamente, por ser muy descriptivos y adaptables a los mismos. La distribución areal general de los depósitos epitermales en México (Figura 1) delineada por Camprubí et al. (1999) abarca los cinturones metalogenéticos de $\mathrm{Pb}-\mathrm{Zn}-\mathrm{Ag}$ y de $\mathrm{Au}-(\mathrm{Ag})$ delineados previamente por Clark et al. (1982), que tienen una distribución parcialmente coincidente pero diferenciada. Aunque, en efecto, puede apreciarse que los cinturones de depósitos con metales básicos predominantes se encuentran hacia la parte interior del margen continental, por otro lado es evidente que en las provincias metalogenéticas mexicanas de la Sierra Madre Occidental, la Mesa Central, y la Sierra Madre del Sur pueden encontrarse ejemplos de ambos tipos de depósitos.

\subsection{Relación con otras tipologías de depósitos}

Vínculos temporales y espaciales entre depósitos metalíferos en pórfidos y depositos epitermales han sido documentados en varias áreas del cinturón Circum-Pacífico, 


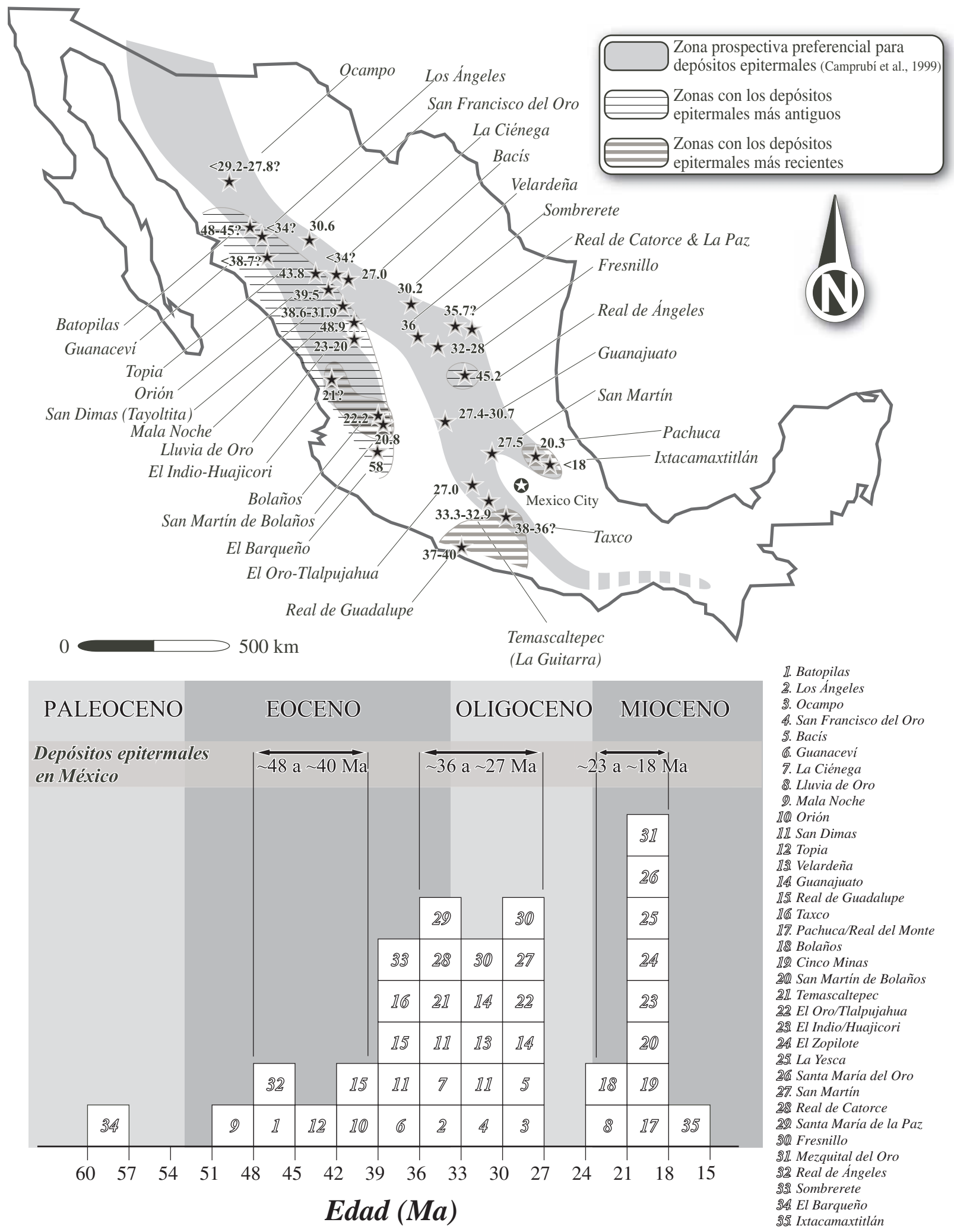

Figura 17. Arriba: Distribución de los depósitos epitermales en México, con sus edades correspondientes conocidas, bien por fechamiento directo de las mineralizaciones, bien por su relación geológica con rocas fechadas (modificado de Camprubí et al., 2003b). En amarillo se indican las zonas que agrupan la presencia de los depósitos más antiguos, y en naranja los más modernos. Por razones de claridad, se omite la localización de otros depósitos, también relacionados por Camprubí et al. (2003b) como Mala Noche en Durango (cercano a San Dimas), Cinco Minas en Jalisco, Mezquital del Oro en Zacatecas, y La Yesca, El Zopilote y Santa María del Oro en Nayarit (cercanos a El Indio y Bolaños). Abajo: Distribución histográfica de las edades de mineralización de los depósitos epitermales en México, con indicación de los tres rangos de edad preferenciales de Camprubí et al. (2003b). Modificado de Camprubí et al. (2006). 
como los depósitos de Lepanto (epitermal ácido), Far Southeast (epitermal alcalino/neutro) y Victoria (pórfido cuprífero) en Filipinas (Arribas et al., 1995; Hedenquist et al., 1996 y 1998; Sillitoe, 1999), Nevados del Famatina y La Mejicana en Argentina (Losada-Calderón y McPhail, 1996), o Maricunga en Chile (Muntean y Einaudi, 2001). En México, a pesar de la presencia de más de 30 manifestaciones de depósitos metalíferos en pórfidos en la parte noroeste del país (Sillitoe, 1977), poco se ha investigado al respecto de la conexión entre estos depósitos y los epitermales de la zona. Un ejemplo de conexión temporal y espacial entre ambos tipos de depósitos en México se encuentra entre el pórfido cuprífero de La Caridad y el deposito epitermal de La Caridad Antigua (Valencia, 2005). En el caso de yacimientos de IS dispuestos en las periferias de centros de mineralización claramente magmáticos, se ha documentado en México una relación genética entre depósitos metalíferos en pórfidos, skarns y depósitos epitermales en Moctezuma en Sonora (Deen y Atkinson, 1988; Atkinson, 1990 y 1996), como también se presenta una situación similar en el depósito de skarn de San Martín en Zacatecas (Rubin y Kyle, 1988; Gonzáles-Partida y Camprubí, 2006), con numerosas vetas epitermales de SI en la misma zona (e.g. veta Noria de Pantaleón), cuyo origen está posiblemente asociado al del skarn (Starling et al., 1997; Rubin y Kyle, 1998; Albinson et al., 2001). Existen evidencias de situaciones similares en Santa María de la Paz en San Luis Potosí (McGibbon, 1979; Gunnesch et al., 1994), Velardeña en Durango (Gilmer et al., 1988) y Real de Asientos en Aguascalientes (Rivera, 1993). Otro aspecto que cabría estudiar es si la gran cercanía entre los depósitos epitermales de BS de Batopilas, y el depósito metalífero en pórfidos de Tahonas en Chihuahua (Wilkerson et al., 1988) responde a una relación temporal y genética, o bien se trata de sobreimpresiones diacrónicas sin relación directa. Los depósitos epitermales de AS de El Sauzal (Charest y Castañeda, 1997; Sellepack, 1997; Gray, 2001) son cercanos a los anteriores, si bien la posible conexión con los mismos es más remota. Aún así, otro aspecto que cabría estudiar sería la posibilidad de que esos depósitos estuvieran relacionados o superpuestos a pórfidos metalíferos similares al de Tahonas.

La posible relación genética y temporal entre magmatismo profundo y depósitos epitermales de SI y BS (McKee et al., 1992; Conrad et al., 1993; Simmons, 1995; Albinson et al., 2001; Enríquez y Rivera, 2001a; Camprubí et al., 2003b), más allá de la evidente conexión entre los depósitos de tipo porfírico, skarns y epitermales, es uno de los temas de investigación en depósitos minerales actualmente en desarrollo y también de mayor proyección. La obtención de edades radiométricas, particularmente de ${ }^{40} \mathrm{Ar} /{ }^{39} \mathrm{Ar}$, que proporciona relaciones temporales con alta resolución, representa una herramienta esencial tanto para relacionar los depósitos con sus posibles fuentes igneas, como para establecer el grado de sincronicidad entre diferentes estilos de mineralización dentro de un mismo yacimiento.

\subsection{Estructura de los depósitos de SI y BS}

En México, pese a la abundancia de depósitos epitermales de SI y BS susceptibles de haber tenido sínteres asociados, se han reportado muy escasos depósitos hidrotermales de sílice de formación superficial, tanto sínteres en el sentido estructural del término como jasperoides cuyo origen se ha interpretado asociado a la formación de depósitos epitermales. Según la información disponible, se describen como sínteres algunos depósitos estratiformes de sílice de origen hidrotermal en Ixtacamaxtitlán en Puebla (Camprubí et al., 2001c; Morales-Ramírez et al., 2003), en el distrito de Santa Gertrudis en Sonora (Murray, 1997; Murray y Atkinson, 1997), y en Dos Hermanas, Sauz de Caleras y Cruzalinas en San Luis Potosí (Mason, 1995). En los distritos de Sombrerete, Colorada y Fresnillo en Zacatecas (Albinson, 1988), se hallaron evidencias de la base de posibles sínteres, en cuanto a la presencia de contenidos reveladores de $\mathrm{Hg}$, de depósitos estratiformes de jasperoides y de alteraciones hidrotermales características de las rocas encajonantes, entre otras. También se ha reportado la presencia de sínteres en El Malacate en Sonora, Lobos en Sinaloa, Ludavina en Baja California, Los Crestones en Durango, y El Salitre (estado desconocido) en reportes mineros recientes disponibles via internet (www.miningrecord.com, www.imdex.com y www.minefinders.com).

En la gran mayoría de los depósitos epitermales de SI y BS en México, los cuerpos mineralizados están dispuestos en vetas y/o cuerpos brechificados de hasta varios quilómetros de extensión lateral, aunque en vertical los horizontes mineralizados con metales preciosos raramente superan los $700 \mathrm{~m}$ (e. g. Geyne et al., 1963; Albinson et al., 2001). En un gran número de casos, las menas se encuentran distribuidas en los cuerpos mineralizados según la clásica mineralización en "bonanzas" asociadas a ebullición (Figs. 5 y 7; Buchanan, 1981). La localización de dichas bonanzas no se encuentra en un rango de profundidades especialmente restringido, a no ser que se haya producido ebullición relativamente cerca de la superficie, sino que suelen hallarse en rango de profundidad de hasta más de $500 \mathrm{~m}$ en cada depósito (Figura 7; Albinson et al., 2001). Sin embargo, la disposición de las menas puede variar significativamente según la historia de la deposición mineral y la naturaleza de los mecanismos de deposición. Por ejemplo, en el caso de Sombrerete en Zacatecas, en que no se han hallado evidencias de ebullición como mecanismo de precipitación, la mineralización se produjo a mayor profundidad de la común, a más de $1000 \mathrm{~m}$ bajo la paleosuperficie, a lo largo de un rango de profundidad de más de 800 m (Albinson, 1988; Albinson et al., 2001). Los depósitos se componen de numerosas vetas, cada una de las cuales suele tener rangos verticales productivos preferenciales que son propios de cada una de ellas (Geyne et al., 1963), que pueden variar sustancialmente dentro de cada veta según la posición relativa de las fuentes de alimentación principal del flujo de fluidos mineralizantes 
(Camprubí et al., 2001b). La disposición de bonanzas de metales preciosos generalmente se encuentra en la parte central de la zona mineralizada, como en Tayoltita (Clarke y Titley, 1988), Topia (Loucks y Petersen, 1988; Loucks et al., 1988), Bacís (Albinson et al., 2001), Pachuca - Real del Monte (Geyne et al., 1963), y Fresnillo (Gemmell et al., 1988; Simmons, 1991), y en profundidad se registra comúnmente un incremento en metales básicos. En la mayoría de casos, las vetas coalescen en profundidad para formar localmente vetas de mayor potencia. En dichas zonas de coalescencia suelen encontrarse las bonanzas más ricas o con mayor volumen.

La mayoría de depósitos epitermales de SI y BS en México son de carácter polifásico y multiepisódico (e.g. Gemmell et al., 1988; Albinson y Rubio, 2001; Albinson et al., 2001; Camprubí et al., 2001a). Esto es, se componen de varias fases de mineralización reconocibles, frecuentemente con distribución y características estructurales, mineralógicas y geoquímicas distintivas. Dichas fases de mineralización, a su vez, suelen estar compuestas por episodios diferentes, que posiblemente corresponden a pulsos discretos de los fluidos mineralizantes, lo que le confiere a este tipo de depósitos su característica estructura interna bandeada. En muchos casos, la aparente complejidad del bandeamiento de minerales de ganga y mena refleja un proceso episódico de cierre y apertura de las vetas, más que la existencia de pulsos discretos de fluidos mineralizantes de origen diverso como se describirá en la siguiente sección.

\subsection{Petrografía de sílice}

El mineral de ganga más importante en yacimientos hidrotermales es el cuarzo y la petrografía del sílice o, en otras palabras, la diferente gama de fases en que se encuentra este mineral de ganga en los yacimientos minerales es cualitativamente diagnóstico de temperaturas de formación, nivel geológico del depósito, así como de diversos procesos hidrotermales. Por fortuna, la identificación de las diferentes fases en que se encuentra la sílice en yacimientos epitermales se facilita por el hecho que la petrografía de cada fase es fácilmente identificable bajo luz transmitida polarizada. El cuarzo en mosaico, ya sea de grano fino o grueso, se observa como un rompecabezas. La calcedonia exhibe una extinción fibrosa perpendicular a la banda de crecimiento. El cuarzo plumoso presenta una extinción, efectivamente, en forma de plumas, y el cuarzo cristalino es típicamente idiomórfico, prismático de base hexagonal. Para obtener una familiarización con los diferentes términos y descripciones detalladas de texturas y tipos de sílice, particularmente enfocado a depósitos epitermales, se refiere al lector a algunas publicaciones específicas. En el artículo más general en este respecto se realizó una revisión de texturas y tipos de cuarzo en yacimientos epitermales de Australia (Dong et al., 1995).
El ejemplo de Sleeper en Nevada, fue importante en la descripción e interpretación de texturas de sílice amorfa recristalizada en depósitos epitermales de BS (Saunders, 1996). La petrografía detallada de una muestra de mano de la Veta Grande de Zacatecas clarificó que la aparente complejidad de vetas con multiples bandas de diferentes tipos de sílice puede explicarse mediante un mecanismo relativamente sencillo de sellamiento y reapertura durante la formación de vetas (Albinson, 1995). De forma colateral, ese trabajo también demuestra que aún queda espacio parqa estudios petrográficos detallados, previos a la realización de estudios geoquímicos convencionales o no convencionales, como guía necesaria para los mismos. La relación geométrica que guardan algunas fases de sílice entre sí dentro del perfil vertical del sistema geotérmico de Broadlands, Nueva Zelanda, ha sido descrito por Simmons y Browne (2000), y para yacimientos epitermales en México por Albinson et al. (2001).

Los términos más comunes de fases de sílice y su interpretación se describen a continuación. El cuarzo "de mosaico" o "jigsaw" representa originalmente sílice amorfa, típicamente coloforme, que recristalizó a una textura parecida a un rompecabezas, ya que la recristalización produce cristales anedrales interpenetrativos. Es también común que el cuarzo amorfo exhiba texturas dendríticas que reflejan la supersaturación de un fluido y la precipitación acelerada a partir de un fluido en ebullición. Este tipo de cuarzo predomina en el ambiente más cercano a la superficie ( $<500 \mathrm{~m}$ de la paleosuperficie) y es el más abundante en depósitos de BS. El cuarzo cristalino también se encuentra en este ambiente geológico, pero es típicamente de baja temperatura y contiene asociaciones de inclusiones fluidas texturalmente "inmaduras", poco o nada recristalizadas. Del otro extremo, los depósitos hidrotermales cordilleranos más profundos (pórfidos de cobre típicamente a más de $2 \mathrm{~km}$ de profundidad, y partes profundas de depósitos epitermales de SI, a $\sim 1 \mathrm{~km}$ de profundidad) contienen predominantemente fases cristalinas de cuarzo de grano grueso con abundantes inclusiones fluidas "maduras", atrapadas a temperaturas elevadas y que reflejan una cinética más acelerada del proceso de recristalización, con o sin estrangulamiento (Bodnar et al., 1985). El ambiente epitermal de profundidad intermedia (500-1000 m bajo la paleosuperficie) se caracteriza por contener un conjunto mixto de estilos petrográficos de sílice, incluyendo cuarzos de mosaico, calcedonia, cuarzo plumoso, y cuarzos cristalinos. La repetición múltiple de secuencias ordenadas de estos tipos de sílice refleja procesos de sellamiento y reapertura de las estructuras que controlan la formación de las vetas (Albinson, 1995). Durante etapas de sellamiento y circulación lenta de fluidos se depositan fases de cuarzo cristalino, mientras que la reapertura de las estructuras, presumiblemente por eventos sísmicos, propicia la separación de fases o ebullición repentina en los fluidos ascendentes, la supersaturación de la sílice de los fluidos, y la estabilización de sílice amorfa (Simmons y 
Browne, 2000). Durante las etapas iniciales de sellamiento se depositan calcedonia y cuarzo plumoso como fases intermedias entre la sílice amorfa inicial, tras una apertura repentina, y cuarzo cristalino prismático durante la etapa final de circulación restringida del fluido. Por consiguiente, cuando el proceso de reapertura y sellamiento de estructuras registra la secuencia completa descrita arriba, las fases de sílice se registran como sigue: (1) sílice amorfa (típicamente dendrítica), (2) calcedonia, (3) cuarzo plumoso, y (4) cuarzo cristalino grueso, con terminaciones euedrales en las cavidades remanentes que, subsecuentemente, se rellenan de sílice amorfa perteneciente al siguiente ciclo. La identificación de cuarzo con textura de mosaico en zonas profundas de algunos depósitos epitermales indica pudo haberse producido la precipitación de sílice amorfa, aunque en cantidades subordinadas, a profundidades significativas $(\sim 1000 \mathrm{~m})$ en la corteza terrestre.

En conclusión, el conjunto de estilos petrográficos de sílice presentes en un depósito epitermal proporciona un diagnóstico petrográfico que, por sí mismo, es indicativo de la posición relativa de un depósitos en nivel geológico concreto. La presencia predominante de cuarzo cristalino grueso, con inclusiones fluidas petrográficamente "maduras" (atrapadas a temperaturas relativamente altas, $>250^{\circ} \mathrm{C}$ ), y la presencia de cantidades muy subordinadas de cuarzo criptocristalino a sílice amorfa, son características típicas de las raices de depósitos epitermales. En contraste, la presencia predominante de cuarzo criptocristalino a sílice amorfa, con cantidades subordinadas de cuarzo cristalino grueso con inclusiones fluidas petrográficamente "inmaduras" (atrapadas a temperaturas relativamente bajas, $<200^{\circ} \mathrm{C}$ ), son características típicas de las partes altas y más superficiales de depósitos epitermales (Albinson et al., 2001). En consecuencia, la validez de todo estudio en inclusiones fluidas (estudios de microtermometría, isótopos estables, isótopos de He, volátiles, y solutos) se refrenda mediante la incorporación de una descripción de los estilos petrográficos de minerales del grupo de la sílice presentes en las muestras de estudio, ya que las técnicas petrográficas ayudan a reconstruir en forma complementaria el nivel geológico de los depósitos hidrotermales cordilleranos, y además contribuyen a establecer adecuadamente los límites de aplicabiolidad de numerosas técnicas de análisis geoquímico.

\subsection{Mineralogía de asociaciones de minerales metálicos}

Los depósitos epitermales de SI y BS en México que presentan una mineralogía de mena y unas asociaciones minerales más complejas son los depósitos de carácter polimetálico. En varios distritos mineros, como PachucaReal del Monte en Hidalgo (Geyne et al., 1963), Guanajuato (Petruk y Owens, 1974; Vassallo, 1988; Randall et al., 1994), Zacatecas (Ponce y Clark, 1988; Albinson, 1995), La Colorada (Chutas y Sack, 2004) y Fresnillo en Zacatecas
(Gemmell et al., 1988; Ruvalcaba-Ruiz y Thompson, 1988), Topia (Loucks et al., 1988) y Velardeña en Durango (Gilmer et al., 1988), y Temascaltepec en el Estado de México (Camprubí et al., 2001a), se ha observado una secuencia de precipitación característica en la gran mayoría de sus asociaciones de minerales metálicos: sulfuros de metales básicos (pirita, esfalerita generalmente rica en $\mathrm{FeS}$, galena, calcopirita, iniciando con pirita y/o arsenopirita; a veces con argentita-acantita), sulfosales de $\mathrm{Cu} \pm \mathrm{Ag}$ (generalmente Ag-tetraedrita-tennantita), sulfosales de Ag (proustita-pirargirita, pearceíta-polibasita, estefanita-arsenoestefanita, miargirita, billingsleyita), y sulfosales de Ag- $\mathrm{Pb}$ (diaforita, andorita, freieslebenita, ramdohrita). Estas asociaciones pueden presentarse tanto en sucesiones pasivas como en sucesiones reactivas. Es frecuente observar una íntima asociación entre electrum, oro o plata nativos con Ag-tetraedrita-tennantita o pirita. En depósitos epitermales de SI y BS de México sólo se ha reportado la presencia de enargita, mineral generalmente considerado como característico del ambiente de AS en San Felipe (Ibarra-Serrano, 1997) y en Temascaltepec (Camprubí et al., 2001a), de forma tardía tras asociaciones de sulfosales de Ag. Discutiremos las implicaciones acerca de la presencia de este mineral en depósitos de SI y BS más tarde. En caso de hallarse presentes asociaciones ricas en Se, con presencia de aguilarita o naumannita, como en Guanajuato (Petruk y Owens, 1974; Vassallo, 1988) y San Martín en Querétaro, estos minerales suelen aparecer tras asociaciones de sulfuros de metales básicos y argentita, asociados con sulfosales de Ag como pearceíta-polibasita.

Otros minerales de ganga en depósitos de SI presentan evidencia de la presencia de fluidos del tipo de AS y diferencian aún más los depósitos de SI de los de BS. El análisis de la mineralogía de arcillas en algunos depósitos de SI indica la presencia de caolinita en las partes más profundas de los mismos. Tal es el caso de la veta Zuloaga en el distrito de San Martín de Bolaños en Jalisco (Albinson y Rubio, 2001), que exhibe una zona profunda con caolinizaciones de alteración de origen hipogénico, reflejando la incursión de fluidos ascendentes de pH bajo. En forma semejante, en la veta El Herrero del distrito de Bacís en Durango, se observa una fase temprana de hidrotermalismo, de la que derivó una asociación de alteración de cuarzo-pirita-caolín. Ésta se encuentra restringida al nivel de explotación 18, que es el más profundo de la mina y se encuentra cerca de la base de la zona mineralizada con metales preciosos. Esta etapa de alteración ácida precede a la formación de las asociaciones de minerales preciosos y constituye, de nuevo, una evidencia de la presencia de fluidos tempranos relativamente ácidos en las raíces de depósitos de SI. La presencia de fluidos generadores de alteración argílica o argílica avanzada en depósitos de SI sugiere para los mismos una evolución parecida a los depósitos de AS. Estos últimos generalmente evidencian la presencia de fluidos ácidos tempranos, que forman un casquete (o lithocap) de alteración argílica avanzada (en 
cuyo caso se estabiliza no sólo la caolinita, sino también la alunita) y de un núcleo de cuarzo oqueroso o masivo, y posteriormente son mineralizados por fluidos de SI. Una evolución similar no se ha encontrado en depósitos de BS, lo que también puede distinguirlos de los de SI. Se estima que mientras más avance la aplicación semi-sistemática de análisis de arcillas en depósitos epitermales de SI, ya sea mediante Difracción de Rayos X o Espectroscopía Infrarroja de Banda Corta (o SWIR), se encontrará que la presencia de alteración argílica avanzada hipogénica en las partes profundas de esos depósitos es mucho más común de lo que se encontrado hasta el momento.

En los pocos depósitos de AS reportados hasta la fecha en México, las asociaciones de mena reportadas son bastante típicas de este tipo de depósito, con oro o electrum, pirita, enargita, tetraedrita-tennantita, esfalerita, famatinita, luzonita, bismutinita, bornita y covellita, entre otros (Sellepack, 1997; Staude, 2001; Valencia et al., 2003). En ellos, las menas están asociadas al núcleo de cuarzo oqueroso (vuggy quartz), en vetas de alta ley con pirita-enargita-oro, barita-oro-minerales de $\mathrm{Bi}$ y Te, entre otras asociaciones, en brechas, y diseminadas en frentes de alteración argílica avanzada (Gray, 2001), en que las vetas suelen representar la fase de mineralización más tardía (Charest y Castañeda, 1997; Staude, 2001).

13.7. Geotermometría de asociaciones de minerales metálicos

Las asociaciones de minerales metálicos no sólo representan muchas horas de diversión para amantes de la petrografía, sino que también pueden potencialmente proveer de importante información acerca de las condiciones fisicoquímicas de la precipitación mineral, como la temperatura. Estas determinaciones de temperatura son especialmente útiles por obtenerse en asociaciones minerales en que no es común obtener inclusiones fluidas para estudios microtermométricos a no ser que se realice mediante el uso de una fuente de infrarrojo, pues estos minerales son opacos. En depósitos mexicanos sólo se han podido analizar algunas inclusiones fluidas bajo luz polarizada en proustita-pirargirita en la veta Santo Niño de Fresnillo (Simmons, 1991), pero se ha podido obtener estimaciones de temperatura en varias asociaciones de minerales metálicos en el depósito de La Guitarra (Camprubí et al., 2001a), congruentes con datos microtermométricos de inclusiones fluidas y que luego pudieron conjuntarse con los mismos para obtener una historia térmica más completa del depósito (Camprubí et al., 2001b).

Según el diagrama de fases miargirita-smithita/trechmannita de Ghosal y Sack (1995), la relación As/(As+Sb) en miargiritas puede usarse para estimar la temperatura de formación mínima. Estas estimaciones de temperatura se obtienen proyectando el valor de $\mathrm{As} /(\mathrm{As}+\mathrm{Sb})$ más alto de cada muestra (obtenido por microanálisis de sonda elec- trónica) sobre la curva de $\alpha$-miargirita-trechmannita. Así, la variación composicional de cristales de miargirita en el depósito La Guitarra (Camprubí et al., 2001a) arrojó temperaturas de equilibración mínimas de aproximadamente $170^{\circ} \mathrm{C}$ en la fase I, $120^{\circ} \mathrm{C}$ en la fase II, y de $180^{\circ}$ a $240^{\circ} \mathrm{C}$ en la fase III.

A partir de complejas paragénesis de minerales de plata del mismo depósito, y considerando la ausencia de evidencias de desequilibrio o recristalización, se utilizaron tres geotermómetros minerales: (1) el cambio dimórfico pirargirita-pirostilpnita a $192 \pm 5^{\circ} \mathrm{C}$ (Keighin y Honea, 1969), (2) el cambio dimórfico proustita-xantoconita a $192 \pm 10^{\circ} \mathrm{C}$ (Hall, 1966 y 1967), y (3) los equilibrios entre estefanita y argentita más pirargirita, o entre estefanita y argentita más Sb-billingsleyita, ambos a $197 \pm 5^{\circ} \mathrm{C}$ (Keighin y Honea, 1969). En estudios experimentales (Keighin y Honea, 1969) se ha determinado que la estefanita se descompone cuando se calienta hasta $197 \pm 5^{\circ} \mathrm{C}$. Los productos de "alta temperatura" derivados de la descomposición de estefanita a argentita con pirargirita, o argentita con Sb-billingsleyita en presencia de exceso de azufre. Puesto que en la fase I del depósito La Guitarra (Camprubí et al., 2001a) se encuentra la asociación argentita + Sb-billingsleyita $\rightarrow$ proustita-pirargirita $\rightarrow$ xantoconita-pirostilpnita, no pueden retrotraerse restricciones acerca de la actividad de azufre en tal asociación. Sin embargo, ello muestra una tendencia de temperatura decreciente durante la precipitación mineral.

En los depósitos de La Colorada en Zacatecas (Chutas y Sack, 2004), las composiciones de las asociaciones tetraedrita-tennantita + pirargirita-proustita + esfalerita, y tetraedrita-tennantita + polibasita-pearceíta + solución sólida $(\mathrm{Ag}, \mathrm{Cu})_{2} \mathrm{~S}+$ esfalerita encapsulada en cuarzo, y esfalerita, indican una temperatura de deposición primaria a $\sim 325^{\circ} \mathrm{C}$ para las asociaciones de minerales metálicos, usando las composiciones de los minerales de la serie tetraedrita-tennantita y las isotermas calculadas por Sack (2000 y 2005) para el campo composicional $\mathrm{Zn} /(\mathrm{Zn}+\mathrm{Fe})-\mathrm{Ag} /(\mathrm{Ag}+\mathrm{Cu}) \mathrm{de}$ estos minerales, y la temperatura obtenida está de acuerdo con los datos microtermométricos de inclusiones fluidas obtenidos a mayores alturas en el depósito por Albinson (1988).

\subsection{Microtermometría de inclusiones fluidas}

\subsubsection{Temperatura y salinidad de los fluidos}

La clasificación de Albinson et al. (2001) de los depósitos epitermales de $\mathrm{BS}+\mathrm{SI}$ de México entre depósitos de $\mathrm{Zn}-\mathrm{Pb}-\mathrm{Ag}, \mathrm{Ag}-\mathrm{Zn}-\mathrm{Pb}, \mathrm{Ag}+\mathrm{Au}+\mathrm{Pb}+\mathrm{Zn}+\mathrm{Cu}, \mathrm{Ag}-\mathrm{Au}, \mathrm{y}$ $\mathrm{Au}-\mathrm{Ag}$, en función de sus contenidos y cocientes entre esos metales, se puede correlacionar grosso modo con las salinidades obtenidas en inclusiones fluidas de 50 depósitos diferentes. Efectivamente, los depósitos más ricos en metales nobles tienen inclusiones fluidas con salinidades mucho más bajas que los depósitos más ricos en metales básicos o polimetálicos, entre $0 \mathrm{y} \sim 6 \mathrm{wt} . \% \mathrm{NaCl}$ equiv., y entre $\sim 2$ 
$\mathrm{y} \sim 20$ wt.\% $\mathrm{NaCl}$ equiv., respectivamente (Albinson et al., 2001, a partir de numerosas fuentes).

El carácter pulsátil de estos depósitos se refleja, no sólo macroscópicamente por su compleja estructura interna, sino también a nivel microscópico, y hasta a nivel de asociación mineral o de cristal. Ello puede comprobarse por medio de cambios de salinidad en inclusiones fluidas albergadas por zonas de un cristal de composición diferente como, por ejemplo, en cristales de esfalerita de Temascaltepec (Camprubí et al., 2001b), cuya composición progresivamente más rica en FeS está acompañada por una disminución de salinidad en las diferentes zonas de los cristales, según pulsos discretos de salmueras de composición diversa. En general, puede observarse que las inclusiones fluidas analizadas en minerales de mena (esfalerita, pirargirita) presentan salinidades mayores que los minerales de ganga con los que éstos están asociados (Simmons, 1991; Albinson et al., 2001; Camprubí et al., 2001b). No sólo eso, sino que las inclusiones analizadas en episodios ricos en mineralizaciones de $\mathrm{Zn}-\mathrm{Pb}-\mathrm{Cu}-(\mathrm{Ag})$ presentan salinidades mayores que las inclusiones analizadas en episodios ricos en mineralizaciones de $\mathrm{Au}-\mathrm{Ag}$ o en episodios estériles de un mismo depósito. Esto suele suceder, en algunos casos, incluso de manera independiente del mineral en que se analizaron inclusiones fluidas (Simmons et al., 1988; Simmons, 1991; Camprubí et al., 2001b). Por lo tanto, la correlación positiva entre salinidad y contenido relativo en metales básicos, con mayor o menor cantidad de plata, se produce tanto entre depósitos diferentes como dentro de un mismo depósito.

En ocasiones, es posible caracterizar salmueras con salinidades anómalamente altas en este tipo de depósitos, en comparación con datos provenientes de otras muestras del mismo depósito (e. g. Camprubí et al., 2001b), independientemente de si las mineralizaciones que contienen inclusiones fluidas de alta salinidad se caracteriza como ricas en metales básicos, oro o plata. La explicación más plausible para la presencia de tales salmueras suele ser que éstas corresponden a líquidos residuales a partir de ebullición, como se ha comprobado tanto en depósitos epitermales (e. g. Sherlock et al., 1995; Scott y Watanabe, 1998) como en sus análogos geotérmicos actuales (Simmons y Browne, 1997). Sin embargo, como se pone en evidencia a partir del estudio sistemático de la mineralogía y las inclusiones fluidas de todas las fases de mineralización de un depósito epitermal, no es posible caracterizar el origen de salmueras problema sin tener elementos de referencia. Estos elementos pueden ser el "comportamiento" de los datos de una misma fase, o entre fases diferentes, o la presencia y distribución de evidencias mineralógicas de ebullición (ver Gemmell et al., 1988; Simmons et al., 1988; Simmons, 1991; Camprubí et al., 2001a y 2001b). La identificación del origen de estas salmueras es especialmente importante en depósitos con una compleja evolución como son típicamente los depósitos epitermales de México, cuya formación involucra numerosas fases y sub-fases de mineralización, con y sin minerales metálicos, con fluidos mineralizantes de orígenes y características químicas distintas, con diferentes procesos de mineralización, etc.

\subsubsection{Estimaciones de la profundidad de formación}

Otro tipo de información valiosa que puede obtenerse mediante el estudio sistemático de inclusiones fluidas en un depósito epitermal de SI o BS es la estimación de la profundidad de formación de las diversas fases de mineralización o asociaciones minerales, en función de la variación en profundidad del punto de ebullición de un líquido con una salinidad determinada (Figura 14; Haas, 1971). Dichas estimaciones son más precisas y válidas cuando se presenta la condición (no siempre fácil de encontrar) de asociaciones de inclusiones fluidas con coexistencia de inclusiones ricas en líquido e inclusiones ricas en vapor. Dicha condición representa en sí evidencia, desde el punto de vista de la petrografía de inclusiones fluidas, de la existencia de separación de fases o ebullición en pulsaciones específicas del paleosistema hidrotermal. Estimaciones de este tipo se han realizado en Real de Catorce en San Luis Potosí (Albinson, 1985), Fresnillo en Zacatecas (Simmons et al., 1988), Sombrerete en Zacatecas (Albinson, 1988), San Martín de Bolaños (Albinson y Rubio, 2001) y El Barqueño en Jalisco (Camprubí et al., 2006), San Martín en Querétaro (Albinson et al., 2001), y Temascaltepec en el Estado de México (Camprubí et al., 2001b). Estas estimaciones pueden corroborarse con la presencia de estructuras reconocibles de formación en superficie o cercana a ella, como sínteres, zonas de alteración derivadas de lixiviación ácida por medio de aguas calentadas por vapor, etc. Aunque este tipo de rasgos superficiales estén ausentes, pueden utilizarse rasgos característicos de la presencia de ebullición (como la presencia de calcita hojosa o sus pseudomorfos, la presencia de adularia pseudoromboédrica o de hábito pseudoacicular, o el atrapamiento heterogéneo de inclusiones fluidas ricas en vapor y ricas en líquido; ver secciones anteriores), para "fijar" la asociación mineral analizada mediante microtermometría de inclusiones fluidas sobre la curva de ebullición correspondiente a la salinidad obtenida (e. g. Camprubí et al., 2001b). Con ello puede estimarse la posición, si no de la paleosuperficie, sí al menos del nivel freático durante la formación de las diversas asociaciones de un depósito epitermal lo que, en su debido caso, puede constituir una herramienta útil para la exploración de asociaciones minerales económicas ocultas.

\subsection{Composición isotópica y origen del S}

En los depósitos de SI y BS de México es muy común que las rocas encajonantes sean de origenes diversos, incluso a escala de distrito, bien magmáticas (volcánicas, subvolcánicas o plutónicas), bien sedimentarias o metasedimentarias. Por ello, la composición isotópica de los sulfuros registra en parte la composición isotópica de 
rocas magmáticas, y en parte la composición isotópica de las rocas sedimentarias o metasedimentarias circundantes. Las $\delta^{34} \mathrm{~S}$ son muy parecidas en depósitos como Guanajuato (Gross, 1975), Fresnillo en Zacatecas (Ruvalcaba-Ruiz y Thompson, 1988), Sultepec y Miahuatlán en el Estado de México (González-Partida, 1981), Temascaltepec en el Estado de México (González-Partida, 1981; Camprubí et al., 2001b) y Real de Ángeles en Aguascalientes (Pearson et al., 1988), entre 0 y -10 por mil. En cambio, en ausencia de rocas sedimentarias o metasedimentarias, como en Velardeña en Durango (Gilmer et al., 1988), la $\delta^{34} \mathrm{~S}$ refleja valores netamente magmáticos, alrededor de 0 por mil. En depósitos de AS, se obtuvieron valores de $\delta^{34}$ S entre -7 a 9 por mil en El Sauzal (Sellepack, 1997), y de -3 a 4 por mil en sulfuros y hasta 18 por mil en sulfatos en La Caridad Antigua (V. Valencia, com. pers., 2004). Datos isotópicos y contextos análogos se han correlacionado de la misma forma en numerosos depósitos del mismo tipo en todo el mundo (Rye y Sawkins, 1974; Hayba et al., 1985; Ahmad et al., 1987; Camus, 1990; McInnes et al., 1990; Sherlock et al., 1995; So et al., 1995; So y Yun, 1996; Willan y Spiro, 1996; Mulshaw et al., 1997; Thiersch et al., 1997). En los casos de Guanajuato y Temascaltepec, se registraron también composiciones isotópicas muy o extremadamente negativas, invocándose en ambos casos la presencia de azufre derivado de sulfatorreducción bacteriana. Sin embargo, aunque en los depósitos epitermales pueda haber fuentes de azufre un tanto diversas, generalmente se ha concluido que el aporte magmático es esencial. Ello puede producirse bien directamente a través de fluidos magmáticos liberados a la corteza frágil por un magma en proceso de cristalización, bien por lixiviación de rocas magmáticas preexistentes. Así, la contribución fundamental de azufre para el transporte de metales durante la formación de depósitos epitermales de SI y BS es análoga a la de los depósitos epitermales de AS, en cuya formación la aportación magmática es indiscutible.

\subsection{Origen de los fluidos}

Según los estudios microtermométricos, de isótopos estables y de He, y de geoquímica de gases en inclusiones fluidas (Simmons et al., 1988; Benton, 1991; Norman et al., 1991 1997b; Simmons, 1991, 1995; Albinson et al., 2001; Camprubí et al., 2001b, 2003c; Camprubí, 2003), los fluidos mineralizantes analizados en depósitos epitermales de SI y BS de México estuvieron constituidos a partir de fluidos de origen diverso (según la clasificación de Norman y Musgrave, 1994; Norman et al., 1997a): (1) meteórico superficial, (2) cortical, o meteórico evolucionado, de circulación profunda, (3) cortical orgánico, (4) magmático, y (5) magmático evolucionado, en mayor o menor proporción de uno u otros. Estos diversos orígenes pueden ser identificados tanto en las asociaciones metálicas como las secciones estériles de los depósitos. Sin embargo, cabe destacar que los fluidos de origen atri- buiblemente magmático presentan una contribución más prominente en asociaciones metálicas, tanto de metales nobles como básicos (Albinson et al., 2001; Camprubí et al., 2003c).

Del mismo modo, mediante el análisis de volátiles en inclusiones fluidas, se han correlacionado mayores contenidos relativos en $\mathrm{H}_{2} \mathrm{~S}$ con una mayor aportación relativa de fluidos de origen magmático o, dicho de otra forma, con un aumento en el carácter magmático de los fluidos mineralizantes (Albinson et al., 2001; Camprubí et al., 2003c). Teniendo en cuenta que la forma más probable de transporte de oro en el ambiente epitermal es mediante complejos tiosulfurados (ver apartados anteriores; Shenberger y Barnes, 1989; Hayashi y Ohmoto, 1991; Gammons y Williams-Jones, 1997), resulta probable o, cuanto menos, no descartable que los metales provengan de los magmas, aunque es igualmente posible que hayan sido lixiviados en profundidad.

Por otro lado, la evidencia aportada por las composiciones isotópicas en oxígeno e hidrógeno en depósitos epitermales de México indica la presencia de fluidos de composición isotópica consistentemente pesada en oxígeno (Albinson et al., 2001; Camprubí et al., 2001b), que no puede ser explicada únicamente invocando la existencia de procesos de ebullición o de intercambio agua-roca, sino que requieren contribuciones significativas de fluidos de origen magmático. Además, también se aprecian composiciones isotópicas de fluidos mineralizantes que son consistentes con mezclas entre fluidos magmáticos y meteóricos superficiales, incluso en fases diferentes del mismo depósito. Sin embargo, son necesarios más trabajos en este sentido en epitermales mexicanos, pues el único depósito en que se han llevado a cabo estudios isotópicos de $\mathrm{O}$ y $\mathrm{H}$ relativos a fluidos mineralizantes de forma sistemática, en base a una detallada caracterización en fases y sub-fases, ha sido en La Guitarra del distrito Temascaltepec, estado de México (Camprubí et al., 2001b).

\subsection{Mecanismos de precipitación}

Aunque no se puede descartar la mezcla de fluidos en la mayoría de casos, se reconoce habitualmente que la ebullición es el principal mecanismo de precipitación mineral en casi todos los depósitos epitermales de SI y BS de México (Simmons et al., 1988; Simmons, 1991; Albinson y Rubio, 2001; Albinson et al., 2001; Camprubí et al., 2001a, 2006), salvo en casos como el de Sombrerete (Albinson, 1988; Albinson et al., 2001), si bien no siempre la presencia de ebullición garantiza la presencia de mineralización metálica (Camprubí et al., 2001a). La razón para ello puede ser que, simplemente, si los fluidos mineralizantes no contienen metales disueltos, realmente no hay nada que precipitar, ni que sea mediante un mecanismo de precipitación tan efectivo como es la ebullición. Así, nuevamente, saber 
qué fluidos transportaron metales al ambiente epitermal y cuáles no es una cuestión clave. Si en futuros estudios se sigue concluyendo sistemáticamente que el influjo episódico de fluidos magmáticos ascendentes es el principal mecanismo responsable de la inyección de metales al ambiente epitermal, como ya sugirieron Simmons et al. (1988), Albinson et al. (2001), and Camprubí et al. (2003c), entonces podremos... cambiar de tema y tratar de resolver otros problemas pendientes.

Los principales criterios mineralógicos y petrográficos diagnósticos de ebullición empleados en el estudio de depósitos epitermales en México han sido (1) la presencia de adularia pseudoromboédrica, (2) la presencia de calcita hojosa o sus pseudomorfos, y (3) la presencia de bandas coloformes de calcedonia y sílice amorfa recristalizada asociadas a otras evidencias de ebullición en la misma asociación mineral. Excepcionalmente, como en el caso de Fresnillo (Simmons et al., 1988) se han encontrado paragénesis de inclusiones fluidas que indican la existencia de un atrapamiento heterogéneo de las dos fases principales resultantes de ebullición, en inclusiones fluidas ricas en vapor y ricas en líquido, lo cual también constituye una evidencia definitiva de la existencia de ebullición. Esto es, por supuesto, si se puede excluir la presencia de recristalizaciones en la inclusiones fluidas que hayan llevadoa a su estrangulamiento, $\mathrm{u}$ otros cambios post-atrapamiento que hayan formado una asociación de inclusiones fluidas (o FIA por sus siglas en inglés) que pueda ser equivocadamente atribuida a atrapamiento heterogéneo. El uso de otros criterios indirectos, como la presencia de brechificaciones hidrotermales se ha usado, generalmente, con cautela, puesto que pueden también originarse brechificaciones similares por acción de fallas activas. Debido al régimen pulsátil que tuvieron los fluidos mineralizantes durante la formación de depósitos epitermales (especialmente los de SI y BS), y a la actividad igualmente episódica de las fallas que controlan su emplazamiento (lo que se traduce en una estructura interna polifásica y multiepisódica), es común que se hayan producido numerosos episodios de ebullición en el mismo depósito, con deposición mineral asociada cada uno de ellos.

Las únicas evidencias mineralógicas y estructurales claras de mezcla de fluidos como mecanismo de precipitación mineral en depósitos epitermales de México las constituyen la presencia de horizontes de alteración argílica avanzada de origen epigenético (e.g. Morales-Ramírez et al., 2003). Sin embargo, en muchos casos se invoca la existencia de mezcla de fluidos en base a tendencias de dilución progresiva en el tiempo o el espacio registradas mediante el estudio de inclusiones fluidas (e.g. Camprubí et al., 2001b). Según la composición de volátiles contenidos en inclusiones fluidas, se puede argüir la presencia de aguas meteóricas superficiales incluso a profundidades de hasta varios cientos de metros bajo la paleosuperficie (Albinson et al., 2001; Camprubí et al., 2003b). Sin embargo, ello no implica necesariamente que dichas aguas hayan intervenido en la precipitación mineral, sino que pueden simplemente haberse incorporado a los fluidos ascendentes mediante celdas de convección. En otros casos, con la presencia de mineralizaciones relativamente confinadas en profundidad (esto es, sin aparente comunicación con la superficie durante su formación, e. g. fase III en Temascaltepec; Camprubí et al., 2001a,b), en ausencia de evidencias de ebullición, cabe explicar la precipitación mineral en base a mecanismos como enfriamiento conductivo, o bien como producto de la reducción de los fluidos mineralizantes por reacción con las rocas encajonantes.

13.12. Clasificación de los depósitos epitermales en México según el estado de sulfuración

\subsubsection{Conocimiento previo}

En esta sección se aborda la problemática y confusión existente sobre el tema de la exclusividad o no exclusividad entre los depósitos de SI y de BS. En la provincia metalogenética del Great Basin en Nevada se aprecia que los dos tipos de depósitos son mutuamente exclusivos. En esa provincia metalogenética los depósitos de SI están localizados primordialmente en el arco andesítico calcialcalino en el sector poniente de la misma y se formaron después de los $38 \mathrm{Ma}$. En contraste, los depósitos de BS están restrigindos espacialmente al sector oriental de la provincia, y están relacionados a magmatismo bimodal de carácter reducido (riolítico/basáltico) en el ambiente tectónico extensional, de rift, del Northern Nevada Rift que generó los depósitos entre 16 y $14 \mathrm{Ma}$ (Sillitoe y Hedenquist, 2003). En las principales provincias metalogenéticas de México (Sierra Madre Occidental y Atiplano Mexicano) no se encuentra una división en espacio y tiempo análoga, sino que ambos tipos de depósitos parecen coexistir, relacionados a magmatismo calcialcalino. Ello no sólo sucede a nivel de provincia metalogenética (Albinson et al., 2001), sino también a nivel de distrito, como se discutirá más adelante.

La aplicación de los conceptos de "estado de sulfuración" en conjunto con el estado de oxidación y la temperatura de fluidos magmáticos-hidrotermales muestra que existe una relación entre estos parámetros y la estabilidad de las especies de sulfuros asociados (Einaudi et al., 2003). Así pues, el estado de sulfuración tipo SI se caracteriza por (1) mineralizaciones con cantidades abundantes de sulfuros (tipo "heavy sulfide"; con contenidos en sulfuros $>10 \%$ ), (2) la presencia predominante de esfalerita baja en FeS, (3) cantidades variables de galena, pirita, calcopirita, tetraedrita, y sulfosales de plata, (4) acompañadas principalmente de variedades cristalinas de cuarzo, carbonatos y silicatos de $\mathrm{Mn}$, fluorita, y relativamente escasa adularia como minerales de ganga, (5) mientras que el estilo de alteración predominante consiste de illita cambiando a sericita en profundidad y a propilitización lateralmente (Einaudi et al., 2003; Sillitoe y Hedenquist, 2003).

Por otro lado, el estado de sulfuración tipo BS se 
caracteriza por (1) la escasa presencia de sulfuros en la mineralización (tipo "light sulfide"; con contenidos en sulfuros $<1 \%$ ), (2) con predominancia de pirita, arsenopirita, sulfosales de plata, acantita, naumannita y eléctrum, (3) asociados a una ganga con variedades de sílice amorfa, cuarzo criptocristalino y cristalino multibandeados, adularia, y calcita hojosa, y (4) un estilo de alteración débil, caracterizada por la presencia de illita o clorita, dependiendo de la composición de la rocas encajonantes (Sillitoe y Hedenquist, 2003).

Los fluidos responsables de la formación de mineralizaciones de SI presentan temperaturas generalmente elevadas, dentro de un rango de $230^{\circ}$ a $300^{\circ} \mathrm{C}$, con salinidades máximas que pueden variar desde $>7.5$ hasta $<23$ wt. $\% \mathrm{NaCl}$ equiv., y los depósitos se formaron a profundidades de hasta $>1 \mathrm{~km}$. En cambio, los fluidos responsables de la formación de mineralizaciones de BS se caracterizan por presentar temperaturas $<240^{\circ} \mathrm{C}$, salinidades máximas de 3.5 wt. $\%$ $\mathrm{NaCl}$ equiv., y los depósitos se formaron a profundidades generalmente $<300 \mathrm{~m}$ (Albinson et al., 2001). Ambos tipos de mineralización ocurren en muchos depósitos en México. Aunque no es un ejemplo de yacimiento grande, el mejor estudiado multidisciplinariamente es el depósito de La Guitarra en el distrito de Temascaltepec (Camprubí et al., 2001a,b, 2003b,c). Ejemplos de mineralización tipo SI en este yacimiento (Fase I) se muestran en las Figuras 18-1 y 18-4, mientras que ejemplos de la mineralización tipo BS (Fase II) se exhiben en las Figuras 18-1 a 18-10.

\subsubsection{Nueva clasificación empírica}

En varias partes del mundo, incluyendo México, se presentan depósitos de SI que exhiben una relación espacial y temporal con sistemas de pórfidos o skarns o, en su caso, con depósitos de AS, y cuyo origen se considera tan en común con los mismos que sus diferencias pueden atribuirse a una evolución y variabilidad del estado de oxidación y sulfuración de los fluidos hacia zonas distales, a partir de su fuente térmica más proximal (el pórfido o skarn) (Einaudi et al., 2003). Diagramas como los de la Figura 19a (Sillitoe y Hedenquist, 2003) muestran la posición espacial de los diferentes tipos de depósitos (pórfidos, AS, $\mathrm{SI})$ relacionados con intrusivos de nivel alto. Aunque, como ya se comentó anteriormente, sí existen depósitos de SI en México claramente identificables dentro de este esquema (Santa María de la Paz en San Luis Potosí, Batopilas en Chihuahua, o la veta Noria de Pantaleón del distrito San Martín en Zacatecas), por otro lado también ya se ha enfatizado que la mayor parte de los yacimientos de SI y BS en México están ubicados en una posición distal por encima de intrusivos profundos ( $>5 \mathrm{~km}$ ) (Albinson et al., 2001). Por consiguiente, los modelos genéticos que traten de explicar toda la gama de depósitos epitermales de AS, SI y BS, depósitos metalíferos en pórfidos y skarns en las provincias metalogenéticas de México deben tomar primero en consideración, como se muestra en la Figura 19b, que el factor determinante para la asociación genética entre los diferentes tipos de depósitos puede ser la profundidad de emplazamiento de los cuerpos magmáticos a los que todos ellos están relacionados. Si se parte de esta base y se toman en consideración la distribución de los componentes de mineralización tanto de tipo SI como de tipo BS en los depósitos epitermales en México, es posible distinguir cuatro diferentes estilos de depósitos alcalinos/neutros, descritos a continuación como tipos $\mathrm{A}, \mathrm{B}, \mathrm{y} \mathrm{C}$.

El "Tipo A" se caracteriza por exhibir solamente mineralización tipo SI ("heavy sulfide") en la distribución vertical del depósito. Ejemplos del Tipo A son yacimientos como Real de Guadalupe y la veta Cobre en el distrito de Taxco en Guerrero, Bolaños y San Martín de Bolaños en Jalisco, Zacualpan en el Estado de México, Sombrerete y Colorada en Zacatecas, y San Francisco del Oro en Chihuahua.

El "Tipo B" es el más común e importante desde el punto de vista económico en México, y exhibe mineralizaciones características de tipo BS con raíces de tipo SI de distribución vertical limitada. En algunos casos, sólo algunas vetas o cuerpos mineralizados de un distrito exhiben esta distribución vertical (como el clavo Rayas en el distrito de Guanajuato), mientras que en otros depósitos la mayor parte de las vetas y los cuerpos mineralizados exhiben raíces polimetálicas. Tal es el caso de las vetas del distrito de Pachuca - Real del Monte en Hidalgo, la veta La Guitarra del distrito de Temascaltepec y la veta San Rafael del distrito de El Oro, en el Estado de México, la veta El Herrero del distrito de Bacís y la veta Cinco Señores del distrito de Tayoltita, en Durango, y las vetas del distrito Colorada en Sonora. Dichas raíces pueden ser tanto ricas como pobres en metales preciosos. Es posible que muchas vetas de este tipo en otros distritos también resguarden mineralizaciones polimetálicas a mayor profundidad de la conocida actualmente, pero éstas no han sido identificadas por falta de exploración profunda. En los dos tipos de depósitos epitermales de SI en México (A y B) las mineralizaciones polimetálicas en profundidad se caracterizan por ser predominantemente de $\mathrm{Zn}-\mathrm{Pb}$ en vez de cúpriferas. Sin embargo, las raíces polimetálicas de algunos depósitos exhiben contenidos significativos de $\mathrm{Cu}$, aunque generalmente $<1 \%$, como es el caso de Avino en Durango, Bolaños en Jalisco, y la veta El Cobre - Babilonia en Taxco, Guerrero. En algunos casos, sin embargo, presentan contenidos en $\mathrm{Cu}$ entre $1 \%$ y $2.5 \%$, como es el caso de la veta Mala Noche en Zacatecas, y las vetas de Angangueo en Michoacán. De cualquier manera, puede aseverarse que la herencia metálica de los depósitos de SI en México tiende a ser relativamente pobre en $\mathrm{Cu}$, y que este metal se presenta en mayores contenidos en depósitos formados a temperaturas más altas y a profundidades mayores, como en los depósitos de tipo skarn.

El "Tipo C" consiste únicamente en mineralización del tipo BS y es común en México, aunque los depósitos de este tipo tienden a ser de tamaño relativamente 


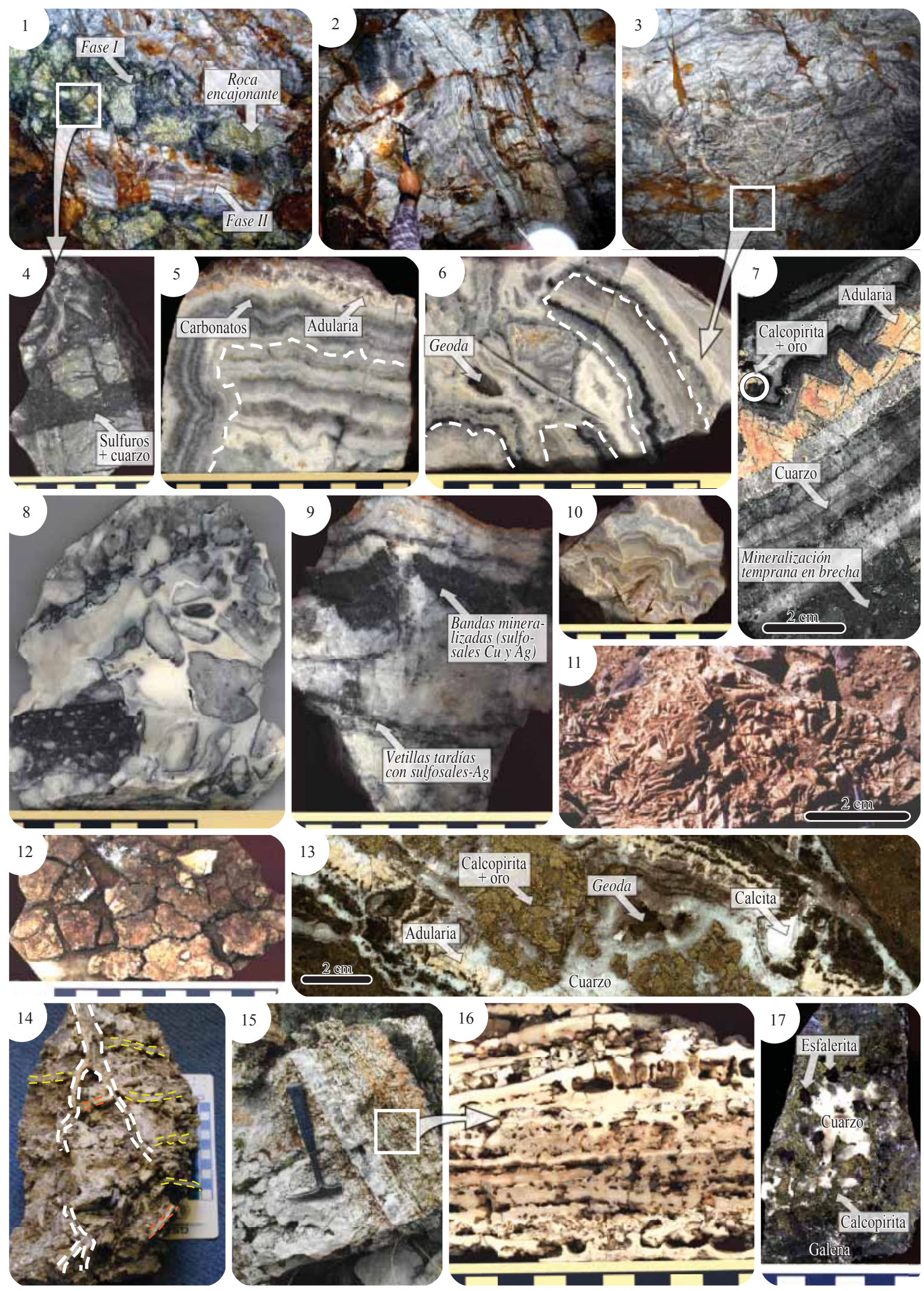


pequeño, con producciones máximas de 1.0 a $3.5 \mathrm{Mt}$, como Pozos en Guanajuato, Concheño en Chihuahua, Guadalupe de los Reyes en Sinaloa, y Pinos en Zacatecas, pero comúnmente con producciones menores a 100,000 toneladas, como Tambor en Sinaloa, El Indio en Nayarit, Lluvia de Oro en Durango, Benito Juárez y Santa Gertrudis en San Luis Potosí, e Ixtapan del Oro en el Estado de México (ver Tabla 1 en Albinson et al., 2001). En prácticamente ninguno de los depósitos del tipo " $\mathrm{C}$ " en México existen evidencias de magmatismo bimodal basáltico-riolítico, contrariamente a los depósitos de $\mathrm{BS}$ en el Northern Nevada Rift. Por consiguiente, está en duda la presencia de magmas reducidos a profundidad como explicación para la formación de los depósitos de tipo "C", como un estilo de mineralización de BS que fuera mutuamente excluyente respecto a las mineralizaciones de tipo SI. Cabe considerar que los depósitos de BS en México también estén ligados genéticamente a magmas calcialcalinos profundos con un estado de oxidación relativamente alto, pero las salmueras necesarias para transportar los metales básicos permanecieron estratificadas en profundidad sin llegar a alcanzar niveles someros de la corteza, como lo sugieren Sillitoe y Hedenquist (2003). Así, podría contemplarse que algunos de estos depósitos pueden, en efecto, contener mineralizaciones significativas de SI a mayor profundidad, pero éstas no se encuentra telescopadas sino separadas verticalmente de las mineralizaciones de BS suprayacentes. Por otro lado, también es posible que depósitos de BS mutuamente excluyentes respecto a depósitos de SI deban su origen a magmas calcialcalinos en profundidad, pero cuyos fluidos mineralizantes jamás tuvieron contenidos en sales suficientes para transportar metales básicos. La exploración de depósitos profundos de SI verticalmente separados pero "apilados" ("stacked") con respecto a depósitos someros de BS representa un reto significativo para los esfuerzos futuros de exploración para depósitos epitermales en México.

Los diferentes tipos de depósitos descritos según su estado de sulfuración se correlacionan con la clasificación

Figura 18. Selección de fotos de depósitos epitermales alcalinos/neutros de México: (1) Fase inicial de mineralización epitermal (fase I), constituida por una brecha con clastos de granitoide propilitizado y una matriz de cuarzo con sulfuros de metales básicos, cortada por una fase posterior (fase II), constituida por bandas de cuarzo y calcedonia, con estructura interna crustiforme simétrica. Interior de galería en la mina La Guitarra, distrito de Temascaltepec, Estado de México. Foto cortesía de Noel C. White. (2) Bandas de cuarzo y calcedonia, con estructura interna crustiforme. Interior de galería en la mina La Guitarra, distrito de Temascaltepec, Estado de México. Foto cortesía de Noel C. White. (3) Bandas de cuarzo y calcedonia con mineralización de Ag y Au (bandas negras), con estructura interna brechificada y crustiforme. Interior de galería en la mina La Guitarra, distrito de Temascaltepec, Estado de México. Foto cortesía de Noel C. White. (4) Mineralización en brecha de la fase I (ver foto 1), constituida por una brecha con clastos de granitoide propilitizado y una matriz de cuarzo con sulfuros de metales básicos. La escala en la parte inferior está en centímetros. Mina La Guitarra, distrito de Temascaltepec, Estado de México. (5) Fase de mineralización estéril en bandas crustiformes, brechificadas y con un segundo crecimiento de bandas sobre las bandas brechificadas. El borde del clasto se marca mediante una línea discontínua blanca. La mineralogía consiste básicamente en una alternancia de bandas de ópalo, calcedonia o cuarzo, carbonatos (siderita y ankerita), y adularia. La escala en la parte inferior está en centímetros. Fase de mineralización IIA (ver Camprubí et al., 2001a) en la mina La Guitarra, distrito de Temascaltepec, Estado de México. (6) Mineralización en bandas crustiformes, brechificadas y con un segundo crecimiento de bandas sobre las bandas brechificadas. El borde de los clastos se marca mediante líneas discontínuas blancas. La mineralogía consiste básicamente en una alternancia de bandas de ópalo, calcedonia o cuarzo, con mineralización polimetálica en las bandas negras. Nótese la presencia de bandas con menas metálicas tanto en los clastos como en las bandas formadas más tempranamente en la matriz. La escala en la parte inferior está en centímetros. Fase de mineralización IIB (ver Camprubí et al., 2001a) en la mina La Guitarra, distrito de Temascaltepec, Estado de México. (7) Mineralización en bandas crustiformes, con cuarzo, illita-smectita (sericita) y clorita, adularia y una asociación de calcopirita y oro precipitada inmediatamente encima de la adularia. La presencia de adularia constituye evidencia de ebullición de los fluidos mineralizantes, y la asociación de minerales metálicas con la misma supone que este mecanismo fue responsable de la precipitación de dichas menas. La veta tiene una estructura simétrica, aunque sólo se muestra la mitad de la misma. Veta Azteca II, distrito de El Barqueño, Jalisco. (8) Detalle de microbrechificación. Las bandas negras contienen escasa mineralización polimetálica. La escala en la parte inferior está en centímetros. Fase de mineralización IIB (ver Camprubí et al., 2001a) en la mina La Guitarra, distrito de Temascaltepec, Estado de México. (9) Mineralización polimetálica en bandas crustiformes, y en vetillas tardías. La escala en la parte inferior está en centímetros. Fases de mineralización IIB y III (ver Camprubí et al., 2001a) en la mina La Guitarra, distrito de Temascaltepec, Estado de México. (10) Mineralización sin menas metálicas en bandas crustiformes de ópalo y calcedonia, con fantasmas de calcita hojosa en la base. Éstos constituyen evidencia textural de ebullición durante la formación de las vetas epitermales. La escala en la parte inferior está en centímetros. Fase de mineralización IIA (ver Camprubí et al., 2001a) en la mina La Guitarra, distrito de Temascaltepec, Estado de México. (11) Fantasmas de calcita hojosa, que constituyen evidencia textural de ebullición durante la formación de las vetas epitermales. Veta Peña de Oro, distrito de El Barqueño, Jalisco. Foto cortesía de Eduardo González-Partida. (12) Grietas de desecación en una lámina de ópalo, parte de un depósito laminar de tipo sínter. Estas grietas de desecación en ópalo constituyen evidencia de precipitación en una paleosuperficie y en condiciones subaéreas o bajo una lamina de agua delgada e intermitente. La escala en la parte inferior está en centímetros. Cerro el Uno, distrito de Ixtacamaxtitlán, Puebla. (13) Mineralización en bandas crustiformes en una veta con estructura simétrica, con cuarzo, calcita, adularia y una asociación de calcopirita y oro. La presencia de adularia constituye evidencia de ebullición de los fluidos mineralizantes, y la asociación de minerales metálicas con la misma supone que este mecanismo fue responsable de la precipitación de dichas menas. Veta Azteca II, distrito de El Barqueño, Jalisco. Foto cortesía de Eduardo González-Partida. (14) Láminas de ópalo (líneas discontínuas en amarillo) brechificadas y recementadas (líneas discontínuas en naranja) por acción de hidrotermalismo tardío, que forma vetas (líneas discontínuas en blanco), parte de un depósito laminar de tipo sínter. La escala a la derecha está en centímetros. Cerro el Uno, distrito de Ixtacamaxtitlán, Puebla. (15) Ópalo masivo y laminado, parte de un depósito laminar de tipo sínter. Cerro el Uno, distrito de Ixtacamaxtitlán, Puebla. Foto cortesía de Jordi Tritlla. (16) Detalle de la laminación de ópalo, parte de un depósito laminar de tipo sínter. La escala en la parte inferior está en centímetros. Cerro el Uno, distrito de Ixtacamaxtitlán, Puebla. (17) Mineralización de sulfuros de metales básicos en mantos de reemplazamiento a partir de vetas epitermales. La escala en la parte inferior está en centímetros. Mina Hueyapa, distrito de Taxco, Guerrero. 
(a)
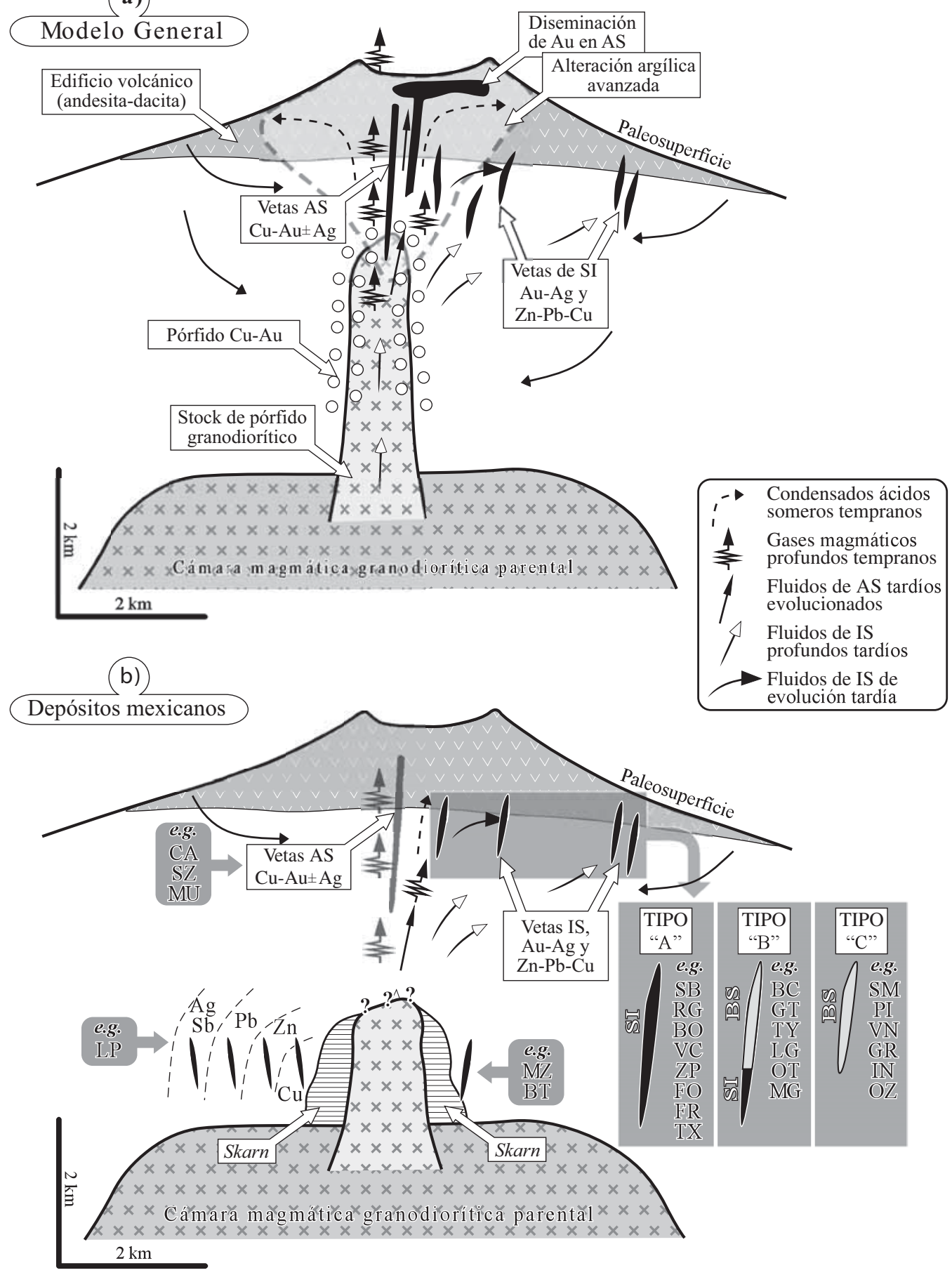

Figura 19. Secciones esquemáticas de los ambientes de formación de depósitos epitermales en arcos volcánicos calcoalcalinos, mostrando la evolución de los fluidos durante su recorrido ascendente, hasta la superficie. A: Redibujado de Sillitoe y Hedenquist (2003), se ejemplifica el contexto general de coexistencia de epitermales de AS y SI con depósitos metalíferos en pórfidos, con un cuerpo intrusivo de nivel alto, como se ha relacionado en depósitos como el conjunto Lepanto - Far Southeast - Victoria en Filipinas (Arribas et al., 1995; Hedenquist et al., 1996, 1998; Sillitoe, 1999). El edificio volcánico se muestra como un estratovolcán, pero podría también hallarse una situación similar en un complejo dómico. B: Dibujado tomando como base el esquema anterior, se ejemplifican los contextos de formación de depósitos epitermales en México, (1) en un contexto similar al interior, con la presencia de un intrusivo de nivel alto y la formación de pórfidos cupríferos y epitermales de AS, y (2) en el contexto más habitual, con la coexistencia de epitermales de SI y BS, con o sin evidencia de la presencia de skarns y la presencia de un cuerpo intrusivo de nivel bajo, según los cuatro tipos de situaciones propuestas en este trabajo: los tipos A, B, C, y D. Clave: (BC) Bacís, Durango (Smith, 1995; Albinson et al., 2001). (BO) Bolaños y San Martín de Bolaños, Jalisco (Lyons, 1988; Scheubel et al., 1988; Albinson y Rubio, 2001). (BT) Batopilas y Tahonas, Chihuahua, epitermal alcalino y pórfido cuprífero, respectivamente (Wilkerson et al., 1988). (CA) La Caridad y La Caridad Antigua, Sonora, pórfido cuprífero y epitermal de AS, respectivamente (Valencia et al., 2003; Valencia, 2005). (CZ) Veta Candelaria en el distrito de Colorada, Zacatecas (Albinson, 1985, 1988). 
de depósitos epitermales de acuerdo a su profundidad de formación (Figura 6), en el sentido que los depósitos tipo "C" de BS se corresponden con los depósitos de ebullición somera (los generalmente denominados "Hot Spring Type"), mientras que los tipo "A" de SI se corresponden con los de ambiente profundo sin evidencias de ebullición. El tipo "B", por otro lado, que exhibe estilos de mineralización característicos tanto de SI como BS y que es el más importantes e las provincias metalogenéticas de México, parece haberse formado predominantemente en el ambiente de profundidad correspondiente a las vetas profundas con ebullición.

\subsubsection{Evolución de los fluidos mineralizantes y relación con los estilos de depósito epitermal}

La coexistencia en múltiples depósitos epitermales en México de mineralizaciones tanto de SI como de BS podría explicarse en base a la existencia de salmueras doblemente estratificadas, en que la salmuera más salina y profunda se introduce a niveles corticales someros durante períodos de fallamiento o de intrusión de diques (Sillitoe y Hedenquist, 2003). A menos que el emplazamiento de múltiples diques se produjera a profundidades no observadas, el funcionamiento efectivo de un mecanismo como este es dudoso ya que en los depósitos epitermales en México es común encontrar una generación de diques de pórfidos, aunque siempre de edad pre-mineralización (e.g. Bacís y La Ciénega en Durango, Zacatecas en Zacatecas, Guadalupe de los Reyes en Sinaloa, y La Guitarra en el Estado de México). Así, el hecho común que numerosas vetas epitermales estén asociadas a diques puede deberse más razonablemente a que el contacto entre los diques y las rocas circundantes constituyen discontinuidades fácilmente aprovechables para la generación de fallas y fracturas y, por ende, para la introducción de fluidos hidrotermales y la formación de vetas. Es más factible, en cambio, la existencia de un mecanismo de orden tectónico para la introducción de salmueras magmáticas a niveles corticales someros, como resultado de un efecto de bombeo sísmico ("seismic pumping”, término acuñado por Sibson et al., 1975) durante períodos de reactivación estructural (Sibson, 1998, 2001; Sibson y Scott, 1998). La introducción de salmueras por encima del límite frágil - dúctil podría llevarse a cabo por el mecanismo "de falla - válvula", y la movilización de las mismas dentro del ambiente epitermal se podría llevar a cabo por medio de un mecanismo de "bomba de succión", como los descritos por Sibson (2001).

La común coexistencia de mineralizaciones de SI y BS, sin embargo, no puede explicarse mediante tal mecanismo como una simple coincidencia sólo en base a la existencia de reservorios estratificados de salmueras, sobre todo tomando en consideración que el estudio detallado de varios depósitos indica que la transición de mineralizaciones de SI a BS representa una evolución en el tiempo y el espacio. El estudio detallado del depósito La Guitarra en el distrito de Temascaltepec muestra claramente ese tipo de evolución (Camprubí et al., 2001a): (1) inicia con la fase I, una mineralización profunda de metales básicos (Figuras 18-1 y 18-4) y esfalerita con contenidos de FeS de hasta 0.25 molar (menor en presencia de una escasa asociación con minerales de plata), con bajos valores de $\mathrm{Ag}$ y virtualmente $\sin \mathrm{Au}$, y con salinidades de los fluidos mineralizantes de hasta 14.4 wt.\% $\mathrm{NaCl}$ equiv.; y (2) las fases II y III subsecuentes consisten en sílice multibandeada (fase II) con valores progresivamente más altos de metales preciosos y esfaleritas con contenidos de FeS de hasta 0.16 (fase II) y 0.12 molar (fase III), y con salinidades de los fluidos mineralizantes generalmente entre 4 y $5 \mathrm{wt} . \% \mathrm{NaCl}$ equiv. Adicionalmente, dentro de cada fase de formación se aprecia una tendencia evolutiva semejante, puesto que todas ellas inician con minerales de metales básicos y terminan con precipitación de minerales de metales preciosos. Cabe aquí hacer un inciso acerca de la presencia de enargita en La Guitarra pues, contrariamente a lo que se esperaría según la tendencia anteriormente expuesta de una disminución en la sulfuración con el tiempo, la enargita se encuentra en último término de una asociación que inició con sulfuros de metales básicos y siguió con oro y sulfosales de $\mathrm{Ag}$ (Camprubí et al., 2001a). Ello implicaría un súbito aumento en la sulfuración (Figura 20), si bien se trata de una evidencia muy local y puede responder a la presencia de un evento hidrotermal extemporáneo respecto a la tendencia general, que no desvirtúa en absoluto a la misma. El estudio detallado de la veta Santo Niño en el distrito de Fresnillo también exhibe tendencias similares a éstas (Gemmell et al., 1988; Simmons, 1991). Asimismo, la veta El Herrero del

Figura 19 (continuación). (FO) San Francisco del Oro, Chihuahua (Grant y Ruiz, 1988). (FR) Fresnillo, Zacatecas (Gemmell et al., 1988; Simmons et al., 1988; Simmons, 1991). (GR) Guadalupe de los Reyes, Sinaloa (Allen et al., 2001). (GT) Clavo Rayas en el distrito de Guanajuato, Guanajuato (Mango et al., 1991). (LG) La Guitarra, distrito de Temascaltepec, estado de México (Camprubí et al., 2001a,b, 2003c) (LP) La Paz, San Luis Potosí (McGibbon, 1979; Gunnesch et al., 1994). (MG) Maguaríchic, Chihuahua (Albinson et al., 2001). (MU) Mulatos, Sonora (Staude, 2001). (MZ) San Martín, Zacatecas, que comprende depósitos de skarn y vets epitermales (Rubin y Kyle, 1988), como la veta Noria de Pantaleón. (OT) El Oro - Tlalpujahua, estado de México/Michoacán (Flores, 1920; Gómez-Caballero et al., 1977). (PA) Pachuca-Real del Monte, Hidalgo (Geyne et al., 1963). (PI) Pinos, Zacatecas. (RG) Real de Guadalupe, Guerrero (Albinson y Parrilla, 1988). (SB) Sombrerete, Zacatecas (Albinson, 1988; Albinson et al., 2001). (SM) San Martín, Querétaro (Muñoz, 1993). (SZ) El Sauzal, Chihuahua (Charest y Castañeda, 1997; Sellepack, 1997; Gray, 2001). (TM) Parte SE del distrito de Temascaltepec, estado de México (Camprubí, 2003). (TX) Taxco, Guerrero (Clark, 1990). (TY) Veta Cinco Señores en el distrito de Tayoltita, Durango (Clarke y Titley, 1988). (VN) Veta San Nicolás, en el distrito de Guanajuato, Guanajuato (Abeyta, 2003). (VC) Veta El Cobre, en el distrito de Taxco, Guerrero (Clark, 1990). (ZP) Zacualpan, Estado de México (Noguez et al., 1988). Ver referencias adicionales en Camprubí (1999), Camprubí et al. (1999, 2003b), Albinson et al. (2001) y en secciones anteriores de este trabajo. 


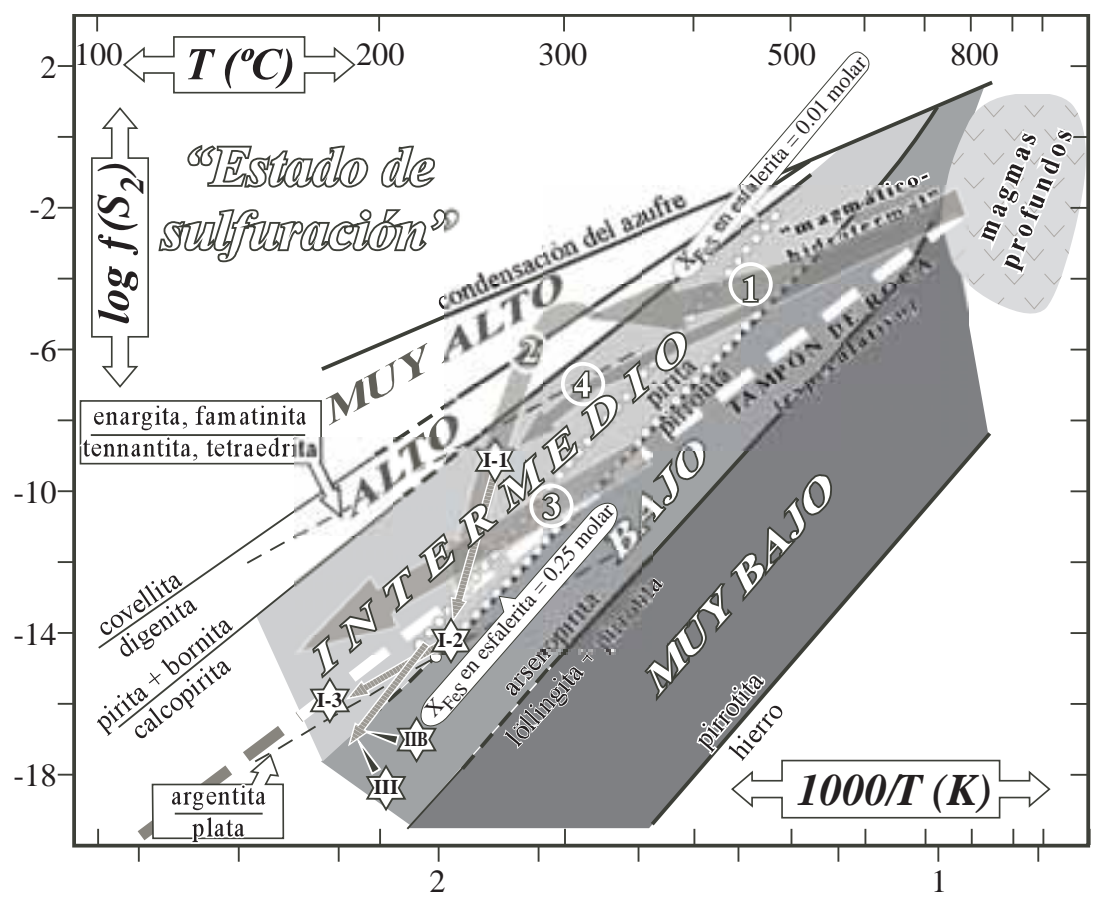

Figura 20. Diagrama de correlación entre temperatura y fugacidad de azufre para los estados de sulfuración relativos de los fluidos hidrotermales en el ámbito de depósitos metalíferos en pórfidos y epitermales, como en la Figura 3, con las trayectorias de sulfuración generales determinadas en las diversas asociaciones de minerales metálicos en el depósito epitermal de La Guitarra, distrito de Temascaltepec en el Estado de México (adaptado de Camprubí et al., 2001a,b). En números romanos, las tres fases de formación de dicho depósito. El asterisco $(*)$ indica la posible trayectoria de sulfuración determinada por la presencia de enargita en la parte final de la asociación metálica de la fase IIB en La Guitarra. Las trayectorias 1 y 2 (en blanco, dentro de círculos) son las descritas por pórfidos cupríferos y vetas de metales básicos asociadas a pórfidos, respectivamente, según Einaudi et al. (2003).

distrito de Bacís, Durango, exhibe (1) una etapa temprana de formación de sulfuros de metales básicos (con valores bajos de metales preciosos) que sólo se presenta en los niveles más profundos del depósito, con salinidades de los fluidos mineralizantes entre 3.3 y $10.6 \mathrm{wt} . \% \mathrm{NaCl}$ equiv., y (2) una etapa posterior con la formación de minerales de metales preciosos relacionada con fluidos con salinidades entre 0.0 y 4.9 wt. $\% \mathrm{NaCl}$ equiv. (ver Apéndice en Albinson et al., 2001). Estas observaciones indican que la concidencia de ambos estilos de mineralización no es casual sino que obedece a una evolución de los fluidos cuyo estado de sulfuración de inicio se encontraba dentro del campo de estabilidad de SI, hacia estados de sulfuración progresivamente más bajos como resultado de la neutralización progresiva de los fluidos por parte de las rocas encajonantes. Éstas pudieron ejercer un control cada vez mayor sobre la química de los fluidos mineralizantes conforme los pulsos hidrotermales se desvanecían. Tal evolución es semejante a la propuesta para la evolución de fluidos de AS a fluidos de SI en distritos como Lepanto en Filipinas y Julcani en Perú (Einaudi et al., 2003; Sillitoe y Hedenquist, 2003). De esta manera, puede decirse que los depósitos epitermales en México generalmente "nacen" con fluidos de SI y "mueren" con fluidos de BS, aunque también exhiben una componente más local y menos conspícua de fluidos de AS. Estos últimos se ponen de manifiesto por la existencia de alteraciones argílicas avanzadas tempranas, en forma de caolinización, en la parte profunda de los sistemas como ya se ha descrito arriba para los depósitos San Martín de Bolaños en Jalisco y Bacís en Durango.

Tomando en perspectiva toda esta información, podría plantearse que la "pregunta del millón de dólares" consiste en determinar qué depósitos de BS en México tienen mayores posibilidades de presentar también raíces de SI con metales básicos de importancia económica, sobre todo si vienen acompañados de metales preciosos. A primera vista, podría parecer que la salinidad máxima de los depósitos de BS es una pista importante para pronosticar la presencia o ausencia de un depósito de SI en profundidad. Mientras más común sea la presencia de salmueras con salinidades altas (>7.5 wt.\% $\mathrm{NaCl}$ equiv.) no relacionables con procesos de ebullición extrema (Simmons y Browne, 1997) y que representen salmueras de origen profundo, se estima que mayor puede ser el potencial para la presencia de mineralizaciones importantes de SI en profundidad. Aun así, como ya se comentó anteriormente, permanece la incertidumbre de si existen mecanismos que puedan producir efectivamente un hidrotermalismo de BS (con salinidades $<3.5$ wt. $\% \mathrm{NaCl}$ equiv.) a niveles corticales someros y que, a profundidades mayores, de igual forma tengan potencial para la formación de depósitos de SI. En este caso también queda en tela de juicio si es práctico o no tratar de localizar tales depósitos. Las respuestas a estas interrogantes serán el enfoque de investigaciones futuras, y lo más probable es que sólo se 
puedan resolver conforme la exploración en yacimientos epitermales avance hacia niveles más profundos. Además, aún hay mucha investigación que realizar en los depósitos epitermales de México, aún hay mucho espacio para estudios detallados, y el futuro de la ciencia está en los detalles (Richard O. Sack dixit).

\section{Agradecimientos}

El presente trabajo tiene una larga historia, que se inició con la tesis doctoral del primer autor a principios del año 1995, como un intento de ordenar las ideas de alguien que ignoraba por aquel entonces casi todo acerca de los depósitos epitermales. Aquel intento derivó en la elaboración de una revisión sobre el conocimiento de los depósitos epitermales, en que se intentaba integrar todo tipo de información acerca de los mismos. Ese propósito es notorio en el texto en su forma actual, por varias razones que incluyen la profusión de citas bibliográficas. Teniendo en cuenta que la redacción del mismo se ha producido, aunque intermitentemente, durante casi diez años, se entiende que no se ha simplemente "vertido" una gran cantidad de citas bibliográficas de forma gratuita, sino que éstas han ido acrecionándose al manuscrito a través de ese tiempo en función de su utilidad para ilustrar los más diversos conceptos. Este trabajo, antes de ser publicado en su forma actual, de hecho ha sido el gérmen de otros trabajos ya publicados (Camprubí et al., 2003a,b). Una gran parte de este trabajo proviene de la versión final de la tesis doctoral mediante el desarrollo de la cual éste se originó (Camprubí, 1999), que es la única versión publicada hasta el momento, corregida y (sobre)aumentada para esta ocasión. Dicha tesis fue financiada por el Fondo para la Investigación de la Unión Europea a través de proyecto Ci1*-CT94-0075 (HSMU 12). Los directores de dicha tesis fueron Àngels Canals y Esteve Cardellach, a quienes A. Camprubí agadece su apoyo. Una de las versiones previas de este trabajo fue eventualmente utilizada para el concurso de oposición para la plaza de Investigador Titular "A" en la UNAM del primer autor en 2003, en lo que supuso una actualización de sus contenidos y que, en su estructura, es el antecedente inmediato del texto actual. Parte de este trabajo ha sido también posible a través de financiamiento adicional mediante los proyectos de investigación J32506-T de CONACyT, IN115999 e IN122604 de PAPIIT-DGAPA, y de asignaciones presupuestales anuales del Instituto de Geología y del Centro de Geociencias de la UNAM, básicamente en lo que respecta a la obtención de nueva información que se ha ido generando desde el año 2000 y que se incorpora aquí. Por sus comentarios críticamente constructivos o motivacionales, sus sugerencias, su ayuda en diversas versiones del texto o partes del mismo y, en definitiva, por su contribución a mejorar y enriquecer el presente trabajo, gracias muy especialmente a Víctor A. Valencia, Carles Canet (quienes también realizaron la revisión formal del mismo), Johannes Horner, Martín Valencia-Moreno, Rosa María Prol-Ledesma, Noel C. White, Fernando Tornos, Joaquín Proenza, Joan-Carles Melgarejo, Lucas Ochoa-Landín, y Xiomara Cazañas. Algunas de las fotos incluidas en este trabajo fueron tomadas por Noel C. White, Jordi Tritlla, y Eduardo González-Partida, quienes las cedieron amablemente para tal fin. Por último, nos unimos a las felicitaciones a la Sociedad Geológica Mexicana por su primer siglo de existencia.

\section{Referencias}

Abeyta, R.L., 2003, Epithermal gold mineralization of the San Nicolás vein, El Cubo mine, Guanajuato, Mexico: trace element distribution, fluid inclusion microthermometry, and gas chemistry: Socorro, New Mexico, E.U.A., New Mexico Institute of Mining and Technology, Tesis de Maestría inédita, $130 \mathrm{p}$.

Ahmad, M., Solomon, M., Walshe, J.L., 1987, Mineralogical and geochemical studies of the Emperor gold telluride deposit, Fiji: Economic Geology, 82, 345-370.

Aiken, C.L.V., Schellhorn, R.W., de la Fuente, M.F., 1988, Gravity of northern Mexico, en Clark, K.F., Goodell, P.C., Hoffer, J.M. (eds.), Stratigraphy, tectonics, and resources of parts of Sierra Madre Occidental province: El Paso, Texas, E.U.A., El Paso Geological Society, Field Conference Guidebook, 119-133.

Albinson, T., 1985, Zoneamientos térmicos y su relación a la distribución de mineral en algunos yacimientos epitermales en México, en Memorias Técnicas XXVI Convención Nacional AIMMGM, Mazatlán, Sinaloa: México, D.F., Asociacion de Ingenieros de Minas, Metalurgistas y Geólogos de México, 17 p.

Albinson, T., 1988, Geologic reconstruction of paleosurfaces in the Sombrerete, Colorada, and Fresnillo district, Zacatecas state, Mexico: Economic Geology, 83, 1647-1667.

Albinson, T., 1995, Bosquejo de la evolución estructural e hidrotermal del distrito de Zacatecas, en Trabajos Técnicos XVI Convención Nacional AIMMGM, Acapulco, Guerrero: México, D.F., Asociacion de Ingenieros de Minas, Metalurgistas y Geólogos de México, 143-170.

Albinson, T., Parrilla, L.V., 1988, Geologic, mineralogic and fluid inclusion characteristics of polymetallic veins, Real de Guadalupe mining district, Guerrero, Mexico: Economic Geology, 83, 1975-1984.

Albinson, T., Rubio, M.A., 2001, Mineralogic and thermal structure of the Zuloaga vein, San Martín de Bolaños District, Jalisco, Mexico: Society of Economic Geologists, Special Publication, 8, 115-132.

Albinson, T., Norman, D.I., Cole, D., Chomiak, B.A., 2001, Controls on formation of low-sulfidation epithermal deposits in Mexico: constraints from fluid inclusion and stable isotope data: Society of Economic Geologists, Special Publication, 8, 1-32.

Allen, G., Thurston, B., Wayne, R., 2001, Geology and gold-silver mineralization in the Guadalupe de los Reyes district, Sinaloa, Mexico: Society of Economic Geologists, Special Publication, 8, 59-70.

Anderson, W., Eaton, P., 1990, Gold mineralization at the Emperor mine, Vatukuola, Fiji: Journal of Geochemical Exploration, 36, 339-374.

Arribas, A. Jr., 1995, Characteristics of high-sulfidation epithermal deposits, and their relation to magmatic fluid, en Thompson, J.F.H. (ed.), Magmas, fluids and ore deposits: Mineralogical Association of Canada, Short Course Series, 23, 419-454.

Arribas, A. Jr., Hedenquist, J.W., Itaya, T., Okada, T., Concepción, R.A., Garcia, J.S. Jr., 1995, Contemporaneous formation of adjacent porphyry and epithermal $\mathrm{Cu}-\mathrm{Au}$ deposits over $300 \mathrm{ka}$ in northern Luzon, Philippines: Geology, 23, 337-340.

Ashley, R.P., 1982, Occurrence model for enargite-gold deposits: U.S. Geological Survey Open-File Report, 82-795, 144-147. 
Atkinson, W.W. Jr., 1990, A variety of types of epithermal mineral deposits at Moctezuma: Abstracts with Programs - Geological Society of America, 22 (7), 41.

Atkinson, W.W. Jr., 1996, Evidence of a porphyry copper deposit below epithermal veins near Moctezuma, Sonora Mexico: Abstracts with Programs - Geological Society of America, 28 (7), 335.

Barnes, H.L., 1979, Solubilities of ore minerals, en Barnes, H.L. (ed.), Geochemistry of hydrothermal ore deposits, 2a edición: New York, New York, E.U.A., John Wiley \& Sons Interscience, 404-460.

Barton, P.B. Jr., 1970, Sulfide petrology: Mineralogical Society of America, Special Paper, 3, 187-198.

Barton, P.B. Jr., Skinner, B.J., 1979, Sulfide mineral stabilities, en Barnes, H.L. (ed.), Geochemistry of hydrothermal ore deposits, 2a edición: New York, New York, E.U.A., John Wiley \& Sons Interscience, 278-403.

Benning, L.G., Seward, T.M., 1996, Hydrosulphide complexing of Au(I) in hydrothermal solutions from $150-400^{\circ} \mathrm{C}$ and $500-1500$ bar: Geochimica et Cosmochimica Acta, 60, 1849-1871.

Benton, L.D., 1991, Composition and source of the hydrothermal fluids of the Santo Niño vein, Fresnillo, Mexico, as determined from $87 \mathrm{Sr} / 86 \mathrm{Sr}$, stable isotope, and gas analyses: Socorro, New Mexico, E.U.A., New Mexico Institute of Mining and Technology, Tesis de Maestría inédita, $55 \mathrm{p}$.

Berger, B.R., 1991, A historical perspective on the nature and genesis of epithermal gold-silver deposits: Economic Geology Monograph, 8, 249-263.

Berger, B.R., Eimon, P.L., 1983, Conceptual models of epithermal precious metal deposits, en Shanks, W.C. (ed.), Cameron volume on unconventional mineral deposits: New York, New York, E.U.A., Society of Mining Engineers, 191-205.

Berger, B.R., Henley, R.W., 1989, Advances in the understanding of epithermal gold-silver deposits, with special reference to the western United States: Economic Geology Monograph, 6, 405-423.

Bodnar, R.J., Reynolds, T.J., Kuehn, C.A., 1985, Fluid inclusion systematics in epithermal systems: Reviews in Economic Geology, 2, 73-96.

Bogie, I., Lawless, J.V., 1987, Controls on the hydrology of large volcanically hosted geothermal systems: implications for exploration for epithermal mineral deposits, en Proceedings Pacific Rim Congress 87: Parkville, Victoria, Australia, Australasian Institution of Mining and Metallurgy, 57-60.

Bonev, I.K., Kerestedjian, T., Atanassova, R., Andrew, C.J., 2002, Morphogenesis and composition of native gold in the Chelopech volcanic-hosted $\mathrm{Cu}-\mathrm{Au}$ epithermal deposit, Srednogorie zone, Bulgaria: Mineralium Deposita, 37, 614-629.

Bonham, H.F. Jr., 1986, Models for volcanic-hosted epithermal precious metal deposits: a review, en Volcanism, hydrothermal systems and related mineralization: Hamilton, New Zealand, Proceedings International Volcanological Congress, Symposium 5, University of Auckland Centre for Continue Education, 13-17.

Bonham, H.F. Jr., 1988, Models for volcanic-hosted precious metal deposits: a review, en Schafer, R.W., Cooper, J.J., Vikre, P.G. (eds.), Bulk mineable precious metal deposits of the Western United States: Reno, Nevada, E.U.A., Geological Society of Nevada, 259-271.

Bornhorst, T.J., Nurmi, P.A., Rasilainen, K., Kontas, E., 1995, Trace element characteristics of selected epithermal gold deposits of North America: Geological Survey of Finland Special Paper, 20, 47-52.

Brathwaite, R.L., Faure, K., 2002, The Waihi epithermal gold-silverbase metal sulfide-quartz vein system: temperature and salinity controls on electrum and sulfide deposition: Economic Geology, 97, 269-290.

Brathwaite, R.L., Simpson, M.P., Faure, K., Skinner, D.N.B., 2001, Telescoped porphyry $\mathrm{Cu}-\mathrm{Mo}-\mathrm{Au}$ mineralisation, advanced argillic alteration and quartz-sulphide-gold-anhydrite veins in the Thames District, New Zealand: Mineralium Deposita, 36, 623-640.

Brown, K.L., 1989, Kinetics of gold precipitation from experimental hydrothermal sulfide solutions: Economic Geology Monograph, 6, 320-327.

Browne, P.R.L., 1978, Hydrothermal alteration in active geothermal fields: Annual Review of Earth and Planetary Sciences, 6, 229-250.
Browne, P.R.L., Ellis, A.J., 1970, The Ohaaki-Broadlands hydrothermal area, New Zealand: mineralogy and related geochemistry: American Journal of Science, 269, 97-131.

Buchanan, L.J., 1981, Precious metal deposits associated with volcanic environments in the Southwest: Arizona Geological Society Digest, $14,237-262$

Buddington, A.F., 1935, High-temperature mineral associations at shallow to moderate depths: Economic Geology, 30, 205-222.

Camprubí, A., 1999, Los depósitos epitermales Ag-Au de Temascaltepec (Estado de México), México: Barcelona, España, Universitat de Barcelona, Col·lecció de Tesis Doctorals Microfitxades, 3528, $252 \mathrm{p}$.

Camprubí, A., 2003, Geoquímica de fluidos de los depósitos epitermales del sureste del Distrito de Temascaltepec, Estado de México: Revista Mexicana de Ciencias Geológicas, 20, 107-123.

Camprubí, A., Prol-Ledesma, R.M., Tritlla, J., 1999, Comments on 'Metallogenic evolution of convergent margins: selected ore deposit models' by S.E. Kesler: Ore Geology Reviews, 14, 71-76.

Camprubí, A., Canals, À., Cardellach, E., Prol-Ledesma, R.M., Rivera, R., 2001a, The La Guitarra Ag-Au low sulfidation epithermal deposit, Temascaltepec district, Mexico: vein structure, mineralogy, and sulfide-sulfosalt chemistry: Society of Economic Geologists, Special Publication, 8, 133-158.

Camprubí, A., Cardellach, E., Canals, À., Lucchini, R., 2001b, The La Guitarra Ag-Au low sulfidation epithermal deposit, Temascaltepec district, Mexico: fluid inclusion and stable isotope data: Society of Economic Geologists, Special Publication, 8, 159-185.

Camprubí, A., Tritlla, J., Corona-Esquivel, R., Centeno, E., Terrazas, A., 2001c, The hydrothermal sinter and kaolinite-Au-Ag deposits of Ixtacamaxtitlán (Puebla, Mexico): preliminary research, en Pietrzynski, A. et al. (eds.), Mineral deposits at the beginning of the 21st century: Lisse, Holanda, Swets \& Zeitlinger Publishers, 711-714.

Camprubí, A., González-Partida, E., Levresse, G., Tritlla, J, CarrilloChávez, A., 2003a, Depósitos epitermales de alta y baja sulfuración: una tabla comparativa: Boletín de la Sociedad Geológica Mexicana, $56,10-18$.

Camprubí, A., Ferrari, L., Cosca, M.A., Cardellach, E., Canals, À., 2003b, Ages of epithermal deposits in Mexico: regional significance and links with the evolution of Tertiary volcanism: Economic Geology, 98, 1029-1037.

Camprubí, A., Norman, D.I., Chomiak, B.A., 2003c, Evidence for fluid sources by quadrupole mass spectrometry in the La Guitarra AgAu epithermal deposit, Temascaltepec district, Mexico: Journal of Geochemical Exploration, 78-79, 593-599.

Camprubí, A., González-Partida, E., Iriondo, A., Levresse, G., 2006, Mineralogy, fluid characteristics and depositional environment of the Paleocene low-sulfidation epithermal $\mathrm{Au}-\mathrm{Ag}$ deposits of the El Barqueño district, Jalisco, Mexico: Economic Geology, 101 en prensa.

Camus, F., 1990, The geology of hydrothermal gold deposits in Chile: Journal of Geochemical Exploration, 36, 197-232.

Camus, F., Skewes, M.A., 1991, The Faride epithermal silver-gold deposit, Antofagasta region, Chile: Economic Geology, 86, 1222-1237.

Candela, P.A., Piccoli, P.M., 1995, Model ore-metal partioning from melts into vapor and vapor/brine mixtures, en Thompson, J.F.H. (ed.), Magmas, fluids and ore deposits: Mineralogical Association of Canada Short Course Series, 23, 101-127.

Canet, C., Prol-Ledesma, R.M., Proenza, J., Rubio-Ramos, M.A., Forrest, M.J., Torres-Vera, M.A., Rodríguez-Díaz, A.A., 2005a, Mn-Ba-Hg mineralization at shallow submarine hydrothermal vents in Bahía Concepción, Baja California Sur, Mexico: Chemical Geology, 224, 96-112.

Canet, C., Prol-Ledesma, R.M., Torres-Alvarado, I., Gilg, H.A., Villanueva, R.E., Lozano-Santa Cruz, R., 2005b, Silica-carbonate stromatolites related to coastal hydrothermal venting in Bahía Concepción, Baja California Sur, Mexico: Sedimentary Geology, 174, 97-113.

Castor, S.B., Boden, D.R., Henry, C.D., Cline, J.S., Hofstra, A.H., McIntosh, W.C., Tosdal, R.M., Wooden, J.P., 2003, The Tuscarora 
$\mathrm{Au}-\mathrm{Ag}$ district: Eocene volcanic-hosted epithermal deposits in the Carlin gold region, Nevada: Economic Geology, 98, 339-366.

Cathles, L.M., 1991, The importance of vein selvaging in controlling the intensity and character of subsurface alteration in hydrothermal systems: Economic Geology, 86, 466-471.

Charest, A., Castañeda, J., 1997, Geología y modelo yacimiento de oro El Sauzal, Chihuahua, Mex., en Trabajos Técnicos XXII Convención Nacional A.I.M.M.G.M., Vol. 1, Acapulco, Guerrero: México, D.F., Asociación de Ingenieros de Minas, Metalurgistas y Geólogos de México, 137-148.

Cheilletz, A., Levresse, G., Gasquet, D., Azizi Samir, M.R., Zyadi, R., Archibald, D., 2002, The giant Imiter silver deposit: Neoproterozoic epithermal mineralisation in the Anti-Atlas, Morocco: Mineralium Deposita, 37, 772-781.

Christie, A.B., Brathwaite, R.L., 1986, Epithermal gold-silver and porphyry copper deposits of the Hauraki Goldfield-A review, en Henley, R.W., Hedenquist, J.W., Roberts, P.J. (eds.), Guide to the active epithermal (geothermal) systems and precious metal deposits of New Zealand; Monograph series on mineral deposits: Berlin, Alemania, Gebruder Bornträger, 129-145.

Chutas, N.I., Sack, R.O., 2004, Ore genesis at La Colorada Ag-Zn$\mathrm{Pb}$ deposit in Zacatecas, Mexico: Mineralogical Magazine, 68, 923-937.

Clark, K.F., 1990, Geology and mineral deposits of the Taxco mining district: Society of Economic Geologists, Guidebook Series, 6, 281-291.

Clark, K.F., Foster, C.T., Damon, P.E., 1982, Cenozoic mineral deposits and subsuction-related magmatic arcs in Mexico: Geological Society of America Bulletin, 93, 533-544.

Clarke, M., Titley, S.R., 1988, Hydrothermal evolution of silver-gold veins in the Tayoltita mine, San Dimas district, Mexico: Economic Geology, 83, 1830-1840.

Clarke, W.B., Beg, M.A., Craig, H., 1969, Excess 3He in the sea: evidence for terrestrial primordial helium: Earth and Planetary Science Letters, 6, 213-220.

Conrad, J.E., McKee, E.H., Rytuba, J.J., Nash, J.T., Utterback, W.C., 1993, Geochronology of the Sleeper deposit, Humboldt County, Nevada: epithermal gold-silver mineralization following emplacement of silicic flow-dome complex: Economic Geology, 88, 317-327.

Cooke, D.R., Bloom, M.S., 1990, Epithermal and subjacent porphyry mineralization, Acupan, Baguio District, Philippines: a fluid-inclusion and paragenetic study: Journal of Geochemical Exploration, $35,297-340$.

Cooke, D.R., Simmons, S.F., 2000, Characteristics and genesis of epithermal gold deposits: Reviews in Economic Geology, 13, 221-244.

Cooke, D.R., McPhail, D.C., Bloom, M.S., 1996, Epithermal gold mineralization, Acupan, Baguio District, Philippines: geology, mineralization, alteration, and the thermochemical environment of ore deposition: Economic Geology, 91, 243-272.

Corbett, G.J., Leach, T.M., 1998, Southwest Pacific rim gold-copper systems: Structure, alteration and mineralisation: Society of Economic Geologists, Special Publication, 6, 238 p.

Craig, H., Lupton, J.E., Horibe, Y., 1978, A mantle helium component in circum-Pacific volcanic gases: Hakone, the Marianas, and Mt. Lassen, en Alexander, E.C., Ozima, M. (eds.), Terrestrial rare gases: Tokyo, Japón, Center Academy Publications Japan, 3-16.

Craig, J.R., Vaughan, D.J., Skinner, B.J., 1996, Resources of the Earth. Origin, use, and environmental impact, Segunda edición: New Jersey, New Jersey, E.U.A., Prentice Hall, 472 p.

Cumming, G.L., Kesler, S.E., Krstic, D., 1979, Isotope composition of lead in Mexican mineral deposits: Economic Geology, 74, 1395-1407.

Cunneen, R., Sillitoe, R.H., 1989, Paleozoic hot spring sinter in the Drummond Basin, Queensland, Australia: Economic Geology, $84,135-142$

Damon, P.E., Shafiqullah, M., Clark, K.F., 1981, Evolución de los arcos magmáticos en México y su relación con la metalogénesis: Revista del Instituto de Geología U.N.A.M., 5, 131-139.

Deen, J.A., Atkinson, W.W. Jr., 1988, Volcanic stratigraphy and ore deposits of the Moctezuma district, Sonora, Mexico: Economic Geology, 83, 1841-1855.
Deen, J.A., Rye, R.O., Munoz, J.L., Drexler, J.W., 1994, The magmatic hydrothermal system at Julcani, Peru: evidence from fluid inclusions and hydrogen and oxygen isotopes: Economic Geology, 89, 1924-1938.

Doe, B.R., Steven, T.A., Delevaux, M.H., Stacey, J.S., Lipman, P.W., Fisher, F.S., 1979, Genesis of ore deposits in the San Juan volcanic field, southwestern Colorado-lead isotope evidence: Economic Geology, 74, 1-26.

Dong, G., Morrison, G.W., 1995, Adularia in epithermal veins, Queensland: morphology, structural state and origin: Mineralium Deposita, 30, 11-19.

Dong, G., Morrison, G., Jaireth, S., 1995, Quartz textures in epithermal veins, Queensland - classification, origin, and implication: Economic Geology, 90, 1841-1856.

Drummond, S.E., Ohmoto, H., 1985, Chemical evolution and mineral deposition in boiling hydrothermal systems: Economic Geology, 80, 126-147.

Einaudi, M.T., Hedenquist, J.W., Inan, E.E., 2003, Sulfidation state of fluids in active and extinct hydrothermal systems: transitions from porphyry to epithermal environments: Society of Economic Geologists, Special Publication, 10, 285-313.

Enríquez, E., Rivera, R., 2001a, Timing of magmatic and hydrothermal activity in the San Dimas district, Durango, Mexico: Society of Economic Geologists, Special Publication, 8, 33-38.

Enríquez, E., Rivera, R., 2001b, Geology of the Santa Rita Ag-Au deposit, San Dimas district, Durango, Mexico: Society of Economic Geologists, Special Publication, 8, 39-58.

Ericksen, G.E., Cunningham, C.G., 1993, Epithermal precious-metal deposits hosted by the Neogene and Quaternary volcanic complex in the Central Andes, en Kirkham, R.V., Sinclair, W.D., Thorpe, R.I., Duke, J.M. (eds.), Mineral Deposit Modeling: Geological Association of Canada, Special Paper, 40, 419-431.

Etoh, J., Izawa, E., Watanabe, K., Taguchi, S., Sekine, R., 2002, Bladed quartz and its relationship to gold mineralization in the Hishikari low-sulfidation epithermal gold deposit, Japan: Economic Geology, 97, 1841-1851.

Ferrari L., López-Martínez, M., Aguirre-Díaz, G., Carrasco-Núñez, G., 1999, Space-time patterns of Cenozoic arc volcanism in central Mexico: from the Sierra Madre Occidental to the Mexican Volcanic Belt: Geology, 27, 303-307.

Ferrari L., López-Martínez, M., Rosas-Elguera J., 2002, Ignimbrite flare up and deformation in the southern Sierra Madre Occidental, western Mexico: implications for the late subduction history of the Farallon plate: Tectonics, 21, 17-1/24.

Flores, T., 1920, Estudio geológico-minero de los distritos de El Oro y Tlalpujahua: Instituto Geológico de México, Boletín, 37.

Foley, N.R., Ayuso, R.A., 1994, Lead isotope compositions as guides to early gold mineralization: the North Amethyst vein system, Creede district, Colorado: Economic Geology, 89, 1842-1859.

Fournier, R.O., 1987, Conceptual models of brine evolution in magmatic-hydrothermal systems, en Decker, R.W., Wright, T.L., Stauffer, P.H. (eds.), Volcanism in Hawaii, vol. 2: U.S. Geological Survey Professional Paper, 1350, 1487-1506.

Fournier, R.O., 1991, The transition from hydrostatic to greater than hydrostatic fluid pressure in presently active continental hydrothermal systems in crystalline rock: Geophysical Research Letters, $18,955-958$.

Fredrickson, G., 1974, Geology of the Mazatlan area, Sinaloa: Austin, Texas, E.U.A., University of Texas at Austin, Tesis Doctoral inédita, $209 \mathrm{p}$.

Gammons, C.H., Williams-Jones, A.E., 1995, Hydrothermal geochemistry of electrum: thermodynamic constraints: Economic Geology, 90, 420-432.

Gammons, C.H., Williams-Jones, A.E., 1997, Chemical mobility of gold in the porphyry-epithermal environment: Economic Geology, 92, 45-59.

Gasparon, M., Hilton, D.R., Varne, R., 1994, Crustal contamination processes traced by helium isotopes: examples from the Sunda arc, Indonesia: Earth and Planetary Science Letters, 126, 15-22.

Gemmell, J.B., Simmons, S.F., Zantop, H., 1988, The Santo Niño sil- 
ver-lead-zinc vein, Fresnillo District, Zacatecas, Mexico: part I. Structure, vein stratigraphy, and mineralogy: Economic Geology, 83, 1597-1618.

Geyne, A.R., Fries, C. Jr, Segerstrom, K., Black, R.F., Wilson, I.F., 1963, Geology and mineral deposits of the Pachuca-Real del Monte District, State of Hidalgo, Mexico: México, D.F., Consejo de Recursos Naturales No Renovables, Publ. 5E, 203 p.

Ghosal, S., Sack, R.O., 1995, As-Sb energetics in argentian sulfosalts: Geochimica et Cosmochimica Acta, 17, 3573-3579.

Gibson, P.C., Noble, D.C., Larson, L.T., 1990, Multistage evolution of the Calera epithermal Ag-Au vein system, Orcopampa district, Southern Peru: first results: Economic Geology, 85, 1504-1519.

Giggenbach, W.F., 1981, Geothermal mineral equilibria: Geochimica et Cosmochimica Acta, 45, 393-410.

Giggenbach, W.F., 1986, The use of gas chemistry in delineationg the origin of fluid discharges over the Taupo volcanic zone: a review: Proceedings of the International Volcanological Congress, New Zealand, 5, 47-50.

Giggenbach, W.F., 1992a, The composition of gases in geothermal and volcanic systems as a function of tectonic setting, en Proceedings 7th International Symposium on Water-Rock Interaction (WRI-7): Rotterdam, Holanda, A.A. Balkema, 873-878.

Giggenbach, W.F., 1992b, Magma degassing and mineral deposition in hydrothermal systems along convergent plate boundaries: Economic Geology, 87, 1927-1944.

Giggenbach, W.F., 1992c, Isotopic shifts in waters from geothermal and volcanic systems along convergent plate boundaries and their origin: Earth and Planetary Science Letters, 113, 495-510.

Giggenbach, W.F., 1995, Variations in the chemical and isotopic composition of fluids discharged from the Taupo Volcanic Zone, New Zealand: Journal of Volcanology and Geothermal Research, 68, 89-116.

Giggenbach, W.F., 1997, the origin and evolution of fluids in magmatichydrothermal systems, en Barnes, H.L. (ed.), Geochemistry of hydrothermal ore deposits, 3a ed.: New York, New York, E.U.A., John Wiley and Sons, 737-796.

Giggenbach, W.F., Glover, R.B., 1992, Tectonic and major processes governing the chemistry of water and gas discharges from the Rotorua geothermal field, New Zealand: Geothermics, 21, 121-140.

Giggenbach, W.F., Matsuo, S., 1991, Evaluation of results from second and third IAVCEI field workshops on volcanic gases, Mt. Usu, Japan, and White Island, New Zealand: Applied Geochemistry, $6,125-141$

Giggenbach, W.F., Poreda, R.J., 1993, Helium isotopic and chemical composition of gases from volcanic-hydrothermal systems in the Philippines: Geothermics, 22. 369-380.

Giggenbach, W.F., Stewart, M.K., 1982, Processes controlling the isotopic composition of steam and water discharges from steam vents and steam-heated pools in geothermal areas: Geothermics, 11, 71-80.

Giggenbach, W.F., Sano, Y., Wakita, H., 1994, Isotopic composition of helium and $\mathrm{CO} 2$ and $\mathrm{CH} 4$ contents in gases produced along the New Zealand part of a convergent plate boundary: Geochimica et Cosmochimica Acta, 57, 3427-3455.

Giles, D.L., Nelson, C.E., 1982, Epithermal lode gold deposits of the circum-Pacific: Transactions 3rd Circum Pacific Energy and Mineral Resources Conference, Honolulu, Hawaii, E.U.A., 273-278.

Gilmer, A.L., Clark, K.F., Conde, C., Hernandez, I., Figueroa, J.I., Porter, E.W., 1988, Sierra de Santa Maria, Velardeña mining district, Durango, Mexico: Economic Geology, 83, 1802-1829.

Gomberg, J., Priestley, K.F., Masters, T.G., Brune, J.N., 1988, The structure of the crust and upper mantle of northern Mexico: Geophysical Journal of the Royal Astronomical Society, 94, 1-20.

Gómez-Caballero, A., Ponce-Sibaja, B.F., Miranda-Gasca, M.A., 1977, Informe de evaluación del distrito minero El Oro, Mex. Tlalpujahua, Mich.: México, D.F., Gerencia de Estudios Especiales, Consejo de Recursos Minerales, Reporte técnico inédito, $80 \mathrm{p}$.

González-Partida, E., 1981, La province filonienne Au-Ag de TaxcoGuanajuato (Méxique): Lorraine, Francia, Institut National Polytechnique de Lorraine, Tesis de doctorado inédita, $234 \mathrm{p}$.

González-Reyna, J., 1956, Riqueza minera y yacimientos minerales de
México: México D.F., Banco de México S.A., 497 p.

Grant, G.J., Ruiz, J., 1988, The Pb-Zn-Cu-Ag deposits of the Granadeña mine, San Francisco del Oro-Santa Bárbara district, Chihuahua, Mexico: Economic Geology, 83, 1683-1702.

Gray, M.D., 2001, Exploration criteria for high sulfidation gold deposits in Mexico, en Corona-Esquivel, R., Gómez-Godoy, J. (eds.), Acta de Sesiones de la XXIV Convención Nacional de la AIMMGM, Acapulco, Guerrero: México, D.F., Asociación de Ingenieros de Minas, Metalurgistas y Geólogos de México, 68-71.

Gross, W.H., 1975, New ore discovery and source of silver-gold veins, Guanajuato, Mexico: Economic Geology, 70, 1175-1189.

Guha, J., Dubé, B., Pilote, P., Chown, E.H., Archambault, G., Bouchard, G., 1988, Gold mineralization patterns in relation to the lithologic and tectonic evolution of the Chibougamau mining district, Quebec, Canada: Mineralium Deposita, 23, 293-298.

Gunnesch, K.A., Torres del Angel, C., Cuba, C.C., Saez, J., 1994, The $\mathrm{Cu}-(\mathrm{Au})$ skarn and $\mathrm{Ag}-\mathrm{Pb}-\mathrm{Zn}$ vein deposits of $\mathrm{La} \mathrm{Paz}$, northeastern Mexico: mineralogic, paragenetic, and fluid inclusion characteristics: Economic Geology, 89, 1640-1649.

Haas, J.L. Jr., 1971, The effect of salinity on the maximum thermal gradient of a hydrothermal system at hydrostatic pressure: Economic Geology, 66, 940-946.

Hall, H.T., 1966, The systems Ag-As-S, Ag-Sb-S, and Ag-Bi-S: Phase relations and mineralogical significance: Providence, Rhode Island, E.U.A., Brown University, Tesis doctoral inédita.

Hall, H.T., 1967, The pearceite and polybasite series: American Mineralogist, v. 52, p. 1311-1321.

Hallberg, A., 1994, The Enåsen gold deposit, central Sweden: a paleoproterozoic high-sulfidation epithermal mineralization: Mineralium Deposita, 29, 150-162.

Harvey, B.A., Myers, S.A., Klein, T., 1999, Yanacocha gold district, northern Peru, en Proceedings of the Pacrim'99 Congress, Bali, Indonesia: Parkville, Victoria, Australia, Australasian Institute of Mining and Metallurgy, 445-459.

Hayashi, K., Ohmoto, H., 1991, Solubility of gold in NaCl- and H2S-bearing aqueous solutions at $250-350^{\circ} \mathrm{C}$ : Geochimica et Cosmochimica Acta, 55, 2111-2126.

Hayba, D.O., Bethke, P.M., Heald, P., Foley, N.K., 1985, Geologic, mineralogic and geochemical characteristics of volcanic-hosted epithermal precious-metal deposits: Reviews in Economic Geology, 2, 129-167.

Heald, P., Foley, N.K., Hayba, D.O., 1987, Comparative anatomy of volcanic-hosted epithermal deposits: acid-sulfate and adularia-sericite types: Economic Geology, 82, 1-26.

Hedenquist, J.W., 1986, Geothermal systems in the Taupo volcanic zone: their characteristics and relation to volcanism and mineralisation, en Smith, I.E.M. (ed.), Late Cenozoic volcanism in New Zealand: Royal Society of New Zealand Bulletin, 23, 134-168.

Hedenquist, J.W., 1987, Mineralization associated with volcanic-related hydrothermal systems in the Circum-Pacific Basin, en Transactions 4th Circum Pacific Energy and Mineral Resources Conference, Singapore, $1-26$

Hedenquist, J.W., 1991, Boiling and dilution in the shallow portion of the Waiotapu geothermal system, New Zealand: Geochimica et Cosmochimica Acta, 55, 2753-2765.

Hedenquist, J.W., 1996, Hydrothermal systems in volcanic arcs. Origin of and exploration for epithermal gold deposits: Genève, Suiza, Département de Minéralogie, Université de Genève, $139 \mathrm{p}$.

Hedenquist, J.W., Aoki, M., 1991, Meteoric interaction with magmatic discharges in Japan and the significance of mineralization: Geology, 19, 1041-1044.

Hedenquist, J.W., Gulson, B.L., 1992, Intrusive and basement rock sources of lead in hydrothermal systems of the Taupo Volcanic Zone, New Zealand: Geochimica et Cosmochimica Acta, 56, 2821-2829.

Hedenquist, J.W., Henley, R.W., 1985a, The importance of CO2 on freezing point measurements of fluid inclusions: evidence from active geothermal systems and implications for epithermal ore deposition: Economic Geology, 80, 1379-1406.

Hedenquist, J.W., Henley, R.W., 1985b, Hydrothermal eruptions in the Waiotapu geothermal system, New Zealand: their origin, associated 
breccias, and relation to precious metal mineralization: Economic Geology, 80, 1640-1668.

Hedenquist, J.W., Lowenstern, J.B., 1994, The role of magmas in the formation of hydrothermal ore deposits: Nature, 370, 519-527.

Hedenquist, J.W., Goff, F., Phillips, F.M., Elmore, D., Stewart, M.K., 1990, Groundwater dilution and residence times, and constraints on chloride source in the Mokai geothermal system, New Zealand, from chemical, stable isotope, tritium and $36 \mathrm{Cl}$ data: Journal of Geophysical Research, 95, 19365-19375.

Hedenquist, J.W., Reyes, A.G., Simmons, S.F., Taguchi, S., 1992, The thermal and geochemical structure of geothermal and epithermal systems: a framework for interpreting fluid inclusion data: European Journal of Mineralogy, 4, 989-1015.

Hedenquist, J.W., Simmons, S.F., Giggenbach, W.F., Eldridge, C.S., 1993, White Island volcanic hydrothermal system as an active analogue of the environment of high sulfidation $\mathrm{Cu}$ and $\mathrm{Au}$ ore deposition: Geology, 21, 731-734.

Hedenquist, J.W., Matsuhisa, Y., Izawa, E., White, N.C., Giggenbach, W.F., Aoki, M., 1994a, Geology, geochemistry, and origin of highsulfidation $\mathrm{Cu}-\mathrm{Au}$ mineralization in the Nansatsu District, Japan: Economic Geology, 89, 1-30.

Hedenquist, J.W., Aoki, M., Shinohara, H., 1994b, Flux of volatiles and ore-forming metals from the magmatic-hydrothermal system of Satsuma Iwojima volcano: Geology, 22, 585-588.

Hedenquist, J.W., Izawa, E., Arribas, A. Jr., White, N.C., 1996, Epithermal gold deposits: styles, characteristics, and exploration: Resource Geology Special Publication, 1, 18 p.

Hedenquist, J.W., Arribas, A. Jr., Reynolds, T.J., 1998, Evolution of an intrusion-centered hydrothermal system: Far Southeast-Lepanto porphyry and epithermal $\mathrm{Cu}-\mathrm{Au}$ deposits, Philippines: Economic Geology, 93, 373-404.

Hedenquist, J.W., Arribas, A. Jr., Urien-Gonzalez, E., 2000, Exploration for epithermal gold deposits: Reviews in Economic Geology, 13, 245-277.

Helgeson, H.C., 1964, Complexing and hydrothermal ore deposition: New York, New York, E.U.A., Pergamon Press, 136 p.

Henley, R.W., 1985, The geothermal framework of epithermal deposits: Reviews in Economic Geology, 2, 1-24.

Henley, R.W., 1991, Epithermal gold deposits in volcanic terranes, en Foster, R.P. (ed.), Gold metallogeny and exploration: London, Reino Unido, Blackie, 133-164.

Henley, R.W., Brown, K.L., 1985, A practical guide to the thermodynamics of geothermal fluids and hydrothermal ore deposits: Reviews in Economic Geology, 2, 25-44.

Henley, R.W., Ellis, A.J., 1983, Geothermal systems, ancient and modern: Earth Science Reviews, 19, 1-50.

Henley, R.W., Truesdell, A.H., Barton, P.B. Jr., Whitney, J.A., 1984, Fluidmineral equilibria in hydrothermal systems: Reviews in Economic Geology, 1, 267 p.

Herdianita, N.R., Rodgers, K.A., Browne, P.R.L., 2000, Routine instrumental procedures to characterise the mineralogy of modern and ancient silica sinters: Geothermics, 29, 65-81.

Herzig, P.M., Hannington, M.D., 1995, Hydrothermal activity, vent fauna, and submarine gold mineralization at alkaline fore-arc seamounts near Lihir Island, Papua New Guinea, en Proceedings Pacific Rim Congress 1995: Parkville, Victoria, Australia, Australasian Institute of Mining and Metallurgy, 279-284.

Herzig, P.M., Petersen, S., Hannington, M.D., 1999, Epithermal-type gold mineralization at Conical Seamount: a shallow submarine volcano south of Lihir Island, Papua New Guinea, en Stanley, C.J. et al. (eds.), Mineral Deposits: Processes to Processing: Rotterdam, Holanda, A.A. Balkema, 527-530

Hilton, D.R., Craig, H., 1989, A helium isotope transect along the Indonesian archipelago: Nature, 342, 906-908.

Hilton, D.R., Hammerschmidt, K., Teufel, S., Friedrichsen, H., 1993, Helium isotope characteristics of Andean geothermal fluids and lavas: Earth and Planetary Science Letters, 120, 265-282.

Huckerby, J.A., Moore, J.McM., Davis, G.R., 1983, Tectonic control of mineralization at Mahd adh Dhahab gold mine, western Saudi Arabia: Institution of Mining and Metallurgy Transactions, 92,
B171-B182.

Ibarra-Serrano, A., 1997, Compañía San Felipe S.A. de C.V., Unidad San Felipe-Mexicali, B.C. Geología y tipos de mineralización del yacimiento San Felipe, en Memorias Técnicas XXII Convención Nacional AIMMGM, vol. 1, Acapulco, Guerrero, México: México, D.F., Asociación de Ingenieros de Minas, Metalurgistas y Geólogos de México, 219-228.

Izawa, E., Yamashita, M., 1995, Truscottite from the Hishikari mine, Kagoshima prefecture: Resource Geology, 45(252), 251.

Izawa, E., Urashima, Y., Ibaraki, K., Suzuki, R., Yokoyama, T., Kawasaki, K., Koga, A., Taguchi, S., 1990, The Hishikari gold deposit: highgrade epithermal veins in Quaternary volcanics of southern Kyushu, Japan: Journal of Geochemical Exploration, 36, 1-56.

Jacobi, P., 1999, The discovery of epithermal Au-Cu-Mo Proterozoic deposits in the Tapajós province, Brazil: Revista Brasileira de Geociências, 29, 277-279.

Jankovic, S., 1997, The Carpatho-Balkanides and adjacent area: a sector of the Tethyan Eurasian metallogenic belt: Mineralium Deposita, $32,426-433$.

Jannas, R.R., Beane, R.E., Ahler, B.A., Brosnahan, D.R., 1990, Gold and copper mineralization at the El Indio deposit, Chile: Journal of Geochemical Exploration, 36, 233-266.

Jannas, R.R., Bowers, T.S., Petersen, U., Beane, R.E., 1999, High-sulfidation deposit types in the El Indio district, Chile: Society of Economic Geologists, Special Publication, 7, 219-266.

John, D.A., Hofstra, A.H., Fleck, R.J., Brummer, J.E., Saderholm, E.C., 2003, Geologic setting and genesis of the Mule Canyon lowsulfidation epithermal gold-silver deposit, north-central Nevada: Economic Geology, 98, 425-464.

Jones, B., Renaut, R.W., Rosen, M.R., 2001a, Microbial construction of siliceous stalactites at geysers and hot springs: Examples from the Whakarewarewa geothermal area, North Island, New Zealand: Palaios, 16, 73-94.

Jones, B., Rosen, M.R., Renaut, R.W., 2001b, "Geyser eggs" from Te Whakarewarewatangaoteopetauaawahiao, North Island, New Zealand: Journal of Sedimentary Research, 71, 190-204.

Keighin, C.W., Honea, R.M., 1969, The system Ag-Sb-S from $600^{\circ} \mathrm{C}$ to $200^{\circ} \mathrm{C}$ : Mineralium Deposita, 4, 153-171.

Keppie, J.D., Ortega-Gutiérrez, F., 1995, Provenance of Mexican terranes: isotopic constraints: International Geology Reviews, 37, 813-824.

Kilinc, I.A., Burnham, C.W., 1972, Partitioning of chloride between a silicate melt and coexisting aqueous phase from 2 to 8 kilobars: Economic Geology, 67, 231-235.

Konhauser, K.O., Phoenix, V.R., Bottrell, S.H., Adams, D.G., Head, I.M., 2001, Microbial-silica interactions in Icelandic hot spring sinter: possible analogues for some Precambrian siliceous stromatolites: Sedimentology, 48, 415-433.

Kwak, T.A.P., 1990, Geochemical and temperature controls on ore mineralization at the Emperor gold mine, Vatukuola, Fiji: Journal of Geochemical Exploration, 36, 297-338.

Lindgren, W., 1922, A suggestion for the terminology of certain mineral deposits: Economic Geology, 17, 202-294.

Lindgren, W., 1933, Mineral Deposits: New York, New York, E.U.A., McGraw-Hill Book Co., 930 p.

Liu, K., Epstein, S., 1984, The hydrogen isotope fractionation between kaolinite and water: Isotope Geoscience, 95, 335-350.

Losada-Calderón, A.J., McPhail, D.C., 1996, Porphyry and high-sulfidation epithermal mineralization in the Nevados del Famatina mining district, Argentina: Society of Economic Geologists, Special Publication, 5, 91-118.

Loucks, R.R., Petersen, U., 1988, Polymetallic fissure vein mineralization, Topia, Durango, Mexico: Part II. Silver mineral chemistry and high resolution patterns of chemical zoning in veins: Economic Geology, 83, 1529-1559.

Loucks, R.R., Lemish, J., Damon, P.E., 1988, Polymetallic fissure vein mineralization, Topia, Durango, Mexico: Part I. District geology, geochronology, hydrothermal alteration, and vein mineralogy: Economic Geology, 83, 1499-1528.

Lupton, J.E., 1983, Terrestrial inert gases: isotope tracer studies and clues 
to primordial components in the mantle: Annual Review of Earth and Planetary Sciences, 11, 371-414.

Lyons, J.I., 1988, Geology and ore deposits of the Bolaños silver district, Jalisco, Mexico: Economic Geology, 83, 1560-1582.

Mamyrin, B.A., Anufriev, G.S., Kamenskii, I.L., Tolstikhin, I.N., 1969, Determination of the isotopic composition of atmospheric helium: Geochemistry International, 7, 498-505.

Mancano, D.P., Campbell, A.R., 1995, Microthermometry of enargitehosted fluid inclusions from the Lepanto, Philippines, high-sulfidation $\mathrm{Cu}-\mathrm{Au}$ deposit: Geochimica et Cosmochimica Acta, 59, 3909-3916.

Mango, H., Zantop, H., Oreskes, N., 1991, A fluid inclusion and isotope study of the Rayas Ag-Au-Cu-Pb-Zn mine, Guanajuato, Mexico: Economic Geology, 86, 1554-1561.

Mason, B.E., 1995, A comparative evaluation of three jasperoid occurrences in the Mesa Central province of Mexico, and their possible relation to sediment-hosted precious metals mineralization: Fort Collins, Colorado, E.U.A., Colorado State University, Tesis de Maestría inédita, $111 \mathrm{p}$.

Matsuhisa, Y., 1986, Effect of mixing and boiling of fluids on isotopic compositions of quartz and calcite from epithermal deposits: Mining Geology, 36, 487-493.

McDowell, F.W., Keizer, R.P., 1977, Timing od mid-Tertiary volcanism in the Sierra Madre Occidental between Durango city and Mazatlan, Mexico: Geologial Society of America Bulletin, 88, 1479-1487.

McGibbon, D.H., 1979, Origin and paragenesis of ore and gangue minerals, La Paz mining district, San Luis Potosí, Mexico: Arlington, Texas, E.U.A., University of Texas at Arlington, Tesis de Maestría inédita, $86 \mathrm{p}$.

McInnes, B.I, Crocket, J.H., Goodfellow, W.D., 1990, The Laforma deposit, an atypical epithermal-Au system at Freegold Mtn., Yukon Territory, Canada: Journal of Geochemical Exploration, 36, 73-102.

McKee, E.H., Dreier, J.E., Noble, D.C., 1992, Early Miocene hydrothermal activity at Pachuca-Real del Monte, Mexico: an example of space-time association of volcanism and epithermal Ag-Au mineralization: Economic Geology, 87, 1635-1637.

McKibben, M.A., Eldridge, C.S., 1990, Radical sulfur isotope zonation of pyrite accompanying boiling and epithermal gold deposition: a SHRIMP study of the Valles Caldera, New Mexico: Economic Geology, 85, 1917-1925.

McKibben, M.A., Williams, A.E., 1989, Metal speciation and solubility in saline hydrothermal fluids: an empirical approach based on geothermal brine data: Economic Geology, 84, 1996-2007.

Meyer, C., Hemley, J.J., 1967, Wall rock alteration, en Barnes, H.L. (ed.), Geochemistry of hydrothermal ore deposits: New York, New York, E.U.A., Holt Rinehart \& Winston, 166-235.

Mitchell, A.H.G., Balce, G.R., 1990, An overview of epithermal gold mineralisation in the Philippines: Journal of Geochemical Exploration, $35,241-296$.

Mitchell, A.H.G., Garson, M.S., 1981, Mineral Deposits and Global Tectonic Settings: London, Reino Unido, Academic Press, 405 p.

Morales-Ramírez, J.M., Tritlla, J., Camprubí, A., Corona-Esquivel, R., 2003, Fluid origin of the Ixtacamaxtitlán hydrothermal deposits, Puebla State, Mexico: Journal of Geochemical Exploration, 78-79, 653-657.

Morán-Zenteno, D.J., Corona-Chávez, P., Tolson, G., 1996, Uplift and subduction erosion in southwestern Mexico since the Oligocene: pluton geobarometry constraints: Earth and Planetary Science Letters, 141, 51-65.

Mosier, D.L., Menzie, W.D., Kleinhampl, F.J., 1986, Geologic and grade-tonnage information on Tertiary epithermal precious- and basemetal vein districts associated with volcanic rocks: U.S. Geological Survey Bulletin, 1666, $39 \mathrm{p}$.

Müller, D., Groves, D.I., 2000, Potassic igneous rocks and associated gold-copper mineralization, 3a edición: Heidelberg - Berlin - New York, Springer-Verlag, $252 \mathrm{p}$.

Müller, D., Kaminski, K., Uhlig, S., Graupner, T., Herzig, P.M., Hunt, S., 2002, The transition from porphyry- to epithermal-style gold mineralization at Ladolam, Lihir Island, Papua New Guinea: a reconnaissance study: Mineralium Deposita, 37, 61-74.

Mulshaw, S.C., Puig, C., Spiro, B., Buchanan, D.L., 1997, Genesis of epizonal mineralization at San Bartolomé in Central Ecuador: textural evidence, fluid inclusions, and stable isotope geochemistry: Economic Geology, 92, 210-227.

Muntean, J.L., Einaudi, M.T., 2001, Porphyry-epithermal transition: Maricunga belt, northern Chile: Economic Geology, 96, 743-772.

Muñoz, F., 1993, Modelo genético de los depósitos de oro proyecto San Martín, Querétaro, en Memorias Técnicas XX Convención Nacional AIMMGM, Acapulco, Guerrero: México, D.F., Asociación de Ingenieros de Minas, Metalurgistas y Geólogos de México, 439-475.

Murray, M., 1997, Structural analysis of disseminated gold deposits in the Santa Gertrudis mining district, Sonora, Mexico: Boulder, Colorado, E.U.A., University of Colorado at Boulder, Tesis de Maestría inédita, $138 \mathrm{p}$.

Murray, M., Atkinson, W.W. Jr., 1997, Structural analysis of disseminated gold deposits in the Santa Gertrudis mining district, Sonora, Mexico: Geological Society of America, 1997 annual meeting Abstracts with Programs - Geological Society of America, 29, 207.

Nesbitt, B.E., 1990, Fluid flow and chemical evolution in the genesis of hydrothermal ore deposits, en Nesbitt, B.E. (ed.), MAC Short Course on fluids in tectonically active regimes of the continental crust: Mineralogical Association of Canada, 261-297.

Nielson, D.L., Moore, J.N., Heizler, M.T., 1999, Lower limits of hydrothermal circulation in the Tiwi geothermal fluid, Luzon, en Proceedings 24th Workshop on Geothermal Reservoir Engineering: Stanford, California, E.U.A., Stanford University, $7 \mathrm{p}$.

Nieto-Samaniego, A.F., Alaniz-Álvarez, S.A., Camprubí, A., 2005, La Mesa Central de México: estratigrafía, estructura y evolución tectónica cenozoica: Boletín de la Sociedad Geológica Mexicana, 57, 285-317.

Noguez, B.A., Flores, M.J., Toscano, A.F., 1988, El distrito minero de Zacualpan, Estado de México, en Salas, G.P. (ed.), Geología económica de México: México, D.F., Fondo de Cultura Económica, 467-473.

Norman, D.I., Musgrave, J.A., 1994, N2-Ar-He compositions in fluid inclusions: indicators of fluid source: Geochimica et Cosmochimica Acta, 58, 1119-1131.

Norman, D.I, Benton, L.D., Albinson, T., 1991, Calculation of $f(\mathrm{O} 2)$ and $f(\mathrm{~S} 2)$ of ore fluids, and pressure of mineralization from fluid inclusion gas analysis for the Fresnillo, Colorada, and Sombrerete $\mathrm{Pb}-\mathrm{Zn}$-Ag deposits, Mexico, en Leroy, J.L., Pagel, M. (eds.), Source, transport and deposition of metals: Rotterdam, Holanda, A.A. Balkema, 209-212.

Norman, D.I, Moore, J.N., Musgrave, J.A., 1997a, Gaseous species as tracers in geothermal systems, en Proceedings 22nd Workshop on Geothermal Reservoir Engineering, Jan. 27-29: Stanford, California, Stanford University.

Norman, D.I, Chomiak, B., Albinson, T., Moore, J.N., 1997b, Volatiles in epithermal systems: the big picture: Geological Society of America 1997 Annual Meeting, Abstracts with Programs, A-206.

Ohmoto, H., 1972, Systematics of sulfur and carbon isotopes in hydrothermal ore deposits: Economic Geology, 67, 551-579.

Panteleyev, A., 1988. A Canadian Cordilleran Model for Epithermal Goldsilver Deposits, en Roberts, R.G., Sheahan, P.A. (eds.), Ore Deposit Models: Geoscience Canada Reprint Series, 3, 31-43.

Panteleyev, A., 1996, Hot-spring Au-Ag, en Lefebure, D.V., Hõy, T. (eds.), Selected British Columbia Mineral Deposit Profiles, Volume 2 - Metallic Deposits: Victoria, British Columbia, Canadá, British Columbia Ministry of Employment and Investment, Open File, 1996-13, 33-36.

Patterson, D.B., Farley, K.A., McInnes, B.I.A., 1997, Helium isotopic composition of the Tabar-Lihir-Tanga-Feni island arc, Papua New Guinea: Geochimica et Cosmochimica Acta, 61, 2485-2496.

Peacock, S.M., 1990, Fluid processes in subduction zones: Science, 248, 329-337.

Pearson, M.F., Clark, K.F., Porter, E.W., 1988, Mineralogy, fluid characteristics, and silver distribution at Real de Ángeles, Zacatecas, Mexico: Economic Geology, 83, 1737-1759. 
Penczak, R.S., Mason, R., 1997, Metamorphosed Archean epithermal $\mathrm{Au}-\mathrm{As}-\mathrm{Sb}-\mathrm{Zn}-(\mathrm{Hg})$ vein mineralization at the Campbell mine, Northwestern Ontario: Economic Geology, 92, 696-719.

Petersen, S., Herzig, P.M., Hannington, M.D., Jonasson, I.R., Arribas, A. Jr., 2002, Submarine gold mineralization near Lihir Island, New Ireland fore-arc, Papua New Guinea: Economic Geology, 97, 1795-1814.

Petruk, W., Owens, D., 1974, Some mineralogical characteristics of the silver deposits in the Guanajuato mining district, Mexico: Economic Geology, 69, 1078-1085.

Pitzer, K.S., Pabalan, R.T., 1986, Thermodynamics of $\mathrm{NaCl}$ in steam: Geochimica et Cosmochimica Acta, 50, 1445-1454.

Plumlee, G.S., 1994, Fluid chemistry evolution and mineral deposition in the main-stage Creede epithermal system: Economic Geology, 89, 1860-1882.

Plumlee, G.S., Rye, R.O., 1986, Extreme sulfur isotope. As, Sb and Ag variations in late-stage botryoidal pyrite from Creede, Colorado: vestiges of a waning hydrothermal system: Geological Society of America, Abstracts with Programs, 18 (6), 719.

Ponce, B.F., Clark, K.F., 1988, The Zacatecas mining district: a Tertiary caldera complex associated with precious and base metal mineralization: Economic Geology, 83, 1668-1682.

Ponce, D.A., Glen, J.M.G., 2002, Relationship of epithermal gold deposits to large-scale fractures in Northern Nevada: Economic Geology, 97, 3-9.

Poreda, R., Craig, H., 1989, Helium isotope ratios in circum-Pacific volcanic arcs: Nature, 338, 473-478.

Prol-Ledesma, R.M., Canet, C., Torres-Vera, M.A., Forrest, M.J., Armienta, M.A., 2004, Vent fluid chemistry in Bahía Concepción coastal submarine hydrothermal system, Baja California Sur, Mexico: Journal of Volcanology and Geothermal Research, 137, 311-328.

Randall, J.A., Saldaña, E., Clark, K.F., 1994, Exploration in a volcanoplutonic center at Guanajuato, Mexico: Economic Geology, 89, $1722-1751$

Reed, M.H., 1992, Origin of diverse hydrothermal fluids by reaction of magmatic volatiles with wall rock, en Hedenquist, J.W. (ed.), Extended abstracts, Japan-U.S. symposium on magmatic contributions to hydrothermal systems: Geological Survey of Japan Reports, 279, 135-140.

Reed, M.H., Spycher, N., 1985, Boiling, cooling and oxidation in epithermal systems: a numerical model approach: Reviews in Economic Geology, 2, 249-272.

Renaut, R.W., Jones, B., Rosen, M.R., 1996, Primary silica oncoids from Orakeikorako Hot Springs, North Island, New Zealand: Palaios, $11,446-458$

Reyes, A.G., 1990, Petrology of Philippine geothermal systems and the application of alteration mineralogy to their assessment: Journal of Volcanology and Geothermal Research, 43, 279-309.

Reyes, A.G., 1991, Mineralogy, distribution and origin of acid alteration in Philippine geothermal systems: Geological Survey of Japan Reports, 277, 59-65.

Reyes, A.G., Giggenbach, W.F., Saleras, J.R.M., Salonga, N.S., Vergara, M.C., 1993, Petrology and geochemistry of Alto Peak, a vapor-cored hydrothermal system: Geothermics, 22, 479-519.

Rice, C.M., Trewin, N.H., 1988, A Lower Devonian gold-bearing hotspring system, Rhynie, Scotland: Transactions of the Institution of Mining and Metallurgy (Section B: Applied Earth Science), 97, B141-B144.

Richards, J.P., 1992, Magmatic-epithermal transitions in alkalic systems: Porgera gold deposit, Papua New Guinea: Geology, 20, 547-550.

Richards, J.P., 1995, Alkalic-type epithermal gold deposits-a review, en Thompson, J.F.H. (ed.), Magmas, fluids and ore deposits: Mineralogical Association of Canada Short Course Series, 23, $367-400$.

Richards, J.P., Kerrich, R., 1993, The Porgera gold mine, Papua New Guinea: magmatic hydrothermal to epithermal evolution of an alkali-type precious metal deposit: Economic Geology, 88, 1017-1052.

Richards, J.P., Bray, C.J., Channer, D.M.DeR., Spooner, E.T.C., 1997,
Fluid chemistry and processes at the Porgera gold deposit, Papua New Guinea: Mineralium Deposita, 32, 119-132.

Rivera, R., 1993, Cocientes metálicos e inclusiones fluidas del distrito minero de Real de Asientos, Aguascalientes. Memorias Técnicas XX Convención Nacional AIMMGM, Acapulco, Guerrero: México, D.F., Asociación de Ingenieros de Minas, Metalurgistas y Geólogos de México, 310-325.

Robert, F., Poulsen, K.H., 1996, World-class Archean, hydrothermal gold deposits: a Canadian perspective: Geological Society of Australia Abstracts, 41, 368.

Ruaya, J.R., Seward, T.M., 1986, The stability of chlorozinc (II) complexes in hydrothermal solutions up to $350^{\circ} \mathrm{C}$ : Geochimica et Cosmochimica Acta, 50, 651-661.

Rubin, J.N., Kyle, J.R., 1988, Mineralogy and geochemistry of the San Martín skarn deposit, Zacatecas, Mexico: Economic Geology, 83, 1782-1801.

Russell, N., Kesler, S.E., 1991, Geology of the maar-diatreme complex hosting precious metal mineralization at Pueblo Viejo, Dominican Republic: Geological Society of America Special Paper, 262, 203-215.

Ruvalcaba-Ruiz, D.C., Thompson, T.B., 1988, Ore deposits at the Fresnillo mine, Zacatecas, Mexico: Economic Geology, 83, 1583-1596.

Rye, R.O., Ohmoto, H., 1974, Sulfur and carbon isotopes and ore genesis: a review: Economic Geology, 69, 826-842.

Rye, R.O., Sawkins, F.J., 1974, Fluid inclusion and stable isotope studies on the Casapalca Ag-Pb-Zn-Cu deposits, central Andes, Peru: Economic Geology, 69, 181-205.

Rye, R.O., Bethke, P.M., Wasserman, M.D., 1992, The stable isotope geochemistry of acid-sulfate alteration: Economic Geology, 87, 225-267.

Sack, R.O., 2000, Internally consistent database for sulfides and sulfosalts in the system Ag2S-Cu2S-ZnS-FeS-Sb2S3-As2S3: Geochimica et Cosmochimica Acta, 64, 3803-3812.

Sack, R.O., 2005, Internally consistent database for sulfides and sulfosalts in the system Ag2S-Cu2S-ZnS-FeS-Sb2S3-As2S3: Update: Geochimica et Cosmochimica Acta, 69, 1157-1164.

Sakai, H., Matsubaya, O., 1977, Stable isotope studies of Japanese geothermal systems: Geothermics, 5, 97-124.

Sakharova, M.S., Ryakhovskaya, S.K, Uspenskaya, M.Ye., 1994, Natural and experimental data on gold crystallization in quartz-adularia assemblages: Geochemistry International, 31, 155-163.

Sander, M.V., Einaudi, M.T., 1990, Epithermal deposition of gold during transition from propylitic to potassic alteration at Round Mountain, Nevada: Economic Geology, 85, 285-311.

Sano, Y., Wakita, H., 1985, Geographical distribution of $3 \mathrm{He} / 4 \mathrm{He}$ ratios in Japan: implications for arc tectonics and incipient magmatism: Journal of Geophysical Research, 90, 8729-8741.

Saunders, J.A., 1996, Retardation of boiling and the genesis of shallow bonanza epithermal gold deposits: evidence from the Sleeper deposit, Nevada: Geological Society of America, Abstracts with Programs, Denver Col., A-94.

Scheubel, F.R., Clark, K.F., Porter, E.W., 1988, Geology, tectonic environment, and structural controls in the San Martín de Bolaños district, Jalisco, Mexico: Economic Geology, 83, 1703-1720.

Schoen, R., White, D.E., Hemley, J.J., 1974, Argillization by descending acid at Steamboat Springs, Nevada: Clays and Clay Minerals, 22, $1-22$.

Schwarz-Schampera, U., Herzig, P.M., Hannington, M.D., 2001, Shallow submarine epithermal-style As-Sb-Hg-Au mineralization in the active Kermadec arc, New Zealand, en Piestrzynski et al. (eds.), Mineral deposits at the beginning of the 21st century: Lisse, Holanda, Swets \& Zeitlinger Publishers, 333-335.

Scott, A.M., Watanabe, Y., 1998, "Extreme" boiling model for variable salinity of the Hokko low sulfidation epithermal Au deposit, southwestern Hokkaido, Japan: Mineralium Deposita, 33, 568-578.

Sellepack, S.M., 1997, The geology and geochemistry of the El Sauzal gold prospect, southwest Chihuahua, Mexico: E1 Paso, Texas, E.U.A., University of Texas at El Paso, Tesis de Maestría inédita, $89 \mathrm{p}$.

Seward, T.M., 1976, The stability of chloride complexes of silver in 
hydrothermal solutions up to $350^{\circ} \mathrm{C}$ : Geochimica et Cosmochimica Acta, 40, 1329-1341.

Seward, T.M., 1984, The transport and deposition of gold in hydrothermal systems, en Foster, R.P. (ed.), Gold'82: Rotterdam. Holanda, A.A Balkema, 753.

Seward, T.M., 1989, The hydrothermal chemistry of gold and its implications for ore formation: boiling and conductive cooling as examples: Economic Geology Monograph, 6, 398-404

Shenberger, D.M., Barnes, H.L., 1989, Solubility of gold in aqueous sulfide solutions from 150 to $350^{\circ} \mathrm{C}$ : Geochimica et Cosmochimica Acta, 53, 269-278.

Sheppard, S.M.F., 1986, Characterization and isotopic variation in natural waters, en Ribbe, P.H. (ed.), Stable isotopes in high temperature geological processes: Mineralogical Society of America, 16, 1-40.

Sheppard, S.M.F., Nielsen, R.L., Taylor, H.P. Jr., 1969. Oxygen and hydrogen isotope ratios of clay minerals from porphyry copper deposits: Economic Geology, 64, 755-777.

Sherlock, R.L., Tosdal, R.M., Lehrman, N.J., Graney, J.R., Losh, S., Jowett, E.C., Kesler, S.E., 1995, Origin of the McLaughlin mine sheeted vein complex: metal zoning, fluid inclusion, and isotopic evidence: Economic Geology, 90, 2156-2181.

Shinohara, H., Iiyama, J.T., Matsuo, S., 1989, Partition of chlorine compounds between silicate melt and hydrothermal solutions, I, partition of NaCl-KCl: Geochimica et Cosmochimica Acta, 53, 2617-2630.

Sibson, R.H., 1998, Brittle failure mode plots for compressional and extensional tectonic regimes: Journal of Structural Geology, 20, 655-660.

Sibson, R.H., 2001, Seismogenic framework for hydrothermal transport and ore depositio: Reviews in Economic Geology, 14, 25-50.

Sibson, R.H., Scott, J., 1998, Stress/fault controls on the containment and release of overpressured fluids: examples from gold-quartz vein systems in Juneau, Alaska, Victoria, Australia, and Otago, New Zealand: Ore Geology Reviews, 13, 293-306.

Sibson, R.H., Moore, J.McM., Rankin, A.H., 1975, Seismic pumping - a hydrothermal fluid transport mechamism: Journal of the Geological Society, London, 131, 653-659.

Silberman, M.L., Stewart, J.H., McKee, E.H., 1976, Igneous activity, tectonics and hydrothermal precious-metal mineralization in the Great Basin during Cenozoic time: AIME Transactions, 260, 253-263.

Sillitoe, R.H., 1977, Metallic mineralization affiliated to subaerial volcanism: a review, en Volcanic processes in ore genesis: Institution of Mining and Metallurgy-Geological Society of London, 99-116.

Sillitoe, R.H., 1988, Environments, styles and origins of gold deposits in western Pacific island arcs, en Bicentennial Gold 88: Geological Society of Australia, Abstracts, 22, 127-138.

Sillitoe, R.H., 1993, Epithermal models: genetic types, geometrical controls and shallow features, en Kirkham, R.V., Sinclair, W.D., Thorpe, R.I., Duke, J.M. (eds.), Mineral Deposit Modeling: Geological Association of Canada Special Paper, 40, 403-417.

Sillitoe, R.H., 1994, Erosion and collapse of volcanos: causes of telescoping in intrusion-centered ore deposits: Geology, 22, 945-948.

Sillitoe, R.H., 1995a, The influence of magmatic-hydrothermal models on exploration strategies for volcano-plutonic arcs, en Thompson, J.F.H. (ed.), Magmas, fluids and ore deposits: Mineralogical Association of Canada Short Course Series, 23, 511-525.

Sillitoe, R.H., 1995b, Exploration of porphyry copper lithocaps: Australasian Istitute of Mining and Metallurgy Publication Series 9/95, 527-532.

Sillitoe, R.H., 1999, Styles of high sulfidation gold, silver and copper mineralisation in porphyry and epithermal environments, en PACRIM'99, Bali, Indonesia, 29-44

Sillitoe, R.H., Bonham, H.F., 1984, Volcanic landforms and ore deposits: Economic Geology, 79, 1286-1298.

Sillitoe, R.H., Hannington, M.D., Thompson, J.F.H., 1996, High-sulfidation deposits in the volcanogenic massive sulfide environment: Economic Geology, 91, 204-212.

Sillitoe, R.H., Hedenquist, J.W., 2003, Linkages between Volcanotectonic Settings, Ore-Fluid Compositions, and Epithermal Precious Metal Deposits: Society of Economic Geologists, Special Publication
Series, 10, 314-343.

Simmons, S.F., 1991, Hydrologic implications of alteration and fluid inclusion studies in the Fresnillo District, Mexico. Evidence for a brine reservoir and a descending water table during the formation of hydrothermal Ag- $\mathrm{Pb}-\mathrm{Zn}$ orebodies: Economic Geology, 86, 1579-1601.

Simmons, S.F., 1995, Magmatic contributions to low-sulfidation epithermal deposits, en Thompson, J.F.H. (ed.), Magmas, fluids and ore deposits: Mineralogical Association of Canada Short Course Series, 23, 455-477.

Simmons, S.F., Browne, P.R.L., 1997, Saline fluid inclusions in sphalerite from the Broadlands-Ohaaki geothermal system: a coincidental trapping of fluids boiled towards dryness: Economic Geology, 92, 485-489.

Simmons, S.F., Browne, P.R.L., 2000, Hydrothermal minerals and precious metals in the Broadlands-Ohaaki geothermal system: implications for understanding low-sulfidation epithermal environments: Economic Geology, 95, 971-999.

Simmons, S.F., Christenson, B.W., 1994, Origins of calcite in a boiling geothermal system: American Journal of Science, 294, 361-400.

Simmons, S.F., Gemmell, J.B., Sawkins, F.J., 1988, The Santo Niño silver-lead-zinc vein, Fresnillo District, Zacatecas, Mexico: part II. Physical and chemical nature of ore-forming solutions: Economic Geology, 83, 1619-1641.

Simpson, M.P., Mauk, J.L., Kendrick, R.G., 2004, Telescoped porphyrystyle and epithermal veins and alteration at the central Maratoto valley prospect, Hauraki Goldfield, New Zealand: New Zealand Journal of Geology \& Geophysics, 47, 39-57.

Smith, L., 1995, Evolución dinámica y ocurrencia de mineralización, veta El Herrero, en Memorias Técnicas XXI Convención Nacional AIMMGM, Acapulco, Guerrero: México, D.F., Asociacion de Ingenieros de Minas, Metalurgistas y Geólogos de México, 13 p.

So, C.-S., Yun, S.-T., 1996, Geochemical evidence of progressive meteoric water interaction in epithermal Au-Ag mineralization, Jeongju-Buan District, Republic of Korea: Economic Geology, 91, 636-646.

So, C.-S., Dunchenko, V.Ya., Yun, S.-T., Park, M.-E., Choi, S.-G., Shelton, K.L., 1995, Te- and Se-bearing epithermal Au-Ag mineralization, Prasolovskoye, Kunashir Island, Kuril island arc: Economic Geology, 90, 105-117.

Spycher, N., Reed, M., 1989, Evolution of a Broadlands-type epithermal ore fluid along alternative P-T paths: implications for the transport and deposition of base, precious and volatile metals: Economic Geology, 84, 328-359.

Starling, T., Uribe, J., Maldonado, D., 1997, Nuevos conceptos que definen los controles estructurales y la evolución del yacimiento de San Martín, Zacatecas, México. Trabajos técnicos XXII Convención Nacional AIMMGM, vol. 1, Acapulco, Guerrero; México, D.F., Asociacion de Ingenieros de Minas, Metalurgistas y Geólogos de México, 327-338.

Staude, J.-M., 1993, Gold, silver, and base metal epithermal mineral deposits around the Gulf of California, Mexico: relationship between mineralization and mayor structures, en Scott, R.W. Jr., Detra, P.S., Berger, B.S. (eds.), Advances related to United States and international mineral resources: developing frameworks and exploration technologies: U.S. Geological Survey Bulletin, 2039, 69-78.

Staude, J.-M., 2001, Geology, geochemistry, and formation of $\mathrm{Au}-(\mathrm{Cu})$ mineralization and advanced argillic alteration in the Mulatos district, Sonora, Mexico: Society of Economic Geologists Special Publication, 8, 199-216.

Staude, J.-M., Barton, M.D., 2001, Jurassic to Holocene tectonics, magmatism, and metallogeny of northwestern Mexico: Geological Society of America Bulletin, 113, 1357-1374.

Steven, T.A., Ratté, J.C., 1960, Geology of ore deposits of the Summitville district, San Juan Mountains, Colorado: U.S. Geological Survey Professional Paper, 343, 70 p.

Steven, T.A., Lipman, P.W., Fisher, F.S., Blenlewski, C.L., Meeves, H.C., 1977, Mineral resources of study areas contiguous to the Uncompahgre Primitive area, San Juan Mountains, southwestern Colorado: U.S. Geological Survey Bulletin, 1391-E, 126 p.

Stoffregen, R.E., 1987, Genesis of acid-sulfate alteration and $\mathrm{Au}-\mathrm{Cu}-\mathrm{Ag}$ 
mineralization at Summitville, Colorado: Economic Geology, 82, 1575-1591.

Stolper, E., Newman, S., 1994, The role of water in the petrogenesis of Mariana trough magmas: Earth and Planetary Science Letters, 121, 293-325.

Strashimirov, S., Petrunov, R., Kanazirski, M., 2002, Porphyry-copper mineralisation in the central Srednogorie zone, Bulgaria: Mineralium Deposita, 37, 587-598.

Taran, Yu., Pokrovsky, B.G., Esikov, A.D., 1989, Deuterium and oxygen-18 in fumarolic steam and amphiboles from some Kamchatka volcanoes: "andesitic waters": Akademiya Nauk SSSR Doklady, 304, 440-443.

Taylor, B.E., 1986, Magmatic volatiles: isotopic variation of C, H, and $\mathrm{S}$, in Valley, J.W., Taylor, H.P. Jr., O’Neil, J.R. (eds.), Stable isotopes: Reviews in Mineralogy, 16, 185-225.

Taylor, B.E., 1992, Degassing of H2O from rhyolite magma during eruption and shallow intrusion, and the isotopic composition of magmatic water in hydrothermal systems, en Hedenquist, J.W. (ed.), Extended abstracts, Japan-U.S. symposium on magmatic contributions to hydrothermal systems: Geological Survey of Japan Reports, 279, 190-194.

Thiersch, P.C., Williams-Jones, A.E., Clark, J.R., 1997, Epithermal mineralization and ore controls of the Shasta $\mathrm{Au}-\mathrm{Ag}$ deposit, Toodoggone District, British Columbia, Canada: Mineralium Deposita, 32, 44-57.

Thompson, T.B., Trippel, A.D., Dwelley, P.C., 1985, Mineralized veins and breccias of the Cripple Creek District, Colorado: Economic Geology, 80, 1669-1688.

Tolstikhin, I.N., Mamyrin, B.A., Khabarin, L.V., 1972, Anomalous helium isotopic composition in some xenoliths: Geochemistry International, 9, 407-409.

Tolstikhin, I.N., Mamyrin, B.A., Khabarin, L.V., Erlikh, E.N., 1974, Isotope composition of helium in ultrabasic xenoliths from volcanic rocks of Kamchatka: Earth and Planetary Science Letters, $22,75-84$.

Torgersen, T., Lupton, J.E., Sheppard, D.S., Giggenbach, W.F., 1982, Helium isotope variations in the thermal areas of New Zealand: Journal of Volcanology and Geothermal Research, 12, 283-298.

Tritlla, J., Camprubí, A., Morales-Ramírez, J.M., Iriondo, A., CoronaEsquivel, R., González-Partida, E., Levresse, G., Carrillo-Chávez, A., 2004, The Ixtacamaxtitlán kaolinite deposit and sinter (Puebla state, Mexico): a magmatic-hydrothermal system telescoped by a shallow paleoaquifer: Geofluids, 4, 329-340.

Truesdell, A.H., Nathenson, M., Rye, R.O., 1977, The effects of subsurface boiling and dilution on the isotopic composition of Yellowstone thermal waters: Journal of Geophysical Research, 82, 3694-3704.

Valencia, V.A., 2005, Evolution of La Caridad porphyry copper deposit, Sonora, and geochronology of porphyry copper deposits in northwest Mexico: Tucson, Arizona, E.U.A.. University of Arizona, Tesis doctoral inédita, $192 \mathrm{p}$.

Valencia, V.A., Ruiz, J., Barra, F., Ochoa-Landín, L., Pérez-Segura, E., Espinoza, E., 2003, La Caridad porphyry Cu-Mo deposit: a porphyry-epithermal transition in the southwest North America Porphyry Copper Province, in Actas $10^{\circ}$ Congreso Geológico Chileno: Concepción, Chile, Universidad de Concepción, $10 \mathrm{p}$.

Valencia-Moreno, M., Ochoa-Landín, L., Noguez-Alcántara, B., Ruiz, J., Pérez-Segura, E., 2005, Características metalogénicas de los pórfidos cupríferos en México y su posición en un contexto global: Boletín de la Sociedad Geológica Mexicana, 57 (4), en prensa.

van Leeuwen, T.M., Leach, T.M., Hawke, A.A., Hawke, M.M., 1990, The Kelian disseminated gold deposit, east Kalimantan, Indonesia: Journal of Geochemical Exploration, 35, 1-61.

van Thournout, F., Salemink, J., Valenzuela, G., Merlyn, M., Boven, A., Muchez, P., 1996, Portovelo: a volcanic-hosted epithermal vein-system in Ecuador, South America: Mineralium Deposita, $31,269-276$
Vassallo, L.F., 1988, Características de la composición mineralógica de las menas de la Veta Madre de Guanajuato: Revista Instituto de Geologia U.N.A.M., 7, 232-243.

Viglino, R.S., Harmon, R.S., Borthwich, J., Nehring, N.L., Mtyka, R.J., White, L.D., Johnston, D.A., 1985 Stable isotope evidence for a magmatic component in fumarole condensates from Augustine volcano, Cook Inlet, Alaska, USA: Chemical Geology, 49, 141-157.

Vikre, P.G., 1985, Precious metal vein systems in the National district, Humboldt County, Nevada: Economic Geology, 80, 360-393.

Vikre, P.G., 1989, Fluid-mineral relations in the Comstock Lode: Economic Geology, 84, 1574-1613.

Wake, B.A., Taylor, G.R., 1988, Major's Creek, N.S.W., Australia - a Devonian epithermal gold deposit: Mineralium Deposita, 23, 239-246.

Walter, M.R., Bauld, J., Brock, T.D., 1972, Siliceous algal and bacterial stromatolites in hot springs and geyser deposits of Yellowstone National Park: Science, 178, 402-405.

Webster, J.D., 1997, Chloride solubility in felsic melts and the role of chloride in magmatic degassing: Journal of Petrology, 38, 1793-1807.

White, D.E., 1982, Vein and dissemination gold-silver deposits of the Great Basin through space and time, en Tooker, E.W. (ed.), Geologic characteristics of sediment- and vocanic-hosted disseminated gold deposits-Search for an occurrence model: U.S. Geological Survey Bulletin, 1646, 5-14.

White, D.E., Brannock, W.W., Murata, K.J., 1965, Silica in hot-spring waters: Geochimica et Cosmochimica Acta, 10, 27-59.

White, N.C., 1991, High sulfidation epithermal gold deposits: characteristics and a model for their origin: Geological Survey of Japan Report, 277, 9-20.

White, N.C., Hedenquist, J.W., 1990, Epithermal environments and styles of mineralization: variations and their causes, and guidelines for exploration: Journal of Geochemical Exploration, 36, 445-474.

White, N.C., Wood, D.G., Lee, M.C., 1989, Epithermal sinters of Paleozoic age in North Queensland, Australia: Geology, 17, 718-722.

White, N.C., Leake, M.J., McCaughey, S.N., Parris, B.W., 1995, Epithermal gold deposits of the southwest Pacific: Journal of Geochemical Exploration, 54, 87-136.

Wilkerson, G., Deng, Q., Llavona, R., Goodell, P., 1988, Batopilas mining district, Chihuahua, Mexico: Economic Geology, 83, 1721-1736.

Willan, R.C., Spiro, B., 1996, Sulphur sources for epithermal and mesothermal veins in Cretaceous-Tertiary magmatic-arc rocks, Livingston Island, South Shetland Islands: Journal of the Geological Society, London, 153, 51-63.

Williams, L.A., Parks, G.A., Crerar, D.A., 1985, Silica Diagenesis, I. Solubility controls: Journal of Sedimentary Petrology, 55, 301-311.

Wood, D.G., Porter, R.G., White, N.C., 1990, Geological features of some Paleozoic epithermal gold occurrences in northeastern Queensland, Australia: Journal of Geochemical Exploration, 36, 413-443.

Yee, N., Phoenix, V.R., Konhauser, K.O., Benning, L.G., Ferris, F.G., 2003, The effect of cyanobacteria on silica precipitation at neutral $\mathrm{pH}$ : implications for bacterial silicification in geothermal hot springs: Chemical Geology, 199, 83-90.

Zartman, R.E., 1974, Lead isotopic provinces in the cordillera of the western United States and their genetic significance: Economic Geology, 69, 792-805.

Manuscrito recibido: Diciembre 12, 2004

Manuscrito corregido recibido: Abril 17, 2005

Manuscrito aceptado: Mayo 1, 2005 